\title{
Ontogenetic braincase development in Psittacosaurus lujiatunensis (Dinosauria: Ceratopsia) using micro-computed tomography
}

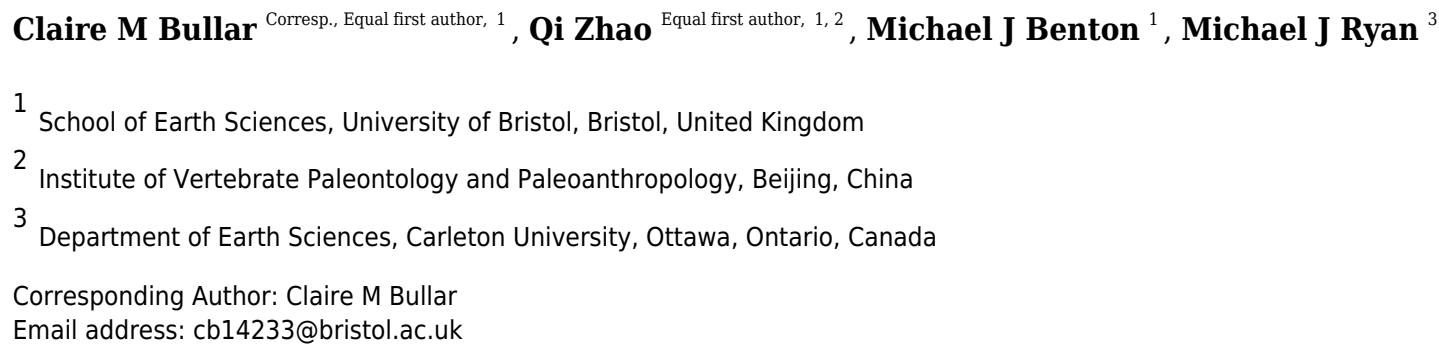

Ontogenetic sequences are relatively rare among dinosaurs, with Ceratopsia being one of the better represented clades, and especially among geologically earlier forms, such as Psittacosaurus. Psittacosaurus is a small, bipedal basal ceratopsian abundant in the Lower Cretaceous deposits of Asia, whose cranial and endocranial morphology has been well studied, but only cursory details have been published on the bones surrounding the brain. Using reconstructions created from micro-computed tomography $(\mu \mathrm{CT})$ scans of wellpreserved skulls from the Barremian-Aptian Yixian Formation, China, we document morphological changes in the braincase of Psittacosaurus lujiatunensis through three growth stages, hatchling, juvenile, and adult, thus providing the first detailed study of ceratopsian braincase morphology through ontogeny. Notable ontogenetic changes in the braincase of $P$. lujiatunensis include a dramatic relative reduction in size of the supraoccipital, an increase in the lateral expansion of the paroccipital processes and a decrease in the angle between the lateral semicircular canal and the palatal plane. These ontogenetic morphological changes in the braincase relate to expansion of the cranium and brain through growth, as well as reflecting the switch from quadrupedal juveniles to bipedal adults as documented in the changing orientation of the horizontal semicircular canal through ontogeny. Recognition of these patterns in a basal ceratopsian has implications for understanding key events in later ceratopsian evolution, such as the development of the parieto-squamosal frill in derived neoceratopsians. 
1 ONTOGENETIC BRAINCASE DEVELOPMENT IN PSITTACOSAURUS

2 LUJIATUNENSIS (DINOSAURIA: CERATOPSIA) USING MICRO-

\section{COMPUTED TOMOGRAPHY}

4 CLAIRE M. BULLAR ${ }^{1}$, QI ZHAO ${ }^{1,2^{*}}$, MICHAEL J. BENTON ${ }^{1}$ and MICHAEL J. RYAN ${ }^{3}$

$5{ }^{1}$ School of Earth Sciences, University of Bristol, Bristol, United Kingdom.

62 Institute of Vertebrate Paleontology and Paleoanthropology, Beijing, China.

$7 \quad{ }^{3}$ Department of Earth Sciences, Carleton University, Ottawa, Ontario, Canada.

$8 *$ Co-first author

10 Corresponding Author:

11 Claire Bullar ${ }^{1}$

12

13 Email address: cb14233@bristol.ac.uk 


\section{Abstract}

16 Ontogenetic sequences are relatively rare among dinosaurs, with Ceratopsia being one of the

17 better represented clades, and especially among geologically earlier forms, such as

18 Psittacosaurus. Psittacosaurus is a small, bipedal basal ceratopsian abundant in the Lower

19 Cretaceous deposits of Asia, whose cranial and endocranial morphology has been well studied,

but only cursory details have been published on the bones surrounding the brain. Using reconstructions created from micro-computed tomography $(\mu \mathrm{CT})$ scans of well-preserved skulls from the Barremian-Aptian Yixian Formation, China, we document morphological changes in the braincase of Psittacosaurus lujiatunensis through three growth stages, hatchling, juvenile, and adult, thus providing the first detailed study of ceratopsian braincase morphology through ontogeny. Notable ontogenetic changes in the braincase of $P$. lujiatunensis include a dramatic relative reduction in size of the supraoccipital, an increase in the lateral expansion of the paroccipital processes and a decrease in the angle between the lateral semicircular canal and the palatal plane. These ontogenetic morphological changes in the braincase relate to expansion of the cranium and brain through growth, as well as reflecting the switch from quadrupedal juveniles to bipedal adults as documented in the changing orientation of the horizontal semicircular canal through ontogeny. Recognition of these patterns in a basal ceratopsian has implications for understanding key events in later ceratopsian evolution, such as the development of the parieto-squamosal frill in derived neoceratopsians. 
36

37

38

\section{Introduction}

Psittacosaurus is an Early Cretaceous genus of Ceratopsia, a diverse and geographically widespread suborder of ornithischian dinosaurs (Dodson et al., 2004; Chinnery-Allgeier \& Kirkland, 2010; Dodson, 2013). Their position within ceratopsian phylogeny has been debated, from being basalmost (e.g., Sereno, 2000; Morschhauser, 2012, Han et al., 2017), to more derived than Yinlong and chaoyangsaurids (e.g., Xu et al., 2006; He et al., 2015; Zheng et al., 2015). Recent work by Han et al. $(2015,2016,2017)$ has suggested a close relationship with chaoyangsaurids. Chaoyangsauridae is a family of basal ceratopsian dinosaurs, that is either sister to Neoceratopsia (e.g., Xu et al., 2002; Han et al., 2018) or its most basal member (e.g., Sereno, 2000; You \& Dodson, 2003).

Ceratopsia underwent a shift from bipedalism to quadrupedalism during their evolution (Weishampel et al. 2004; Xu et al., 2006). Conversely, Psittacosaurus underwent a significant postural shift during ontogeny, as quadrupedal hatchlings developed into facultative bipeds during growth. Evidence for the postural shift comes from allometric studies of limb ratios and histology (Zhao et al., 2013, 2014). Skeletal evidence shows relative shortening of the forelimbs during growth, and histological evidence shows relative slowing of growth of the forelimbs and increasing growth rates for hindlimb elements (femur, tibia) when they reached maturity, at an age of approximately 4 years (Zhao et al., 2013). P. mongoliensis, $P$. sibiricus and $P$. lujiatunensis are the largest species of Psittacosaurus, all three reaching up to $2 \mathrm{~m}$ in length. $P$. lujiatunensis is prevalent in the Early Cretaceous Lujiatun deposits of the Yixian Formation in Liaoning Province of China. Hedrick \& Dodson (2013) posited that three species of Lujiatun Psittacosaurus (Hongshanosaurus houi, Psittacosaurus lujiatunensis and Psittacosaurus major) are synonymous and represent different taphomorphotypes rather than individual species. Here, 
59 we accept their results and follow their taxonomic assignments. Associated volcanic beds have 60 provided radioisotopic dates for the Lujiatun volcaniclastic sediments of approximately $126 \mathrm{Ma}$

61 (Chang et al., 2017). The fossiliferous layers exhibit evidence of rapid burial due to volcanic

62 activity (Rogers et al., 2015) and subsequent exceptional preservation.

63 The integration of advanced computed tomography (CT) techniques into palaeontological studies

64 has enabled extensive, in-depth morphological reviews and non-destructive investigations into

65 both extinct and extant taxa (e.g., Chapelle \& Choiniere, 2018; Hoffman et al., 2018; Neenan \&

66 Scheyer, 2012; Walsh \& Knoll, 2018). While several studies have touched upon the braincase of

67 Psittacosaurus (Coombs, 1982; Zhou et al., 2007; Dodson et al., 2010; Sereno, 2010), few have

68 used CT data to explore internal structures (Zhou et al., 2007).

69 Here we describe three braincases, each belonging to individuals of $P$. lujiatunensis at different

70 ontogenetic stages. Using the methodology of Zhao et al. (2014), we determined the approximate

71 ages of these specimens from their base skull lengths. Using sutural fusion as a proxy for age is

72 ambiguous at best and varies in different taxa and skeletal location (Brown \& Schlaikjer, 1940;

73 Scannella \& Horner, 2011; Longrich \& Field, 2012; Bailleul et al., 2016). When used in

74 conjunction with other techniques, however, sutural fusion has been accepted as a rough proxy

75 for determining age in some vertebrates (Brochu, 1996; Sampson et al., 1997), and we follow

76 this principle of using combined evidence.

\section{Materials and Methods}

78 The smallest skull (IVPP V15451) belongs to a hatchling under one year old, as determined by

79 its size, lack of fusion, and partial disarticulation within the braincase (Fig. 1). The second

80 specimen (IVPP V22647) is fully articulated and well fused (Fig. 1). The level of fusion present 
81 and the size of the specimen indicates an age of approximately two years. The largest skull

82 (IVPP V12617) is a fully fused mature Psittacosaurus, determined to be 10 years old at the time

83 of death, based on the lines of arrested growth (Zhao et al., 2013) (Fig. 1).

84 Specimens were scanned using the CAS (Chinese Academy of Sciences) $\mu$ CT scanner at the

85 Institute of Vertebrate Palaeontology and Palaeoanthropology (IVPP), Beijing. Avizo 8

86 (Visualization Science Group) was used to virtually reconstruct and segment the braincase into

87 3D models. The hatchling skull was partially disarticulated, and so segmentation was relatively

88 quick and straightforward, but both older specimens were well fused in comparison. Using

89 structures such as semicircular canals, cranial nerve pathways, arteries, and undulations on the

90 bone surface, we were able to divide both braincases into their constituent elements.

91 Measurements of individual bones were taken in Avizo and the angles between the plane of the

92 lateral semicircular canal and the palatal plane were calculated following the method in

93 Schellhorn (2018).

94

95 Institutional abbreviations

96 IVPP, Institute of Vertebrate Palaeontology and Palaeoanthropology, Beijing, China;

98 Results

99 Hatchling braincase description

100 The relatively undeformed skull of the hatchling Psittacosaurus (IVPP V15451) is compact and

101 rounded in comparison to the older specimens (Fig. 1). It is complete except for the nasals, 
102 prefrontals and orbitosphenoids. It measures $23.6 \mathrm{~mm}$ long (rostral to occipital condyle (OC)) by

$10315.5 \mathrm{~mm}$ tall (basipterygoid processes to frontal-parietal contact).

104 The foramen magnum (FM) is circular (Fig. 2D). Approximately $70 \%$ of the wall of the FM is

105 made up by the exoccipitals (lateral walls), the rest is an equal measure of supraoccipital dorsally

106 and basioccipital ventrally.

107 The basioccipital (BO) contacts the basisphenoid anteriorly and the exoccipitals laterodorsally

108 (Fig. 3D). It measures $5.4 \mathrm{~mm}$ anteroposteriorly by $5.8 \mathrm{~mm}$ transversely across its widest point.

109 It forms the posterior floor of the braincase and contributes to the majority of the basal tubera

110 (Fig. 2A: bo) with the basisphenoid contributing to the anteroventral-most regions. The basal

111 tubera hang $1.2 \mathrm{~mm}$ below the occipital condyle and are separated by a pronounced medial

112 groove (Fig. 3C, 3E and 3F). Their apices are rounded, blunt and the orientation of the long axis

113 of the tubera is in the sagittal plane (Fig. 3C: bt).

114 The occipital condyle is anteroposteriorly compressed resulting in an oval appearance in dorsal

115 and ventral views (Fig. 3C), with a shallow dorsal depression for the entry of the spinal cord

116 (Fig. 3E). It measures $3 \mathrm{~mm}$ wide by $2 \mathrm{~mm}$ high. The basioccipital makes up the entirety of the

117 occipital condyle with the exoccipitals resting on either side of the FM depression (Fig. 2D:

118 eoas). There is no dorsal restriction of the condylar neck and little lateral constriction. The

119 condylar neck is ventrally constricted, with its maximum constriction occurring proximal to the

120 condyle making it dorsoventrally compressed and relatively thin in lateral view (Figs. 2B and

$1213 \mathrm{~A})$.

122 The flat dorsal surface of the basioccipital is anteriorly inclined and slopes away from the notch

123 formed by its contribution to the foramen magnum. Two ridges extend anterolaterally from the 
124 opening of the FM to a plateau that lies on the dorsal surface of the basal tubera. The exoccipital

125 articular surfaces are lateral to these ridges (Fig. 3D: eoas). The basioccipital of the hatchling

126 specimen only contributes to approximately $15 \%$ of the foramen magnum, but comprises the

127 entire occipital condyle (Fig. 2D).

128 The basisphenoid contacts the prootic dorsally and the basioccipital posteriorly, but is

129 indistinguishable from the parasphenoid even at this early stage of ontogeny. This basisphenoid-

130 parasphenoid complex (BPC) is complete and well preserved comprising the anterior floor of

131 the braincase (Fig. 2B: bs). It measures $10.3 \mathrm{~mm}$ long (without the contribution to the basal

132 tubera). The most prominent features of the complex are the four processes that radiate from the

133 corners of the cuboid basisphenoid body, the basal tubera and the basipterygoid processes. The

134 basipterygoid processes project anterolaterally, diverge at an angle of approximately $81^{\circ}$ and

135 measure approximately $3 \mathrm{~mm}$ in length. The anterior tips of the basipterygoid processes are

136 flared and flattened to articulate with the pterygoids (Fig. 4F: ptas). The ventral surface of the

137 basisphenoid is concave. The troughed cultriform process of the parasphenoid extends anteriorly

138 from the basisphenoid, passing beyond the distal-most surface of the basipterygoid processes

139 (Fig. 4: cp, bpp). It measures $7 \mathrm{~mm}$, approximately $2 / 3$ of the total length of the

140 parabasisphenoid. Note that for the purposes of these descriptions, the "troughs" that separate the

141 cultriform process from the basipterygoid processes will be called the paracultriform troughs

142 (Fig. 4D: pct). The paracultriform troughs in the juvenile specimen are gentle and rounded. The

143 furrow that separates the basal tubera continues anteriorly and separates the basipterygoid

144 processes.

145 The sella turcica (pituitary fossa) is a deep depression in the anterodorsal surface of the

146 basisphenoid which would have held the pituitary gland (Fig. 4D: st). It is triangular when 
147 viewed dorsally. This fossa continues to the cerebral carotid artery canal which then divides into

148 two circular carotid foramen which exit the basisphenoid laterally, ventral to the prootics. The

149 ridges on either side of the trough of the cultriform process meet anterior to the sella turcica

150 which is separated from the former by a large laterally compressed midline blade extending

151 down the cultriform process. The basisphenoid meets the basioccipital posterodorsally at the

152 basal tubera (Fig. 2B). The contribution of the basisphenoid to the basal tubera consists of thin,

153 posteriorly projecting, plate-like extensions ventral to the main bulk of the tubera (approximately

$15420 \%$ of the tubera). A well pronounced, smooth, flattened ridge dominates the posterodorsal

155 surface of the basisphenoid and forms the contact surface for the prootic (Figs. 4A, 4B, 4D and

156 4E: pras). This slightly anteriorly inclined platform extends laterally and anteriorly bordering the

157 posterolateral edges of the sella turcica.

158 The sub-oval, plate-like supraoccipital dominates the occipital surface and tapers dorsally in

159 thickness (Fig. 2D: so). It measures $8.7 \mathrm{~mm}$ wide by $3.6 \mathrm{~mm}$ tall. The dorsal margin of the

160 supraoccipital articulates with the posterior most edge of the parietals, whilst the ventral border

161 contacts the paroccipital processes. The boundaries with the paroccipital processes are poorly

162 defined; however, the thin $(<1 \mathrm{~mm})$ supraoccipital flares lateroventrally to $2.4 \mathrm{~mm}$ to meet them

163 (Fig. 5C: eoas). The supraoccipital contributes approximately $20 \%$ of the dorsal wall of the

164 foramen magnum. In caudal view, a V-shaped notch approximately one-fifth the depth of the

165 supraoccipital is present at the mid-point of the dorsal margin. (Fig. 5E). A low midline ridge

166 extends from the base of the notch to the ventral margin (Fig. 5E: somr). The anterior surface is

167 concave where the hindbrain would have sat (Figs 5C, 5D and 5F). The posterior semicircular

168 canal traverses through the lateral wings of the supraoccipital (Fig. 5F: sccp). 
169 The paroccipital processes make up most of the lateroposterior surface of the braincase (Fig.

170 2D: pp) and are composed of exoccipitals and opisthotics which are so well fused that their

171 suture is obliterated. The processes contact the supraoccipital dorsally, the prootic anteriorly and

172 the basioccipital ventrally; there is also a small area of contact with the parietal lateral to the

173 supraoccipital contact. The anterior boundary of the paroccipital processes can only be inferred

174 due to high levels of fusion in this region. The paroccipital processes of the hatchling specimen

175 are stunted and subrectangular. A single paroccipital process has a length of $6.2 \mathrm{~mm}$ and a height

176 of $2.8 \mathrm{~mm}$ giving a height/length ratio of almost 1:2. Cranial nerve pathways X-XII pass through

177 the exoccipitals, exiting posterolaterally underneath the processes. They are visible when the

178 braincase is viewed posteriorly. The exoccipital-opisthotic complex of the hatchling does not

179 contribute to the occipital condyle, but does contribute approximately $70 \%$ of the wall of the FM

180 (Figs. 2D and 6E). A trunk of the exoccipital extends medioventrally from the FM to contact the

181 basioccipital at the top of the occipital condyle (Fig. 6D). The exoccipitals house a section of the

182 semicircular canals. Dorsal to the paroccipital processes are unpaired foramina which most likely

183 allowed for the passage of the vena capitis dorsalis (Fig. 6D: ved?).

184 The laterosphenoid articulates with the prootic posteriorly, the parietal posterodorsally and the

185 frontal anterodorsally. It measures $5.2 \mathrm{~mm}$ by $4.2 \mathrm{~mm}$ and is blocky and triangular in lateral

186 view. It has a flared 'wishbone' shape in cross section (Fig. 7C). The laterosphenoid sits

187 anterodorsally to the prootic and contributes to the anterolateral wall of the braincase (Fig. 2A:

188 1s). The laterosphenoid at this stage in growth appears very fragile and thin. The medial surface

189 of the laterosphenoid is concave and flares posteriorly resulting in a triangular appearance. The

190 lateral surface of the laterosphenoid is convex and comes to a central point called the 
191 laterosphenoid head (Figs. 7A and 7B: 1sh). The laterosphenoid makes up the dorsal boundary of

192 the foramina for cranial nerve V (trigeminal nerve).

193 The prootic of Psittacosaurus is a complex element that forms much of the lateral braincase wall

194 and houses the majority of the inner ear. The prootic contacts the paroccipital processes

195 posteriorly, the laterosphenoid anteriorly, and the basisphenoid ventrally (Fig. 2A: pr). It

196 measures $7.1 \mathrm{~mm}$ dorsoventrally and $3.9 \mathrm{~mm}$ mediolaterally. It is sub-triangular when viewed

197 dorsally. It is morphologically similar to the prootic of the perinatal Alligator mississippiensis

198 reconstructed in Dufeau \& Witmer (2015). A large notch for cranial nerve V can be seen on the

199 anterior surface of the prootic, but it is not entirely enclosed by the prootic (Figs. 8A-8D: cranial

200 nerve, CN V). A prominent median ridge extends down the medial surface of the prootic (Fig.

201 8D: prmr). Anterior to this ridge lies a concavity spanning the entire height of the prootic. Within

202 this anterior concavity and posterior to the trigeminal foramen lies the foramen for CN VII

203 (facial nerve) (Figs. 8A-8D). Posterior to this median ridge lies the space for the cochlear duct

204 and vestibule of the inner ear. The pathway of the anterior semicircular canal can be seen

205 extending anteroposteriorly across the dorsal edge of the prootic when viewed dorsally (Fig. 8F:

206 sccp. This section of the canals is loosely held within the prootic and is not entirely enclosed

207 within the bone.

208 The parietal is contacted by the frontal anteriorly, the laterosphenoid anteroventrally, the

209 supraoccipital posteroventrally and the squamosals posterolaterally. It is located on the

210 posterodorsal surface of the braincase and comprises approximately half of the dorsal surface of

211 the braincase (Fig. 2C: pa). It measures $7.4 \mathrm{~mm}$ anteroposteriorly and $14.1 \mathrm{~mm}$ across its widest

212 point. The posterior edge of the parietal is an inverted ' $\mathrm{V}$ ' shape in cross section, whilst the

213 anterior is convex (Fig. 9). The ventral surface of the parietal is deeply concave which is 
214 mirrored in the convex dorsal surface continuing the rounded dome-like skull roof that originates

215 from the frontal. The hatchling parietal lacks a sagittal ridge. The upper temporal fenestra forms

216 rounded indentations in the lateral margins of the parietal and a process extends posteroventrally

217 to contact the squamosals.

218 Frontal contacts include the parietal posteriorly, the nasal anteriorly, the laterosphenoid

219 posteroventrally and the postorbital posterolaterally (Fig. 10: paas, nas, lsas, poas). The

220 prefrontals would also have contacted the frontal, but there is no indication of where this contact

221 lies. The frontals measure $11.2 \mathrm{~mm}$ anteroposteriorly and $15.8 \mathrm{~mm}$ transversely across their

222 widest point. The frontals of the hatchling exhibit extreme dorsal doming which contributes

223 greatly to the overall roundness of the skull (Fig. 2). Two deep rounded concavities are present

224 on the ventral side of these elements, which is the location of the cerebral hemispheres (Fig. 10C:

$225 \mathrm{cc})$. They measure $11.1 \mathrm{~mm}$ across their widest point. The hourglass indentation that marks the

226 anterior regions of the brain is anterior to these bulbous depressions. The interfrontal suture

227 cannot be discerned and there is no crest present on the dorsal surface of the frontal. The frontal

228 is anteriorly transversely thin and widens posteriorly, the widest point being posterior to the

229 orbits. Dorsally, two small $(0.6 \mathrm{~mm})$ epiossifications lie symmetrically either side of the midline

230 - this is the first time these structures have been observed in Ceratopsia. The frontal contributes

231 to the dorsal edge of the large eye socket. The eye socket creates a rounded concave border on

232 the anterolateral edges of the frontal where a ventral lip is present (Figs. 10A and 10B: om). The

233 supra-orbital wall is orientated in a sagittal plane, meaning that the wall is fully visible laterally.

234 In dorsal and ventral views, the orbits cut concavities into the anterolateral sides of the frontals. 
237 The juvenile specimen (IVPP V22647) proved difficult to segment due to poor preservation and 238 obliterated sutures.

239 The skull has undergone uniaxial dorsoventral compression giving it a blocky appearance with 240 an extremely flattened skull roof (Fig. 1C). The lack of a rostral also means that it appears

241 rectangular in lateral view. Unlike the other specimens, the occipital surface of the juvenile is

242 orientated posteriorly with no ventral inclination. It measures $76 \mathrm{~mm}$ (rostral - OC) by $30 \mathrm{~mm}$

243 (basipterygoid processes - frontal).

244 The foramen magnum is oval, with a flattened dorsal margin (Fig. 11D). Whether this is due to 245 the taphonomic deformation is unclear. The foramen magnum is made up of $50 \%$ exoccipitals 246 (laterally), approximately 35\% supraoccipital (dorsally) and 15\% basioccipital (ventrally).

247 The basioccipital contacts of the juvenile include the basisphenoid anteriorly and the 248 paroccipital processes posterodorsally. As in the hatchling, the basioccipital forms the posterior 249 half of the braincase floor. It measures $14 \mathrm{~mm}$ anteroposteriorly and $16.6 \mathrm{~mm}$ across its widest 250 point. The basal tubera are poorly preserved compared to those of the hatchling and adult

251 specimens. The tubera are approximately $5 \mathrm{~mm}$ long and are separated by what appears to be a 252 very shallow medial groove (Fig. 12E: btg), but the depth of this feature may be the product of 253 the taphonomic deformation and compression. Ventrally, the tubera have a loose, rounded L 254 shape and no strong orientation (Fig. 12C: bt). Posteriorly, they are dorsoventrally compressed 255 and ventrally extend no further than the OC (Figs. 11D, 12A, 12B and 12E).

256 The occipital condyle of the juvenile Psittacosaurus specimen is dorsoventrally flattened and, 257 like the hatchling, is made up entirely of the basioccipital (Fig. 11D: bo). Whether this 258 compression is due to post-mortem deformation or was present in vivo is not clear. As both the 
259 FM and OC are oval in the juvenile specimen and round in the other two specimens, the former

260 is most probable. The OC measures $7.7 \mathrm{~mm}$ wide by $5.4 \mathrm{~mm}$ tall. There is a well pronounced

261 condylar neck which exhibits ventral constriction. Similar to the OC of the hatchling, the neck

262 restricts proximal to the condyle making it anterodorsally compressed and relatively thin in

263 lateral view (Fig. 12: cdn).

264 A shallow groove on the dorsal surface of the basioccipital marks the ventral-most margin of the

265 foramen magnum (Fig. 11D). Because the braincase is fused, the dorsal surface of the

266 basioccipital is hard to distinguish. However, it is clear that the majority of the dorsal surface of

267 the basioccipital is taken up by contact points for the two exoccipitals (Fig 12D: eoas). The

268 basioccipital seems to taper ventrolaterally at these surfaces, meaning it appears triangular when

269 viewed posteriorly or anteriorly (Figs. 12E and 12F). The basioccipital constitutes $60 \%$ of the

270 basal tubera, with the basisphenoid contributing approximately $20 \%$ more than it did in the

271 hatchling.

272 The basisphenoid contacts the prootic dorsally and the basioccipital posteriorly. The pterygoid

273 articular surface sits on the anterior-most surface of the basipterygoid processes (Fig. 13F: ptas).

274 The basisphenoid-parasphenoid complex measures $30.8 \mathrm{~mm}$ anteroposteriorly by $20 \mathrm{~mm}$ across

275 the widest point of the basipterygoid processes. As with the hatchling, the boundary between the

276 basisphenoid and parasphenoid of the juvenile is completely obscured by extreme sutural fusion.

277 The basipterygoid processes project anterolaterally from the main body of the basisphenoid and

278 diverge at an angle of approximately $70^{\circ}$. They measure approximately $8.7 \mathrm{~mm}$ in length and

279 expand distally. The juvenile parasphenoid is complete and the cultriform process exhibits

280 minimal deformation (Fig. 13: cp). The cultriform process is long, thin and troughed. It measures

$28123 \mathrm{~mm}$ in length and, as in the hatchling, it contributes to approximately two-thirds of the total 
282 parabasisphenoid length. The paracultriform troughs are more angled and abrupt than the curving

283 troughs of the hatchling (Fig. 13: pct). The sella turcica sits on the dorsal surface of the

284 parabasisphenoid, posterior to the cultriform process (Fig. 13D: st). It is oval when viewed

285 dorsally. The carotid foramina lie lateroventrally to the sella turcica (Figs. 13A and 13B: cfo).

286 The basisphenoid contributes to a larger proportion of the basal tubera (approximately $45 \%$ ) than

287 in the hatchling specimen, although the location of the boundary remains the same.

288 The supraoccipital of the juvenile contacts the exoccipitals dorsolaterally and the parietal

289 dorsally. It measures $9.8 \mathrm{~mm}$ at its widest point (ventral margin). The boundaries of the

290 supraoccipital are inferred as they were unclear, making it hard to segment. It is anteroposteriorly

291 triangular in shape (Fig. 14). The supraoccipital contributes to the dorsal portion (approximately

292 25\%) of the foramen magnum (Fig 11D: so). The supraoccipital lies at the midpoint between the

293 adult's thin, rod-like supraoccipital and the relatively large, plate-like supraoccipital that

294 contributes to much of the posterior surface of the hatchling's skull. The posterior semicircular

295 canals are situated in the paroccipital processes rather than the supraoccipital as in the hatchling.

296 The paroccipital process contacts the basioccipital ventrally, the supraoccipital medially, the

297 parietal dorsally and the prootic anteriorly. Most of the paroccipital processes are missing and

298 fractured. Only the medial-most section of paroccipitals remains (Fig. 15: pop). A length to

299 width ratio for the processes cannot be calculated as they are so incomplete. The exoccipitals

300 make up approximately two thirds of the foramen magnum (Fig. 11D). Cranial nerve exits X-XII

301 are located high up just below the lateral expansion of the exoccipitals which is similar to the

302 hatchling. The location of the exit of the vena capitis dorsalis from the paroccipital processes is

303 unclear due to poor preservation. A section of the posterior semicircular canal sits within the

304 paroccipital. 
305 The laterosphenoid of the juvenile contacts the prootic posteriorly, the parietal posterodorsally

306 and the frontal anterodorsally. It measures $15.4 \mathrm{~mm}$ anteroposteriorly and has a width of $6.8 \mathrm{~mm}$.

307 It is morphologically very similar to the hatchling, differing only in being anteroposteriorly

308 elongated. It is flared and triangular in cross section near the posterior boundary (Fig. 16). The

309 laterosphenoid head is located anteriorly and is dorsoventrally flattened in comparison to the

310 blocky central head of the hatchling (Fig. 16A: 1sh). A process extends down from the

311 laterosphenoid creating the anterodorsal corner of the exit for $\mathrm{CN} \mathrm{V}$.

312 The prootic contacts the paroccipital process posteriorly, the parietal posterodorsally, the

313 laterosphenoid anteriorly, and the basisphenoid ventrally. The boundaries between the prootics,

314 paroccipital processes and the parietal were difficult to infer. They measure $12.8 \mathrm{~mm}$ in height,

315 assuming that the parietal-prootic contact is roughly correct. The prootics create the posterior and

316 ventral walls of $\mathrm{CN} \mathrm{V}$ with the preprootic strut making up the anterior margin (Fig. 17: pps).

317 Posterior to the notch for CN V the prootic thickens and a series of anteroposterior ridges extend

318 across the medial surface. The median ridge seen in the hatchling specimen does not appear to be

319 so prominent in the juvenile. CN VII exits through the prootic posterior to this thickened strut

320 (Figs. 17C and 17D). There is also a second opening next to CN VII which extends into the inner

321 ear. On the lateral surface of the prootic there is a ' $\mathrm{V}$ ' shaped ridge extending anteroposteriorly.

322 The parietal is contacted anteriorly by the frontals, anteroventrally by the laterosphenoids,

323 lateroventrally by the prootics, posterolaterally by the squamosals and posteroventrally by the

324 supraoccipital. It also contacts the parietal posteroventrally, but this cannot be seen because of

325 damage and poor preservation. The contacts between the parietal, paroccipital processes and the

326 prootics are inferred due to damage and deformation. It measures $16.3 \mathrm{~mm}$ anteroposteriorly and

327 approximately $25 \mathrm{~mm}$ across the anterior-most margin. It is flattened, and a shallow sagittal crest 
328 has formed (Fig. 18D: sc). The apparent flatness is likely due to either taphonomic deformation

329 or the early stage in development. Although the posterior portion of the parietal is broken and

330 damaged, a small parietal shelf can be inferred (Fig. 18: ps?). The upper temporal fenestrae

331 create concavities in the lateral margins of the parietal. The parietal borders the posterior margin

332 of the upper temporal fenestra where they meet the squamosal distally.

333 The frontal contacts the parietal posteriorly, the nasal anteriorly, the laterosphenoid

334 posteroventrally, the postorbital posterolaterally and the prefrontal anterolaterally, marked by a

335 notch (Fig. 19D: no). The frontals measure $30.6 \mathrm{~mm}$ anterodorsally and $36.5 \mathrm{~mm}$ transversely

336 across the widest point. Unlike those of the hatchling, the juvenile's frontals are flattened, with

337 only the anterior section of the cerebral concavities being present on the ventral surface (Fig.

338 18C: cc). The frontal of the juvenile is sub-triangular, flaring posteriorly, with the widest point

339 being the contact with the postorbital (Fig. 19D: poas). The hourglass shape of the anterior

340 region of the brain is preserved on the ventral surface of the frontal. The margin between the

341 brain cavity and the orbits is well defined. The small frontal ossicles that were present on the

342 hatchling specimen are no longer evident. A shallow frontal crest extends medially down the

343 dorsal surface, where the two frontals meet in the sagittal suture. Laterally and parallel to this

344 crest are two shallow ridges, although whether these are a product of taphonomic deformation is

345 unclear. The orbits occupy shallow lateral concavities into the ventral surface of the frontal (Fig.

346 19: om).

348 Adult braincase description 
349 The specimen IVPP V12617 was approximately 10 years old at the time of death (Zhao et al.,

350 2013). It was previously referred to Hongshanosaurus houi but that taxon is synonymized by

351 most with Psittacosaurus lujiatunensis (Sereno, 2010; Hedrick \& Dodson, 2013).

352 The cranium has a rounded anterodorsal surface, with a domed skull roof (Fig. 1E). It measures

$353146 \mathrm{~mm}$ in length (OC- rostral) by $60 \mathrm{~mm}$ in height. The skull has undergone some dorsoventral

354 compression (Hedrick \& Dodson, 2013), but the occipital condyle appears to have been

355 comparatively unaffected by dorsoventral deformation and so we take the braincase to be

356 negligibly deformed. The occipital surface of the skull is orientated posteroventrally, as is the

357 case in the hatchling, but this orientation may be a result of the compression.

358 The circular foramen magnum is made up of the exoccipitals laterally $(60 \%)$, supraoccipital

359 dorsally (10\%) and basioccipital ventrally (30\%) (Fig. 20D).

360 The basioccipital contacts the basisphenoid anteriorly and the exoccipitals laterodorsally. It is

361 complete, with minimal to no deformation. The element measures $26.4 \mathrm{~mm}$ anteroposteriorly and

$36232 \mathrm{~mm}$ across its widest point. The basioccipital takes up approximately $30 \%$ of the margin of

363 the foramen magnum, which is double that of the younger specimens. The posterior portion of

364 the basioccipital forms the occipital condyle and the anterior section contributes to the basal

365 tubera. The basioccipital contributes to approximately $50 \%$ of the basal tubera, with the

366 basisphenoids making up the other half. The basal tubera are dorsoventrally and mediolaterally

367 larger than the OC which differs from those of the hatchling which are approximately half the

368 size of the condyle. The distinct groove separating the basal tubera is smaller and shallower

369 relative to the main body of the basioccipital than those in the hatchling (Fig. 21E: btg). The

370 basal tubera are anteroposteriorly flattened and are orientated mediolaterally (Fig. 21C: bt). The

371 basioccipital is deeper than those of the younger individuals. 
372 The occipital condyle is heart-shaped (Fig. 20D: boc) because the foramen magnum indents the

373 dorsal margin. It is composed entirely of the basioccipital, as is the case with the younger

374 specimens described here. The basioccipital-exoccipital contact was very well fused and so some

375 sections were inferred. The basioccipital-exoccipital contact is higher up and closer to the flaring

376 processes than in the younger specimens (Fig. 20D). This means that the basioccipital

377 contributes to the base of the paroccipital processes, although cranial nerves X-XII still exit

378 from the base of the exoccipitals. The occipital condyle measures approximately $14.3 \mathrm{~mm}$ wide

379 by $11.9 \mathrm{~mm}$ deep. When viewed ventrally, the occipital condyle is triangular (Fig. 20B). Similar

380 to the condylar neck of the hatchling and juvenile, there is some ventral constriction. This mature

381 specimen differs from those in that the point of greatest constriction occurs closer to the basal

382 tubera than to the occipital condyle.

383 The ventral margin of the foramen magnum is inscribed deeper into the dorsal surface of the

384 basioccipital than in the younger specimens (Fig. 21D: ng) and widens anteriorly over the tubera.

385 The dorsal surface of the basioccipital is triangular in outline. The contact separating the

386 basioccipital and basisphenoid is visible as a transverse groove extending across the basal tubera

387 (Figs. 20A and 20B).

388 The basisphenoid-parasphenoid complex of the adult contacts the prootic dorsally and the

389 basioccipital posteriorly (Fig. 20). It measures approximately $24 \mathrm{~mm}$ anteroposteriorly and 35.9

$390 \mathrm{~mm}$ across the basipterygoid processes. The basisphenoid is well preserved but, as with the other

391 specimens, cannot be differentiated from the parasphenoid due to sutural fusion. It is a

392 dorsoventrally deeper and more robust element than in the younger individuals. The

393 basipterygoid processes measure approximately $14.3 \mathrm{~mm}$ in length and are ventrally projected

394 compared to those of the younger individuals (Fig. 22: bpp). They diverge at an angle of 
395

396

397

399

400

401

402

403

404

405

406

407

408

409

410

411

412

413

414

415

416

417

approximately $44^{\circ}$ making the paracultriform troughs thin and angular. The distal expansion of the basipterygoid processes is more extreme in IVPP V12617. The cultriform process is broken and incomplete, and only the tall, thin and blade-like portion, which is also present in the hatchling, is preserved (Fig. 22: cp). No prominent trough appears along the dorsal surface of the process as it does in the hatchling and juvenile specimens, but it may not be preserved due to damage. The sella turcica differs from those of the younger specimens in being more compact and sub-diamond in shape (Fig. 22D: st). This leads on to the cerebral carotid artery canal (Figs. 22A and 22B: cfo). These carotid foramina are positioned anteriorly compared to the younger specimens.

The supraoccipital contacts the parietal anteriorly and the paroccipitals ventrolaterally; but, it should be noted that the fused and obscured sutures make the exact points of contact difficult to determine. It measures $12.3 \mathrm{~mm}$ dorsoventrally and, at $6.8 \mathrm{~mm}$ wide, is the thinnest supraoccipital in this study. It only contributes to approximately $10 \%$ of the foramen magnum (Fig. 20D: so), a much smaller proportion than in the younger skulls. The supraoccipital appears extremely reduced, forming a small rod-like nuchal crest dorsal to the foramen magnum (Fig. 23). The dorsal extension of the supraoccipital forms a ridge that extends dorsally from the foramen magnum to the ventral edge of the parietal. Unlike the supraoccipital of younger specimens, it appears that it does not sit in contact with the hindbrain. The semicircular canals do not invade the supraoccipital.

The paroccipitals contact the basisphenoid ventrally, prootic anteriorly, parietal dorsally and supraoccipital mediodorsally. Distally, the paroccipital processes support the squamosals and contact the quadrate. These processes flare out from the foramen magnum in a pair of wing-like processes that expand laterally into large tabs (Fig. 20: pp). They measure $59.3 \mathrm{~mm}$ in length by 
$41819.6 \mathrm{~mm}$ in height giving a ratio of nearly 1:3. The processes are anteroposteriorly compressed

419 (Fig. 24). When viewed dorsally, the pair has a concave posterior surface (Fig. 24E and 24F) as

420 the distal portions extend posterolaterally. Cranial nerves X-XII exit medioventrally through the

421 exoccipitals and, unlike in the hatchling, are not visible posteriorly. Unfortunately, these

422 foramina are hard to distinguish and, as a result, only two can be seen. These foramina are

423 positioned more laterally, slightly lower, and further from the lateral expansion of the

424 paroccipital processes than in the younger specimens. Semicircular canal foramina can be seen

425 on the anterior surface (Fig. 24H). The exoccipitals make up approximately $60 \%$ of the foramen

426 magnum margin.

427 The laterosphenoid contacts the prootic posteroventrally, the frontal anterodorsally and the

428 orbitosphenoid anteromedially. The laterosphenoids of the adult are robust and nearly triangular

429 in cross section (Fig. 25). They measure $25.9 \mathrm{~mm}$ anteroposteriorly and $14.5 \mathrm{~mm}$ wide

430 anteriorly. Like those of the juvenile, the laterosphenoid is posteroanteriorly elongated, and the

431 head is dorsoventrally flattened and located on the anterior surface (Figs 25A and 25B: 1sh). The

432 laterosphenoid is concave medially and convex laterally. In lateral and medial views, it appears

433 to taper anteriorly (Figs. 25A and 25B), but when viewed anteriorly it appears to taper

434 posteriorly (Figs. 25E and 25F). The laterosphenoid only contributes to the dorsal-most margin

435 of the anterolaterally oriented foramen for CN V.

436 The thin posterior margin of the orbitosphenoid forms the articular surface for the

437 laterosphenoid (Fig. 26: 1sas). The orbitosphenoid measures approximately $27 \mathrm{~mm}$

438 dorsoventrally. This left orbitosphenoid is the only example preserved in our specimens. It is

439 mediolaterally thin and delicate in this mature specimen making it understandable why this 
440 element is rarely preserved in smaller individuals. The optic nerve exits medially where it

441 inscribes a concavity in the orbitosphenoid (Fig. 26).

442 The boundaries of the prootics are difficult to distinguish, particularly the dorsal-most contacts.

443 Inferred contacts include the basisphenoid ventrally, laterosphenoid anterodorsally, parietal

444 posterodorsally and the paroccipital processes posteriorly. It is possible that it does not contact

445 the parietal and an anterior portion of the exoccipitals inserts between the two elements. The

446 prootic of the adult is a tall and relatively robust element (Fig. 27) that measures $29.2 \mathrm{~mm}$ in

447 height and $13.5 \mathrm{~mm}$ in width. The bone surrounding the semicircular canals is damaged, and so

448 boundaries between the prootic and exoccipital are obliterated. The anterior canal and parts of

449 the horizontal semicircular canal are well entombed in the prootic, which differs from the

450 hatchling (Fig. 27G: sccp). The anterior sections of the semicircular canals can be seen exiting

451 the posterior surface of the prootic (Fig. 27G). The medial surface of the prootic lacks both the

452 medial ridge of the hatchling and the transverse ridges of the juvenile. With the exception of the

453 cranial nerves, the medial surface is concave and smooth. CN V is almost entirely enclosed in the

454 prootic due to the presence of a large, robust preprootic strut (Fig. 27: pps).

455 The parietal contacts include the frontal anteriorly, prootic anteroventrally, paroccipitals

456 posteroventrally and the supraoccipital posteriorly. The parietal lies posteriorly on the dorsal

457 surface of the braincase and contributes approximately 50\% of the braincase roof (Fig. 20C: pa).

458 The posterior position of the parietal differs from the parietal of the hatchling specimen which

459 sits dorsally to the brain. Although the posterior section of the parietal is missing, the preserved

460 parietal suggests that a small shelf projected over the occipital surface. A midline ridge spans the

461 height of the posterior surface of the parietal shelf (Fig. 28E: pmr) forming the supraoccipital

462 articular surface. A sagittal crest is a prominent feature of the adult parietals (Figs. 28A, 28B and 
463 28D: sc) and spans the length of the dorsal surface. The mid-lateral portions of the parietal taper

464 laterally to form the margins of the upper temporal fenestra.

465 Frontal contacts include the parietal posteriorly, laterosphenoids ventrally and the nasals

466 anteriorly. It is unclear where the prefrontal contact would sit (Fig. 29D: no?). The frontal

467 measures $54 \mathrm{~mm}$ anteroposteriorly and $51.5 \mathrm{~mm}$ across its widest point and is dorsoventrally

468 very thin $(<5 \mathrm{~mm})$ along the midline. Much like the frontal of the juvenile, this element is

469 relatively flat in the adult (Fig. 29). It appears sub-rectangular in dorsal view. Ventrally, the

470 hourglass impression of the anterior region of the brain is present and only the anterior-most

471 section of the cerebrum impressions is preserved. These impressions are shallower than the

472 bulbous impressions of the hatchling specimen. A low, blunt sagittal crest is present on the

473 dorsal surface of the frontal (Fig. 29:fc). As is the case with the juvenile frontal, the orbit wall is

474 orientated in the coronal plane obscuring the orbit from lateral view. When viewed dorsally, the

475 orbital margin (Fig. 29: om) inscribes anterolateral concavities into the sides of the frontal.

\section{Discussion}

\section{Skull proportions}

479 A comparison of the three skulls (Table 1) reveals that several elements remain relatively

480 isometric throughout growth. The salient allometric changes that accompany growth include 481 approximately $40 \%$ elongation of the paroccipital processes (relative to basal skull length), a

482 dramatic reduction in supraoccipital height (approximately 50\% smaller relative to basal skull

483 length) and width (approximately 90\% smaller relative to basal skull length), approximately 50\%

484 reduction in width of the laterosphenoids and the frontals (relative to basal skull length), and

485 over $50 \%$ increase in the height of the basal tubera (relative to basal skull length). Measurements 
486 taken from the juvenile braincase do not correspond closely to those taken from the other

487 individuals in that the height to width ratios of the elements do not follow the same trend as in

488 the other two specimens. This is most likely due to taphonomic deformation (mainly

489 dorsoventral compression) or unavoidable inaccuracies during segmentation because of suture 490 obscurity or obliteration.

491 The orientation and morphology of the basioccipital component of the basal tubera changes

492 during growth. The basal tubera of the hatchling are oriented in the sagittal plane (Fig. 30A and

493 30B). The tubera of the juvenile are starting to develop into the anteroposteriorly compressed

494 tubera of the adult basioccipital, but they still retain some of the mediolateral compression

495 observed in the basioccipital of the hatchling, which creates a loose ' $\mathrm{L}$ ' shape (Fig. 30C and

496 30D). The robust basal tubera of the adult are oriented transversely (Fig. 30E and 30F). As the

497 individual grows, we also see a larger contribution of the basisphenoid to the basal tubera, which

498 might explain this morphological change. The basioccipital of adult individuals of Bagaceratops

499 rozhdestvenskyi differs from that of $P$. lujiatunensis in that it contributes very little to the basal

500 tubera (Maryańska \& Osmólska, 1975). Unlike the basal tubera of Yinlong (Han et al., 2016) and

501 pachycephalosaurids (Maryańska et al., 2004), the basisphenoid contribution of P. lujiatunensis

502 is not visible in caudal view.

503 During growth, we see an increase in the size of the basal tubera relative to the rest of the

504 braincase. The height to width ratio of the tubera also changes from 1:2 in the two younger

505 specimens, to 1:1 in the adult. The tubera of the adult are wide, plate-like, but clearly bilobate.

506 Neoceratopsians such as Liaoceratops, Auroraceratops and Archaeoceratops have a singular

507 clear plate beneath the occipital condyle with a shallower median cleft (Dodson et al., 2010).

508 Basal tubera act as ligament and muscle attachment sites, stabilizing the head on the neck. This 
509 enlargement of the attachment area may be attributed to the expansion of the parietal shelf and

510 subsequent increase in relative weight of the skull. The growth of the basal tubera likely

511 permitted strengthening of the lateroflexion muscles, such as the m. longissimus (Ostrom,1961),

512 required for movement of the neck in conjunction with the developing skull. This expansion is

513 observed in other non-avian dinosaurs (e.g. Carpenter, 1982; Jacobs et al., 1994; Huebner \&

514 Rauhut, 2010).

515 The occipital condyles studied here, with the possible exception of the juvenile (likely due to

516 sutural obscurity resulting in segmentation imprecision), are made up entirely of the

517 basioccipital, with no evident contribution from the exoccipitals. Several descriptions of

518 Psittacosaurus suggest this is the case (Sereno et al., 1988; Sereno, 1992; Xu, 1997; You \& Xu,

519 2005; Zhou et al., 2006; Brinkman et al., 2001; You et al., 2008). This contradicts Averianov et

520 al. (2006) and Sereno (2010), both of whom suggested that the exoccipitals likely contributed to

521 the occipital condyles, as is the case in some other dinosaurs including more derived

522 ceratopsians.

523 The length ratio of the basioccipital and basisphenoid (disregarding the cultriform process) is

524 approximately 1:1 and this remains relatively static throughout growth (Table 1). Further, the

525 cultriform process stays the same length relative to total basisphenoid length. The cultriform

526 process also moves dorsally as the basisphenoid deepens throughout ontogeny. The anterolateral

527 projection of the basipterygoid processes observed here are present in all psittacosaurids (Sereno

528 et al., 1988; You et al., 2008; Dodson et al., 2010) and similar rostrally projecting processes are

529 present in several basal neoceratopsians including Archaeoceratops (Dodson et al., 2010) and

530 Protoceratops (Brown \& Schlaikjer, 1940; Chinnery \& Weishampel, 1998; Dodson et al., 2010).

531 Conversely, posteroventrally projecting basipterygoid processes are found in the 
532 Leptoceratopsidae (Chinnery \& Weishampel, 1998; Ott, 2006) and the Ceratopsidae (Hatcher et

533 al., 1907; Dodson \& Currie; 1990; Chinnery \& Weishampel, 1998). Throughout growth, these

534 basipterygoid processes become progressively more ventrally projecting. The angle at which the

535 basipterygoid processes diverge also decreases from $81^{\circ}$ to $44^{\circ}$. This may be to accommodate the

536 dorsoventral expansion of the skull during growth. When viewed dorsally, the sella turcica

537 changes from triangular to sub-diamond-like in shape.

538 The supraoccipital contributes to the dorsal margin of the foramen magnum in each specimen

539 reported here. This is also the case in Protoceratops (Brown \& Schlaikjer, 1940), Leptoceratops

540 (Sternberg, 1951) and Bagaceratops (Maryańska \& Osmólska, 1975). The supraoccipital

541 bisecting the exoccipitals and contributing to the dorsal margin of the foramen magnum is also

542 thought to be a juvenile character within Ceratopsidae (Gilmore, 1917; Lehman, 1989), having

543 been recorded in immature specimens of Triceratops (Goodwin et al., 2006; Horner \& Goodwin,

544 2006), Brachyceratops (Gilmore, 1917) and Chasmosaurus (Lehman, 1989). This contribution to

545 the foramen magnum is then lost in adult ceratopsids as the exoccipitals exclude the

546 supraoccipital from the roof of the braincase (Hatcher et al., 1907; Brown \& Schlaikjer, 1940;

547 Dodson \& Currie, 1989; Forster, 1996; Dodson et al., 2004). The supraoccipital in $P$.

548 lujiatunensis appears to undergo a reduction in size and dramatic change in shape. The large,

549 thin, plate-like supraoccipital of the hatchling reduces in size (relative to basal skull length) with

550 age and becomes rod-like with a wider ventral base. The midline crest running down the

551 posterior face of the supraoccipital in the hatchling and adult skulls most likely separates an

552 attachment site for epaxial muscles, as is the case for other ceratopsians such as Triceratops

553 (Goodwin et al., 2006). Unlike the other individuals, the juvenile supraoccipital shows no

554 evidence of a caudal midline ridge, but this area is incomplete. While the supraoccipital forms 
555 most of the occipital surface of the hatchling skull, much of this surface of the adult skull appears

556 to be taken up by the parietal. As P. lujiatunensis grows, the contribution of the supraoccipital to

557 the foramen magnum decreases. A more extreme version of this, where the supraoccipital is fully

558 excluded from the foramen magnum by the exoccipitals, is documented during growth of

559 ceratopsids such as Triceratops (Goodwin et al., 2006). The posterior semicircular canal of $P$.

560 lujiatunensis is situated in the supraoccipital of the hatchling, whereas it remains within the

561 confines of the paroccipital processes in the older specimens. It is important to note that

562 compression of the adult skull (Hedrick \& Dodson, 2013) may have affected sutural boundaries

563 and segmentation accuracy in this area. While You \& Xu (2005) and Taylor et al. (2016) also

564 report a heavily reduced supraoccipital in IVPP V12617, other reconstructions of adult

565 Psittacosaurus have depicted the supraoccipital as being wider than it is tall (e.g. Sereno, 1987;

566 Sereno et al., 1988; Zhou et al., 2006). It is therefore possible that the supraoccipital of the adult

567 was more laterally extensive than is apparent in this specimen.

568 The paroccipital processes expand laterally during growth of $P$. lujiatunensis. The small,

569 rectangular processes of the hatchling become long and slightly distally flared. These gracile,

570 long and dorsoventrally narrow elements are similar to those of basal neoceratopsians such as

571 Montanoceratops (Chinnery \& Weishampel, 1998), Leptoceratops (Sternberg, 1951),

572 Bagaceratops (Maryańska \& Osmólska, 1975) and Proceratops (Brown \& Schlaikjer, 1940).

573 Ceratopsid exoccipitals tend to be stouter, more robust, and highly flared distally, contacting the

574 squamosal to support the large parieto-squamosal frill (Brown \& Schlaikjer, 1940; Ostrom \&

575 Wellnhofer, 1990; Forster, 1996; Chinnery \& Weishampel, 1998). Goodwin et al. (2006) note

576 that the paroccipital processes of the juvenile Triceratops appear to anticipate the structural

577 requirements of adulthood and are already flared, in contact with the ventral surface of the 
578 squamosal, and laterally expanded to form the buttress for the frill. The expansion of the

579 paroccipital processes of $P$. lujiatunensis increases the surface area of the attachment site of the

580 m. obliquus capitis magnus, for lateral and dorsoventral movement of the head. This might have

581 been necessary to accommodate the weight of the mature skull with developed parieto-

582 squamosal shelf and flared jugals, a hypothesis also used to explain the large exoccipitals in

583 ceratopsids (Goussard, 2006). This muscular growth may also be linked to the posited postural

584 shift during ontogeny (Zhao et al., 2013) and the associated possibility of a change in feeding

585 mechanism - i.e. grazing juveniles develop into facultative browsers. Much like those of

586 Bagaceratops (Maryańska \& Osmólska, 1975), the contribution of the exoccipitals to the

587 occipital condyle of $P$. lujiatunensis is minimal/ absent. The exoccipitals do not contact each

588 other, being separated ventrally by the basioccipital and dorsally by the supraoccipital, as in

589 other basal ceratopsians such as Yinlong (Han et al., 2016). In basal Neoceratopsia, the

590 exoccipitals also contribute to the ventral portion of the foramen magnum, excluding the

591 basioccipital (You \& Dodson, 2004).

592 The laterosphenoid undergoes some morphological change and becomes more robust as the

593 individual grows. Laterally, it is triangular and transforms to become anteroposteriorly

594 elongated. The laterosphenoid head displaces anteriorly as the laterosphenoid elongates. The $m$.

595 pseudotemporalis superficialis, $m$. tensor periorbitae and $m$. levator pterygoideus are assumed to

596 have had attachment sites on the laterosphenoid (Holliday, 2009).

597 The semicircular canals are loosely held within the prootic of the hatchling, which is partially

598 why it was difficult to segment. The prootic develops into a robust element and the semicircular

599 canals of the two older specimens are encased firmly within. The foramen for cranial nerve V

600 becomes orientated more anteriorly through growth along with the development of a pronounced 
601 preprootic strut. A small foramen in the middle of the hatchling and juvenile prootics is thought

602 to be for transmitting cranial nerve VII. If this is the case, this is shared with Montanoceratops

603 (Chinnery \& Weishampel, 1998) and Bagaceratops (Maryańska \& Osmólska, 1975).

604 Initially, the parietal and frontal are convex in accordance with the round skull shape which is 605 also observed in a juvenile specimen of Bagaceratops (Maryańska \& Osmólska, 1975). These 606 bones become flatter and, as observed in Coombs (1982), a sagittal crest develops with age, a 607 clear indication of strengthening adductor mandibulae jaw muscles (Sereno et al., 2010). This 608 crest is also present in several basal ceratopsians including Yinlong (Han et al., 2015), 609 Liaoceratops (Xu et al., 2002), Archaeoceratops (You \& Dodson, 2003) and Bagaceratops 610 (Maryańska \& Osmólska, 1975). Neither the hatchling described here nor the juvenile specimen 611 of Bagaceratops described by Maryańska \& Osmólska (1975) have a developed parietal crest, so 612 a defined sagittal crest is likely an adult character. During growth, a small parietal shelf extends 613 posteriorly over the occipital surface. This ontogenetic 'frill' growth is also seen in basal 614 neoceratopsians such as Protoceratops (Maryańska \& Osmólska, 1975; Fastovsky et al., 2011) 615 and Bagaceratops (Maryańska \& Osmólska, 1975). Ceratopsids, such as Triceratops, develop a 616 large frill during growth, but an incipient frill is already present in juvenile specimens (Goodwin 617 et al., 2006; Currie et al., 2016). As the parietal expands during growth, the supraoccipital 618 shrinks (relative to basal skull length) and the contact between the parietal and the paroccipital 619 processes extends across the full width of the processes. The fronto-parietal sutural contact of 620 Protoceratops migrates posteriorly with growth (Maryańska \& Osmólska, 1975), which differs 621 from $P$. lujiatunensis whose contact appears to remain relatively stationary.

622 The frontals contact the same elements throughout growth. Substantial negative allometry can be 623 observed in the width of the frontals during growth (Table 1). As in juvenile Bagaceratops 
624 (Maryańska \& Osmólska, 1975), they remain dorsally convex and contribute to the overall

625 roundness of the skull roof. Unlike Bagaceratops (Maryańska \& Osmólska, 1975), the frontal of

626 P. lujiatunensis contributes to a large portion of the orbital margin. A frontal crest develops with

627 age. The juvenile has well defined, deep bulbous concavities where the cerebral hemispheres sat.

628 The cerebral depressions on the frontal become shallower and less defined during growth, likely

629 due to increasing distance between the brain and the braincase through maturation (Jerison,

630 1973). In cross section, the small convexities present on the midline of the dorsal surface of the

631 frontals appear to be separate, individual ossicles. There are several indicators that these are not

632 an artefact of the scanning process. Firstly, they mirror each other either side of the midline

633 ridge, displaying almost perfect bilateral symmetry. Had the specimen not been set perfectly in

634 the scanner, this would be off. Secondly, the cross section through these ossicles shows the same

635 texture and contrast values as the rest of the skull. We are also confident that these ossicles are

636 not broken sections from other elements due to the perfect circular shape and lack of any broken

637 or damaged surfaces. The midline symmetry also supports this. We considered the possibility

638 that these structures had a function similar to that of an egg-tooth and helped the baby

639 Psittacosaurus to hatch. This is, however, unlikely as the egg-tooth of archosaurs (including

640 putative examples in other non-avialan dinosaurs) is generally found on the tip of the snout (e.g.

641 Rahn et al., 1979; García, 2007). It is unlikely but possible that they could represent a pathology

642 or a mutation as they have not been observed in other juvenile ceratopsians, including hatchling

643 Psittacosaurus (Coombs, 1982). They could be epiossifications much like those seen on the

644 parieto-squamosal frill, but these frontal ossicles are lost during growth.

645

646 Semicircular canals 
647 The semicircular canal pathways are not clear in the hatchling IVPP V15451 and, consequently,

648 some sections have been inferred (Fig. 31A). This could be due to cartilaginous surroundings at a

649 young age, and this is more likely than simply poor preservation, as none of the reviewed

650 hatchling specimens has a complete housing for the inner ear. A theorized pathway has been

651 created using what remains of the hatchling's bony labyrinth (Fig. 31A) and the morphology of

652 the canals in the two older specimens.

653 The semicircular canals of the juvenile are dorsoventrally short. It is possible that this was the

654 case in vivo, but it is quite likely a result of the taphonomic compression that has affected the

655 skull as a whole. Because this stunted morphology spans the entire inner ear, the height

656 relationship between the anterior and posterior semicircular canals is preserved. The posterior

657 semicircular canal is approximately two-thirds the height of the anterior canal (Fig. 31C).

658 The semicircular canals of the adult are well preserved and maintain their in vivo morphology.

659 Much like those of the juvenile, the anterior semicircular canals are at least twice as large as the 660 posterior semicircular canals (Fig. 31E).

661

662 Lateral (horizontal) semicircular canal (LSC). It has been determined that Psittacosaurus

663 changed its posture during growth. Juveniles (including IVPP V16902) are reconstructed as

664 quadrupeds, based on the similar lengths of their forelimbs and hindlimbs (Zhao et al., 2013).

665 There is a lot of evidence for bipedality in adult Psittacosaurus. The forelimbs are half the length

666 of the hindlimbs (Osborn, 1923; Maryańska \& Osmólska, 1975; Sereno, 1990; Zhao et al., 2013)

667 and observed modifications of the pelvis suggest that they were able to support more weight

668 cranially (Chinnery, 2004). Similarly, Psittacosaurus display bipedal character states for all 
669 osteological correlates set out by Maidment \& Barrett (2014). Bipedality in adult Psittacosaurus

670 is also supported by the robustness and mobility of the forelimbs, which led Chinnery (2004) to

671 suggest that they could be used to manipulate the surrounding environment. Further evidence

672 comes from Maidment et al. (2014) who calculated the centre of mass for adult Psittacosaurus

673 was located dorsal to the hindfoot, allowing for bipedal locomotion. Psittacosaurus are

674 frequently reconstructed, when adult, as facultative bipeds, dropping their bodies and arms to the 675 ground when feeding, for example, but rearing high to detect danger or feed on leaves high on a 676 tree. This postural shift was confirmed by bone histological analysis of forelimb and hindlimb 677 bones, in which the femur of juveniles and adults shows evidence of faster growth than the 678 humerus (Zhao et al., 2013). Bone histology also demonstrated that the shift in posture likely 679 occurred during the third year of life, emphasizing the negative allometric growth of the forelimb 680 relative to overall body length as the animal became more and more adapted to bipedality during 681 ontogeny, after age 4 (Zhao et al., 2013).

682 We seek to test this idea by reference to the lateral semicircular canal in the three growth stages, 683 from hatchling to adult. The linkage between the lateral semicircular canal orientation and head 684 posture has been discussed for nearly a century. Although some studies advocated that the 685 orientation of the LSC is variable at both intraspecific and interspecific scales (Duijm, 1951; 686 Taylor et al., 2009; Marugán-Lobón et al., 2013; Coutier et al., 2017), the LSC is generally 687 considered to remain earth-horizontal when the head is in its 'natural' alert position (Lebedkin, 688 1924; Witmer et al., 2003; Chatterjee \& Templin, 2004; Sereno et al., 2007; Witmer et al., 2008; 689 Araujo et al., 2017; Coutier et al., 2017; Benoit et al., 2017; Schellhorn, 2018).

690 When working with semicircular canals, it is important to be sure that the method of measuring 691 orientation is plausible, and indeed our data may contribute to the debate. When Witmer et al. 
692 (2003) used the orientation of the LSC to assume the resting posture of the pterosaur head, critics

693 (e.g., Taylor et al., 2009) pointed out that in living tetrapods the LSC is not always held

694 horizontal. For example, these authors noted that extant animals often hold their heads oriented

695 so the LSC is tilted upwards by $12^{\circ}$ in monkeys, $16^{\circ}$ in rabbits, $20^{\circ}$ in guinea-pigs and domestic

696 cats, and $22^{\circ}$ in humans (Graf et al., 1995, Spoor \& Zonneveld, 1998). In birds, Duijm (1951)

697 showed that in most species the LSC was held horizontal, but in some species, values were as

698 much as $20^{\circ}$ below or $30^{\circ}$ above horizontal. Similarly, Magurán-Lobón et al. (2013) showed that

699 LSC orientation was not a reliable indicator of head orientation at rest. However, in studies of

700 modern xenarthrans (Coutier et al., 2017) and rhinos (Schelhorn, 2018), the LSC was near

701 enough horizontal to provide a good indicator of head orientation.

702 We propose to use our study of Psittacosaurus as a test of these opposing views. The angles

703 between the plane of the LSC and the palatal plane were calculated in our study, following the

704 method in Schellhorn (2018). Our analysis shows that the angles are very variable in the

705 ontogenetic series of Psittacosaurus lujiatunensis, but they show a clear trend of decline during

706 ontogenetic growth. The angle is $38^{\circ}$ in the hatchling stage, and changes to $25^{\circ}$ in the juvenile,

707 and reaches $15^{\circ}$ in the adult. Based on the isometric growth line of Psittacosaurus lujiatunensis

708 (Zhao et al., 2014), we can estimate the hatchling specimen is less than one year old, and the

709 juvenile specimen is approximately two years old. The adult specimen is ten years old, according

710 to bone histology. Under the assumption that the plane of the LSC is earth-horizontal, we

711 reconstruct the head posture of Psittacosaurus in different growth stages (Fig. 32). In our

712 reconstruction, the nose-down head posture is quite obvious in the hatchling stage, which implies

713 quadrupedal locomotion as the angle between the skull and neck vertebrae would be too high for

714 a bipedal stance (Coutier, 2017). The nose rises up in the juvenile stage, and points forward in 
715 the adult stage. These changes of head posture are consistent with the previous study on posture

716 shift from quadrupedal to bipedal during growth in Psittacosaurus (Zhao et al., 2013). The larger

717 angle present in the hatchling specimen would not be congruent with a bipedal stance (Coutier et 718 al., 2017).

719 Cranial nerves X-XII. There have been many interpretations and configuration of the foramina

720 exiting through the exoccipitals below the paroccipital processes in early ceratopsians (e.g.,

721 Averianov et al., 2006; Brown \& Schlaikjer, 1940; Chinnery \& Weishampel, 1998; Forster,

722 1996; Maryańska \& Osmólska, 1975; Xu, 1997; Brinkman et al., 2001). Here, $\mathrm{CNXII}_{3}$ is the

723 posterior-most foramen and is the largest in the hatchling and juvenile specimens. It is doubtful

724 that $\mathrm{CN} \mathrm{X}$ and CN XI would have individual exits, as they are confluent in ceratopsids and so it

725 seems unlikely that they would separate just to converge again (Brown \& Schlaikjer, 1940;

726 Averianov et al., 2006). As noted by Averianov et al. (2006), the foramen for $\mathrm{CN} \mathrm{XII}_{1+2}$ is small

727 and can be overlooked, which is why often Psittacosaurus can sometimes be mistakenly

728 described as having only two foramina in the exoccipital (e.g., Xu, 1997). This is most likely the

729 case for the adult described here, as only two cranial nerve foramina can be seen exiting the

730 exoccipital, unlike the hatchling and juvenile specimens, which have three clear, separate

731 foramina (Fig. 33). Note that poor contrast values in the adult scan made segmentation difficult

732 in this region.

733

734 Conclusion

735 Braincases are often neglected in cranial descriptions and ontogenetic studies because they are

736 believed to exhibit little variation and are often inaccessible. While some braincase elements 
737 grew in an isometric fashion, many grew at different rates (Table 1). Salient ontogenetic changes

738 in the braincase of Psittacosaurus lujiatunensis (Fig. 34) include:

739 1. The basal tubera expand dorsoventrally and laterally.

740 2. The angle of divergence of the basipterygoid processes drops from $81^{\circ}$ to $44^{\circ}$.

741 3. The supraoccipital appears to undergo a dramatic reduction in size from a large, plate-like

742 element to a transversely compressed rod. One caveat is that the accuracy of

743 segmentation in this area may have been affected by damage.

4. The small sub-rectangular paroccipital processes of the hatchling laterally expand and become long and 'strap-like'.

5. The laterosphenoid becomes anteroposteriorly elongated and the laterosphenoid head displaces rostrally.

6. A sagittal crest develops along the midline of the parietal.

7. A small parietal shelf develops.

751

752

753

754

755

756

757

758

759

8. The width of the frontals relative to basal skull length decreases dramatically during growth.

9. The angle of the lateral semicircular canal decreases from $38^{\circ}$ to $15^{\circ}$. This is the first evidence to illustrate the variation of orientation of the LSC in the ontogenetic growth of a species of dinosaur, and it confirms that, at least for this genus, the LSC orientation is well aligned with expectations of head posture. The head was held nose-down in quadrupedal hatchlings and more horizontal in bipedal adults. This shift is in accordance with matching of the occipital condyle and the vertebral column.

Braincases are generally more conservative than other areas of the skeleton that are associated with highly adaptive functions, and so can be valuable in a phylogenetic context (Bakker et al., 
760 1988; Coria \& Currie, 2002). Element characteristics that change dramatically during growth

761 should be excluded from a phylogenetic analysis as ontogenetic variation may be misinterpreted

762 as phylogenetic variation. Elements that remain similar in relative size or morphology

763 throughout growth may prove to be useful phylogenetic characters and should be investigated

764 further. In this case, the proportions of the basioccipital, paroccipital height, parietal length and

765 basal tubera width should be explored in a phylogenetic context, as the relative growth of these

766 elements appears to be close to constant (Table 1).

767 This is the first time that frontal ossicles have been recorded in basal ceratopsians. The function

768 and origins of these ossicles are unknown. More examples and further analysis of these

769 structures are required to make any reliable assumptions.

770

771 Acknowledgements. We thank Yun Feng, the technician at IVPP, for scanning the specimens. We

772 also thank James Brown for his artistic assistance with the Psittacosaurus silhouettes.

\section{REFERENCES}

775 Araujo R, Fernandez V, Polcyn MJ, Fröbisch J, Martins, RMS. 2017. Aspects of

776 gorgonopsian paleobiology and evolution: insights from the basicranium, occiput, osseous

777 labyrinth, vasculature, and neuroanatomy. PeerJ 5:e3119.

778 Averianov AO, Voronkevich AV, Leshchinskiy S, Fayngertz, AV. 2006. A ceratopsian

779 dinosaur Psittacosaurus sibiricus from the Early Cretaceous of West Siberia, Russia and its

780 phylogenetic relationships. Journal of Systematic Palaeontology 4:359-395. 
781

782

783

784

785

786

787

788

789

790

791

792

793

794

795

796

797

798

799

800

801

802 803

Bailleul AM, Scannella JB, Horner JR, Evans DC. 2016. Fusion patterns in the skulls of modern archosaurs reveal that sutures are ambiguous maturity indicators for the Dinosauria. PLOS ONE 11:e0147687.

Bakker RT, Williams M, Currie PJ. 1988. Nanotyrannus, a new genus of pygmy tyrannosaur from the latest Cretaceous of Montana, Hunteria 1:1-30.

Benoit J, Manger BS, Norton L, Fernandez V, Rubidge BS. 2017. Synchrotron scanning reveals the palaeoneurology of the head-butting Moschops capensis (Therapsida, Dinocephalia). PeerJ 5: e3496.

Brinkman DB, Eberth DA, Ryan MJ, Chen PJ. 2001. The occurrence of Psittacosaurus xinjiangensis Sereno and Chow, 1988 in the Urho area, Junggar Basin, Xinjiang, People's Republic of China. Canadian Journal of Earth Sciences 38, 1781-1786.

Brochu CA. 1996. Closure of neurocentral sutures during crocodilian ontogeny: implications for maturity assessment in fossil archosaurs. Journal of Vertebrate Paleontology 16, 49-62.

Brown DB, Schlaikjer DEM. 1940. The structure and relationships of Protoceratops. Transactions of the New York Academy of Sciences 2, 99-100.

Chang SC, Gao KQ, Zhou CF, Jourdan F. 2017. New chronostratigraphic constraints on the Yixian Formation with implications for the Jehol Biota. Palaeogeography, Palaeoclimatology, Palaeoecology 487, 399-406.

Chapelle KE, Choiniere JN. 2018. A revised cranial description of Massospondylus carinatus Owen (Dinosauria: Sauropodomorpha) based on computed tomographic scans and a review of cranial characters for basal Sauropodomorpha. PeerJ 6:e4224.

Chatterjee S, Templin RJ. 2004. Posture, locomotion, and paleoecology of pterosaurs. Geological Society of America Special Papers 376, 1-64. 
804 Chinnery BJ. 2004. Morphometric analysis of evolutionary trends in the ceratopsian postcranial 805 skeleton. Journal of Vertebrate Paleontology 24, 591-609.

806 Chinnery-Allgeier BJ, Kirkland JI. 2010. An update on the paleobiogeography of ceratopsian 807 dinosaurs. In: Ryan MJ, Chinnery-Allgeier BJ, Eberth DA, eds. New perspectives on horned 808 dinosaurs: The Royal Tyrrell Museum Ceratopsian Symposium. Bloomington: Indiana $809 \quad$ University Press, 387-404.

810 Chinnery BJ, Weishampel DB. 1998. Montanoceratops cerorhynchus (Dinosauria: Ceratopsia) and relationships among basal neoceratopsians. Journal of Vertebrate Paleontology 18, 569585.

Coombs Jr WP. 1982. Juvenile specimens of the ornithischian dinosaur Psittacosaurus.

$814 \quad$ Palaeontology 25, 89-107.

815 Coutier F, Hautier L, Cornette R, Amson E, Billet G. 2017. Orientation of the lateral

816 semicircular canal in Xenarthra and its links with head posture and phylogeny. Journal of 817 Morphology 278, 704-717.

818 Coria RA, Currie PJ. 2002. The braincase of Giganotosaurus carolinii (Dinosauria:

819 Theropoda) from the upper cretaceous of Argentina. Journal of Vertebrate Paleontology 22, $820 \quad 802-811$.

821 Currie PJ, Holmes RB, Ryan MJ, Coy C. 2016. A juvenile chasmosaurine ceratopsid 822 (Dinosauria, Ornithischia) from the Dinosaur Park Formation, Alberta, Canada. Journal of $823 \quad$ Vertebrate Paleontology 36:e1048348.

Dodson P. 2013. Ceratopsia increase: history and trends. Canadian Journal of Earth Sciences 825 50, 294-305. 
826 Dodson P, Currie PJ. 1990. Neoceratopsia. In: Weishampel DB, Dodson P, Osmólska H, eds.

827 The Dinosauria. University of California Press, Berkeley. 593-618.

828 Dodson P, Forster CA, Sampson SD. 2004. Ceratopsidae. In: Weishampel DB, Dodson P, 829 Osmólska H, eds. The Dinosauria. University of California Press, Berkeley. 494-513.

830 Dodson P, You H, Tanoue K. 2010. Comments on the basicranium and palate of basal

831 ceratopsians. In: Ryan MJ, Chinnery-Allgeier BJ, Eberth DA, Ralrick PE, eds. New

832 Perspectives on Horned Dinosaurs: The Royal Tyrrell Museum Ceratopsian Symposium.

833 Indiana University Press, Bloomington, Indiana. 221-233.

834

835

836

837

838

839

840

841

842

843

844

845

846

847

Dong ZM, Azuma Y. 1997. On a primitive neoceratopsian from the Early Cretaceous of China. 68-89. In: Dong ZM, ed. Sino-Japanese Silk Road Dinosaur Expedition. China Ocean Press, Beijing, 114 pp.

Dufeau DL, Witmer LM. 2015. Ontogeny of the middle-ear air-sinus system in Alligator mississippiensis (Archosauria: Crocodylia). PLOS ONE 10:e0137060.

Duijm M. 1951. On the head posture of some birds and its relation to some anatomical features. Proceedings of the Koninklijke Nederlandse Akademie van Wetenschappen, Series C 54, $260-271$.

Fastovsky DE, Weishampel DB, Watabe M, Barsbold R, Tsogtbaatar KH, Narmandakh P. 2011. A nest of Protoceratops andrewsi (Dinosauria, Ornithischia). Journal of Paleontology 85, 1035-1041.

Forster CA. 1996. New information on the skull of Triceratops. Journal of Vertebrate Paleontology 16, 246-258.

García RA. 2007. An "egg-tooth"-like structure in titanosaurian sauropod embryos. Journal of Vertebrate Paleontology 27, 247-252. 
849 Gilmore CW. 1917. Brachyceratops, a ceratopsian dinosaur from the Two Medicine Formation 850 of Montana, with notes on associated fossil reptiles. US Government Printing Office 103, 185145.

852 Goodwin MB, Clemens WA, Horner JR, Padian K. 2006. The smallest known Triceratops 853 skull: new observations on ceratopsid cranial anatomy and ontogeny. Journal of Vertebrate $854 \quad$ Paleontology 26, 103-112.

855 Goussard F. 2006. The skull of Triceratops in the palaeontology gallery, Muséum National 856 d'Histoire Naturelle, Paris. Geodiversitas 28, 467-476.

857 Graf W, De Waele C, Vidal PP. 1995. Functional anatomy of the head-neck movement system 858 of quadrupedal and bipedal mammals. Journal of Anatomy 186, 55-74.

859

860

861

862

863

864

865

866

867

868

869

870

871

Han FL, Forster CA, Clark J, Xu X. 2015. A new taxon of basal ceratopsian from China and the early evolution of Ceratopsia. PLOS ONE 10:e0143369.

Han FL, Forster CA, Clark JM, Xu X. 2016. Cranial anatomy of Yinlong downsi (Ornithischia: Ceratopsia) from the Upper Jurassic Shishugou Formation of Xinjiang, China. Journal of Vertebrate Paleontology 36:e1029579.

Han FL, Forster CA, Xu X, Clark JM. 2017. Postcranial anatomy of Yinlong downsi (Dinosauria: Ceratopsia) from the Upper Jurassic Shishugou Formation of China and the phylogeny of basal ornithischians. Journal of Systematic Palaeontology 16:1159-1187.

Hatcher JB, Osborn HF, Marsh OC. 1907. The Ceratopsia. US Government Printing Office 49: $1-300$.

He Y, Makovicky PJ, Wang K, Chen S, Sullivan C, Han FL, Xu X. 2015. A new Leptoceratopsid (Ornithischia, Ceratopsia) with a unique ischium from the Upper Cretaceous of Shandong Province, China. PLOS ONE 10:e0144148. 
872 Hedrick BP, Dodson P. 2013. Lujiatun psittacosaurids: understanding individual and

873 taphonomic variation using 3D geometric morphometrics. PLOS ONE 8:e69265.

874 Hoffman DK, Heckert AB, Zanno LE. 2018. Under the armor: X-ray computed tomographic

875 reconstruction of the internal skeleton of Coahomasuchus chathamensis (Archosauria:

876 Aetosauria) from the Upper Triassic of North Carolina, USA, and a phylogenetic analysis of $877 \quad$ Aetosauria. PeerJ 6:e4368.

878 Holliday CM. 2009. New insights into dinosaur jaw muscle anatomy. The Anatomical Record 292, 1246-1265.

880

881

882

883

884

885

886

887

888

889

890

891

892

893

894

Horner JR, Goodwin MB. 2006. Major cranial changes during Triceratops ontogeny. Proceedings of the Royal Society of London B: Biological Sciences 273, 2757-2761.

Huebner TR, Rauhut OW. 2010. A juvenile skull of Dysalotosaurus lettowvorbecki (Ornithischia: Iguanodontia), and implications for cranial ontogeny, phylogeny, and taxonomy in ornithopod dinosaurs. Zoological Journal of the Linnean Society 160, 366-396.

Jacobs LL, Winkler DA, Murry PA, Maurice JM. 1994. A nodosaurid scuteling from the Texas shore of the Western Interior Seaway. In: Carpenter K, Hirsch KF, Horner JR, eds. Dinosaur eggs and babies. Cambridge: Cambridge University Press, 337-346.

Jerison H. 1973. Evolution of the brain and intelligence. New York: Academic Press.

Lebedkin S. 1924. Uber die Lage des Canalis semicircularis bei Säugern. Anatomischer Anzeiger 58, 449-460. [in German].

Lehman TM. 1989. Chasmosaurus mariscalensis, sp. nov., a new ceratopsian dinosaur from Texas. Journal of Vertebrate Paleontology 9, 137-162.

Longrich NR, Field DJ. 2012. Torosaurus is not Triceratops: ontogeny in chasmosaurine ceratopsids as a case study in dinosaur taxonomy. PLOS ONE 7:e32623. 
895 Maidment SC, Barrett PM. 2014. Osteological correlates for quadrupedality in ornithischian 896 dinosaurs. Acta Palaeontologica Polonica 59, 53-70

897

898

899

900

901

902

903

904

905

906

907

908

909

910

911

912

913

914

915

916

917

Maidment SC, Henderson DM. \& Barrett, PM. 2014. What drove reversions to quadrupedality in ornithischian dinosaurs? Testing hypotheses using centre of mass modelling. Naturwissenschaften 101, 989-1001.

Marugán-Lobón J, Chiappe LM, Farke AA. 2013. The variability of inner ear orientation in saurischian dinosaurs: testing the use of semicircular canals as a reference system for comparative anatomy. PeerJ 1:e124.

Maryańska T, Osmólska H. 1975. Protoceratopsidae (Dinosauria) of Asia. Palaeontologia Polonica 33, 133-181.

Morschhauser EM. 2012. The anatomy and phylogeny of Auroraceratops (Ornithischia: Ceratopsia) from the Yujingzi Basin of Gansu Province, China. Unpublished PhD thesis, University of Pennsylvania, $629 \mathrm{pp}$.

Neenan JM, Scheyer TM. 2012. The braincase and inner ear of Placodus gigas (Sauropterygia, Placodontia) — a new reconstruction based on micro-computed tomographic data. Journal of Vertebrate Paleontology 32, 1350-1357.

Osborn HF. 1923. Two Lower Cretaceous dinosaurs of Mongolia. American Museum Novitates

$$
\text { 95, } 1-3 \text {. }
$$

Ostrom JH. 1961. A new species of hadrosaurian dinosaur from the Cretaceous of New Mexico. Journal of Paleontology 35:575-577.

Ostrom JH, Wellnhofer P. 1990. Triceratops: an example of flawed systematics. In: Carpenter K, Currie PJ, eds. Dinosaur Systematics: Approaches and Perspectives. New York:

$$
\text { Cambridge University Press. 245-254. }
$$


918 Ott CJ. 2007. Cranial anatomy and biogeography of the first Leptoceratops gracilis (Dinosauria:

919 Ornithischia) specimens from the Hell Creek Formation, Southeast Montana. In: Carpenter

920 K, ed. Horns and Beaks: Ceratopsian and Ornithopod Dinosaurs. Bloomington: Indiana

921 University Press. 213-233. 369 pp.

922 Rahn H, Ar A, Paganelli CV. 1979. How bird eggs breathe. Scientific American 240, 46-55.

923 Rogers CS, Hone DW, McNamara ME, Zhao Q, Orr PJ, Kearns SL, Benton MJ. 2015. The

924 Chinese Pompeii? Death and destruction of dinosaurs in the Early Cretaceous of Lujiatun,

925 NE China. Palaeogeography, Palaeoclimatology, Palaeoecology 427, 89-99.

926 Sampson SD, Ryan MJ, Tanke DH. 1997. Craniofacial ontogeny in centrosaurine dinosaurs

927 (Ornithischia: Ceratopsidae): taxonomic and behavioral implications. Zoological Journal of 928 the Linnean Society 121, 293-337.

929 Scannella JB, Horner JR. 2011. 'Nedoceratops': an example of a transitional 930 morphology. PLOS ONE 6:e28705.

931 Schellhorn R. 2018. A potential link between lateral semicircular canal orientation, head 932 posture, and dietary habits in extant rhinos (Perissodactyla, Rhinocerotidae). Journal of 933 Morphology 279:50-61.

934 Sereno PC. 1987. The ornithischian dinosaur Psittacosaurus from the Lower Cretaceous of Asia 935 and the relationships of the Ceratopsia. Unpublished Ph.D. dissertation, Columbia $936 \quad$ University, New York, 554 pp.

937 Sereno PC. 1990. Psittacosauridae. In: Weishampel DB, Dodson P, Osmólska H, eds.. The 938 Dinosauria. Berkeley: University of California Press, 579-592. 
939 Sereno PC. 1992. New data on parrot-beaked dinosaurs (Psittacosaurus). In: Carpenter K,

940 Currie PJ, eds. Dinosaur systematics. Approaches and perspectives. Cambridge: Cambridge

$941 \quad$ University Press, 203-210.

942 Sereno PC. 2000. The fossil record, systematics and evolution of pachycephalosaurs and

943 ceratopsians from Asia. In: Benton MJ, Shishkin MA, Unwin DM, Kurochkin EN, eds. The

944 age of dinosaurs in Russia and Mongolia. Cambridge: Cambridge University Press, 450-

$945 \quad 516$.

946 Sereno PC. 2010. Taxonomy, cranial morphology, and relationships of parrot-beaked dinosaurs

947 (Ceratopsia: Psittacosaurus). In: Ryan MJ, Chinnery-Allgeier BJ, Eberth DA, eds. New

948 perspectives on horned dinosaurs: The Royal Tyrrell Museum ceratopsian symposium.

949 Bloomington: Indiana University Press, 21-58.

950 Sereno PC, Chao S, Cheng Z, Rao C. 1988. Psittacosaurus meileyingensis (Ornithischia:

951 Ceratopsia), a new psittacosaur from the Lower Cretaceous of northeastern China. Journal

952 of Vertebrate Paleontology 8:366-377.

953 Sereno PC, Wilson JA, Witmer LM. Whitlock JA, Maga A, Ide O, Rowe TA. 2007.

954 Structural extremes in a Cretaceous dinosaur. PLOS ONE 2:e1230.

955 Sereno PC, Xijin Z, Lin T. 2010. A new psittacosaur from Inner Mongolia and the parrot-like

956 structure and function of the psittacosaur skull. Proceedings of the Royal Society of London

957 B: Biological Sciences 277, 199-209.

958 Spoor F, Zonneveld F. 1998. Comparative review of the human bony labyrinth. American

959 Journal of Physical Anthropology 107, 211-251. 
960 Sternberg CM. 1951. Complete skeleton of Leptoceratops gracilis Brown from the Upper

961 Edmonton Member on Red Deer River Alberta. Bulletin of the National Museum of Canada

$962 \quad 123,225-255$.

963 Taylor AC, Lautenschlager S, Zhao Q, Rayfield EJ. 2017. Biomechanical evaluation of

964 different musculoskeletal arrangements in Psittacosaurus and implications for cranial

965 function. The Anatomical Record 300, 49-61.

966 Taylor MP, Wedel MJ, Naish D. 2009. Head and neck posture in sauropod dinosaurs inferred

967 from extant animals. Acta Palaeontologica Polonica 54, 213-220.

968 Walsh SA, Knoll F. 2018. The evolution of avian intelligence and sensory capabilities: the fossil

969 evidence. In: Bruner E, Ogihara N, Tanabe H, eds. Digital Endocasts. Springer, Tokyo, 59-

$970 \quad 69.289 \mathrm{pp}$.

971

972

973

974

975

976

977

978

979

980

981

982

\section{Weishampel DB, Barrett PM, Coria RA, Le Loeuff J, Xu X, Zhao X, Sahni A, Gomani}

EMP, Noto CR. 2004. Dinosaur distribution. In: Weishampel DB, Dodson P, Osmólska H, eds. The Dinosauria, second edition. University of California Press, Berkeley, 517-606. 861

pp.

Witmer LM, Chatterjee S, Franzosa J, Rowe T. 2003. Neuroanatomy of flying reptiles and implications for flight, posture and behaviour. Nature 425, 950-953.

Witmer LM, Ridgely RC, Dufeau DL, Semones MC. 2008. Using CT to peer into the past: 3D visualization of the brain and ear regions of birds, crocodiles, and nonavian dinosaurs. In: Endo H, Frey R, eds. Anatomical imaging. Springer, Tokyo, 67-87. 110 pp.

Xu X. 1997. A new psittacosaur (Psittacosaurus mazongshanensis sp. nov.) from Mazongshan area, Gansu Province, China. In: Dong ZM, ed. Sino-Japanese Silk Road Dinosaur Expedition. China Ocean Press, Beijing, 48-67. 114 pp. 
983 Xu X, Forster CA, Clark JM, Mo J. 2006. A basal ceratopsian with transitional features from 984 the Late Jurassic of northwestern China. Proceedings of the Royal Society, Series B 273 , $985 \quad 2135-2140$.

986 Xu X, Makovicky PJ, Wang XL, Norell MA, You HL. 2002. A ceratopsian dinosaur from 987 China and the early evolution of Ceratopsia. Nature 416, 314-317.

988 You H, Dodson P. 2003. Redescription of neoceratopsian dinosaur Archaeoceratops and early 989 evolution of Neoceratopsia. Acta Palaeontologica Polonica 48, 261-272.

990 You H, Dodson P. 2004. Basal Ceratopsia. In: Weishampel DB, Dodson P, Osmólska H, eds. 991 The Dinosauria. University of California Press, Berkeley, 478-493. 861 pp.

992 You HL, Tanoue K, Dodson P. 2008. New data on cranial anatomy of the ceratopsian dinosaur 993 Psittacosaurus major. Acta Palaeontologica Polonica 53, 183-196.

994 You H, Xu X. 2005. An adult specimen of Hongshanosaurus houi (Dinosauria:

995 Psittacosauridae) from the Lower Cretaceous of western Liaoning Province, China. Acta 996 Geologica Sinica (English edition) 79, 168-173.

997 Zhao Q, Benton MJ, Sullivan C, Sander PM, Xu X. 2013. Histology and postural change 998 during the growth of the ceratopsian dinosaur Psittacosaurus lujiatunensis. Nature $999 \quad$ Communications 4, 2079.

1000 Zhao Q, Benton MJ, Xu X, Sander PM. 2014. Juvenile-only clusters and behaviour of the 1001 Early Cretaceous dinosaur Psittacosaurus. Acta Palaeontologica Polonica 59, 827-833. 1002 Zheng WJ, Jin XS, Xu X. 2015. A psittacosaurid-like basal neoceratopsian from the Upper 1003 Cretaceous of central China and its implications for basal ceratopsian evolution. Scientific $1004 \quad$ Reports 5, 14190. 
1005 Zhou CF, Gao KQ, Fox RC, Chen SH. 2006. A new species of Psittacosaurus (Dinosauria:

1006 Ceratopsia) from the Early Cretaceous Yixian Formation, Liaoning, China. Palaeoworld 15, $1007 \quad 100-114$.

1008 Zhou CF, Gao KQ, Fox RC, Du XK. 2007. Endocranial morphology of psittacosaurs

1009 (Dinosauria: Ceratopsia) based on CT scans of new fossils from the Lower Cretaceous,

1010 China. Palaeoworld 16, 285-293. 


\section{Figure 1}

Ontogenetic sequence of $P$. lujiatunensis.

(A) Hatchling (IVPP V15451) in lateral view. (B) Hatchling in dorsal view. (C) Juvenile (IVPP

V22647) in lateral view. (D) Juvenile in dorsal view. (E) Adult (IVPP V12617) in lateral view. (F)

Adult in dorsal view. All shown to the same scale; scale bar represents $20 \mathrm{~mm}$. 


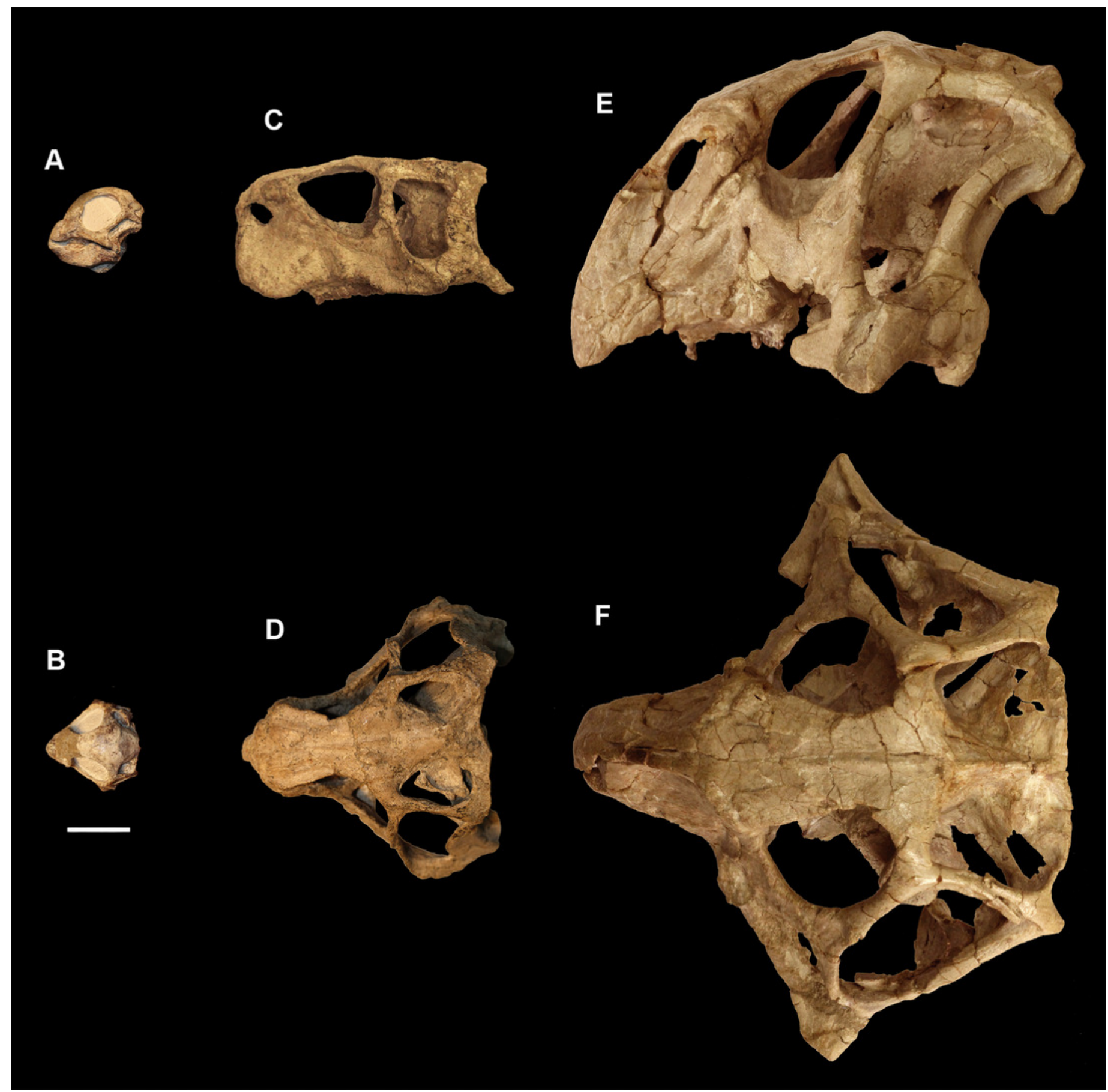


Figure 2

Segmented braincase of a hatchling P. lujiatunensis (IVPP V15451).

(A) Lateral view. (B) Ventral view. (C) Dorsal view. (D) Posterior view. (E) Anterior view. bo, basioccipital; bpc, basisphenoid-parasphenoid complex; fr, frontal; Is, laterosphenoid; pa, parietal; pp, paroccipital processes; pr, prootic; so, supraoccipital. Scale bar represents 10 $\mathrm{mm}$. 


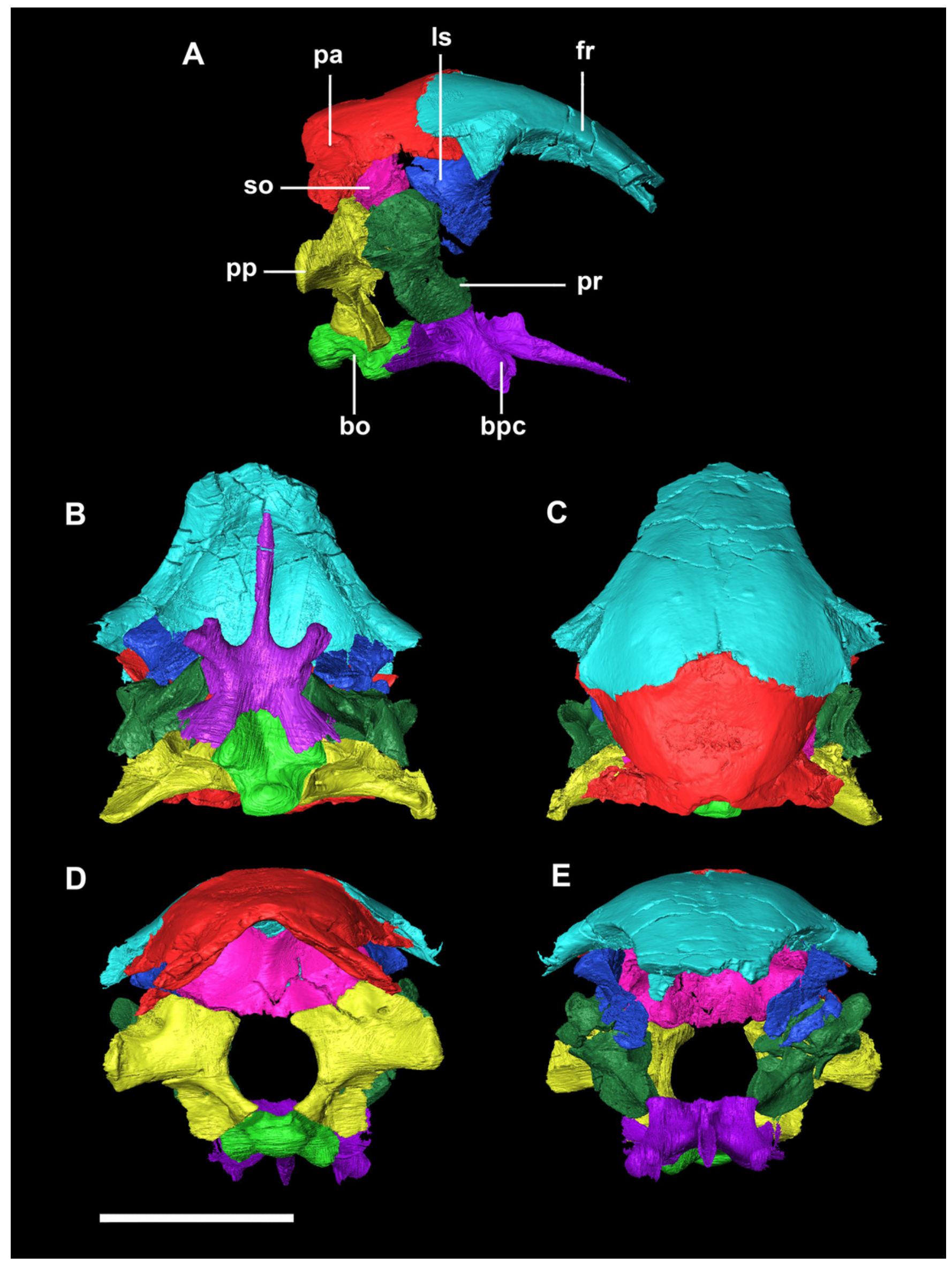




\section{Figure 3}

Basioccipital of hatchling P. lujiatunensis (IVPP V15451).

(A) Left lateral view. (B) Right lateral view. (C) Ventral view. (D) Dorsal view. (E) Posterior view. (F) Anterior view. boc, basioccipital condyle; bsas, basisphenoid articular surface; bt, basal tubera; btg, basal tubera groove; cdn, condylar neck; eoas, exoccipital articular surface; ng, neural groove. Scale bar represents $5 \mathrm{~mm}$. 

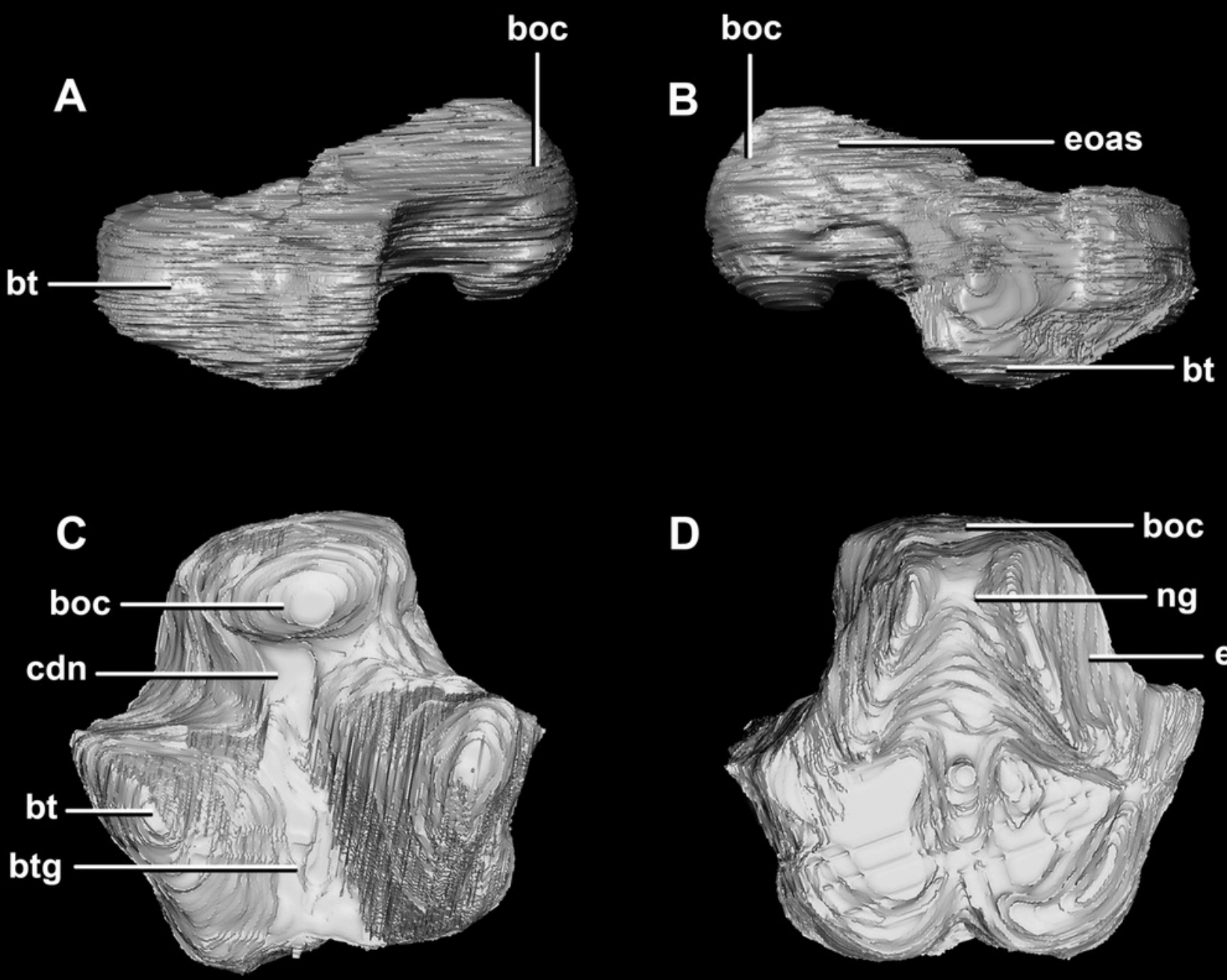

D
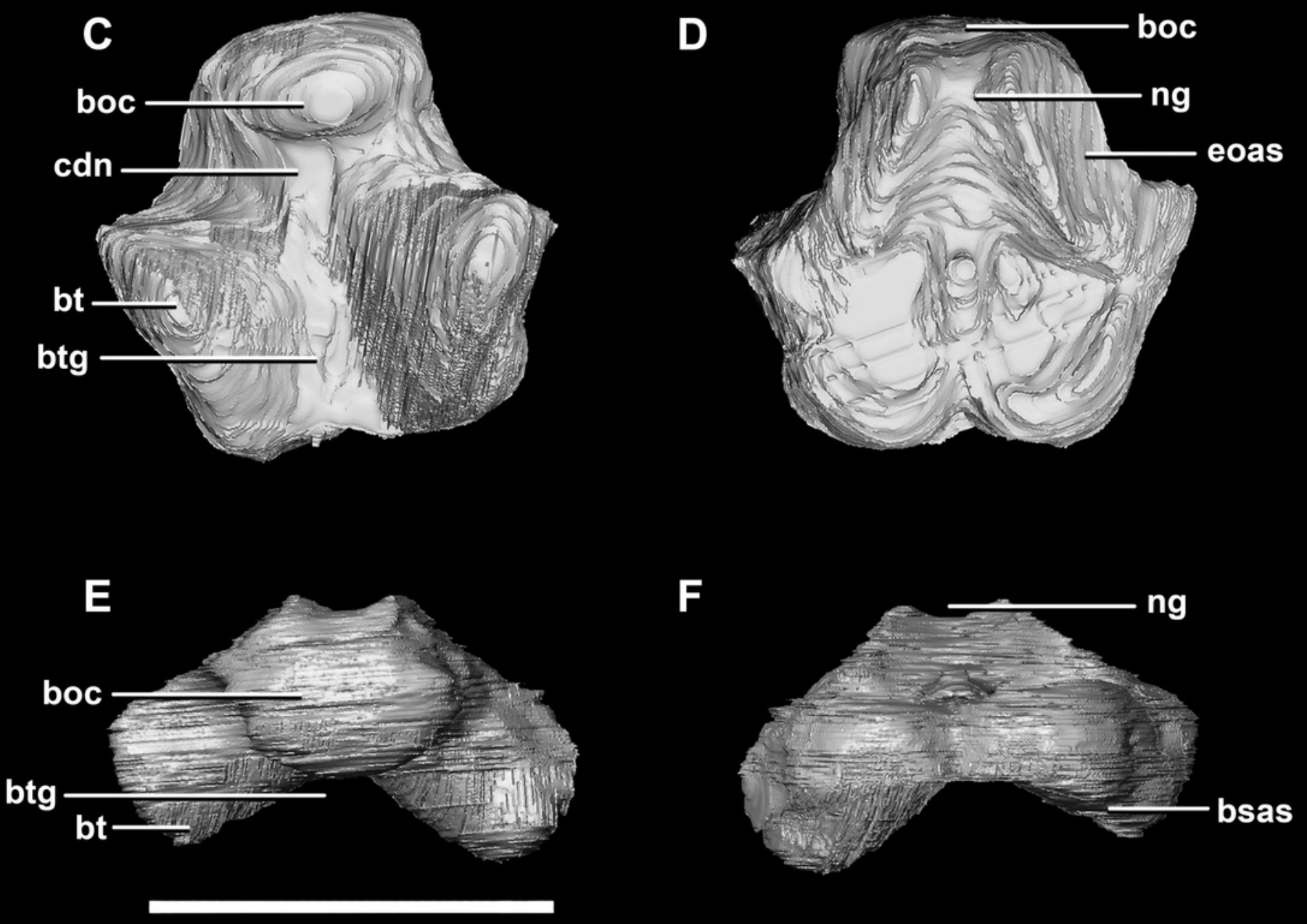


\section{Figure 4}

Basisphenoid of hatchling P. lujiatunensis (IVPP V15451).

(A) Left lateral view. (B) Right lateral view. (C) Ventral view. (D) Dorsal view. (E) Posterior view. (F) Anterior view. boas, basioccipital articular surface; bpp, basipterygoid process; bt, basal tubera; cfo, carotid foramen; $c p$, cultriform process; pct, paracultriform trough; pras, prootic articular surface; ptas, pterygoid articular surface; st, sella turcica. Scale bar represents $5 \mathrm{~mm}$. 


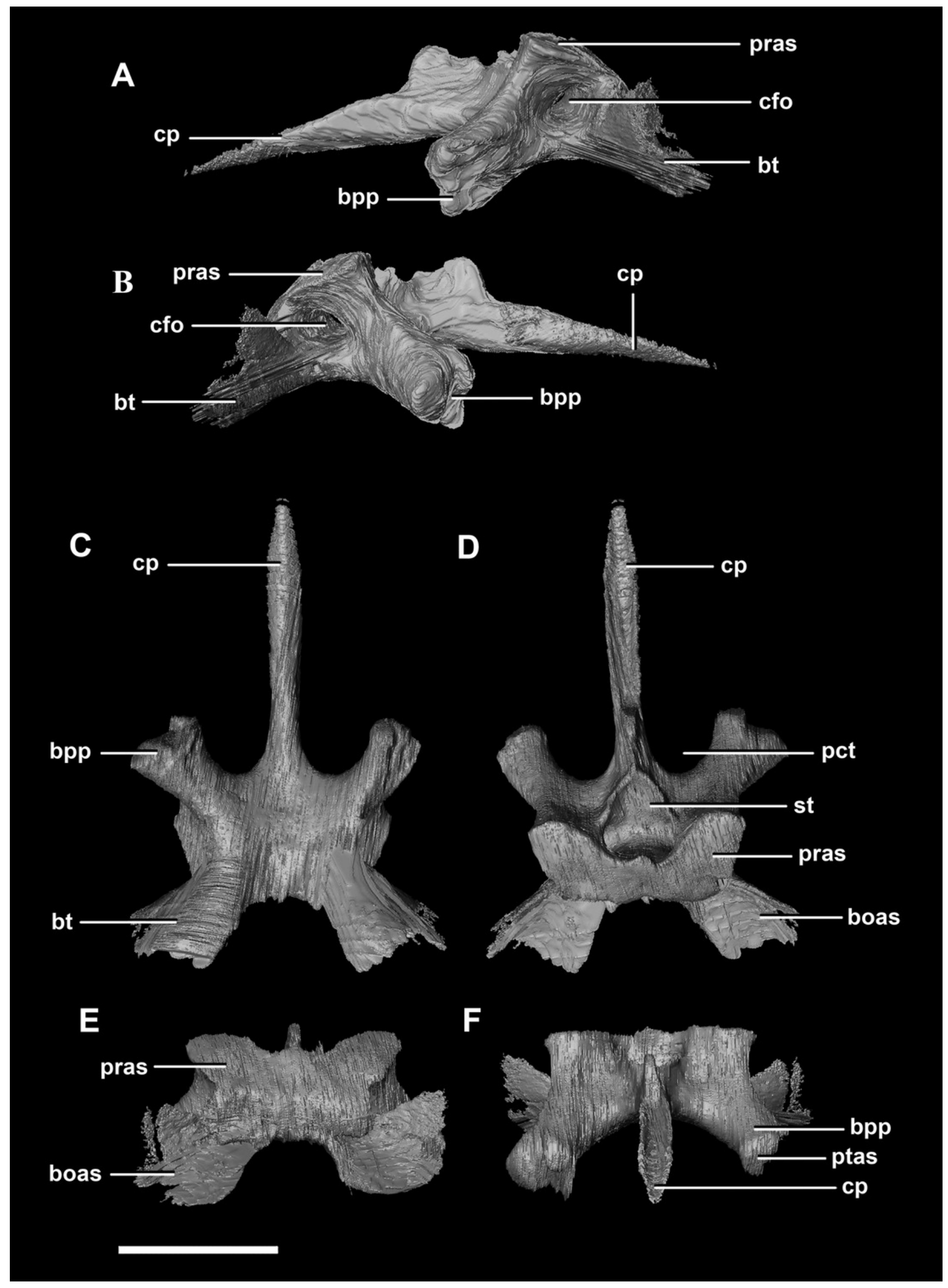




\section{Figure 5}

Supraoccipital of hatchling P. lujiatunensis (IVPP V15451).
(A) Left lateral view.
(B) Right lateral view.
(C) Ventral view.
(D) Dorsal view.
(E) Posterior

view. (F) Anterior view. eoas, exoccipital articular surface; paas, parietal articular surface; pras, prootic articular surface; sccp, semicircular canal pathway; somr, supraoccipital midline ridge. Scale bar represents $5 \mathrm{~mm}$.

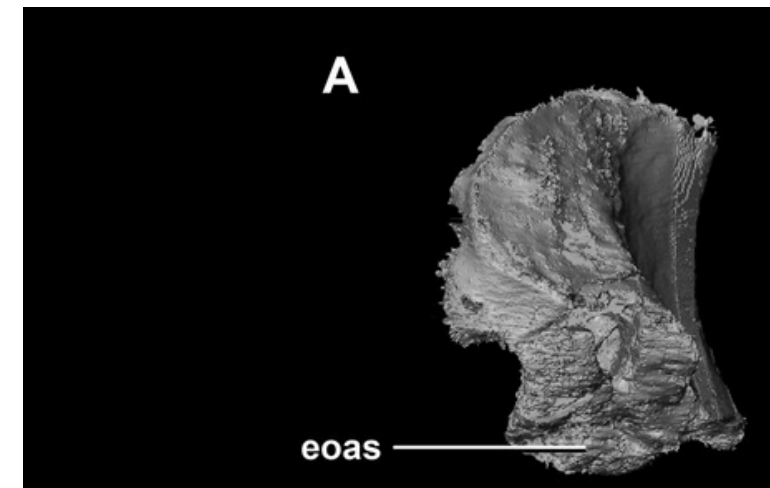

B

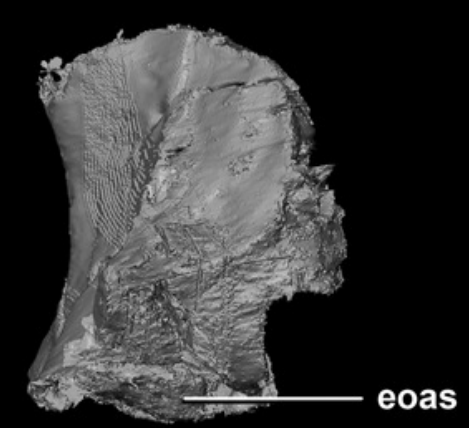

C
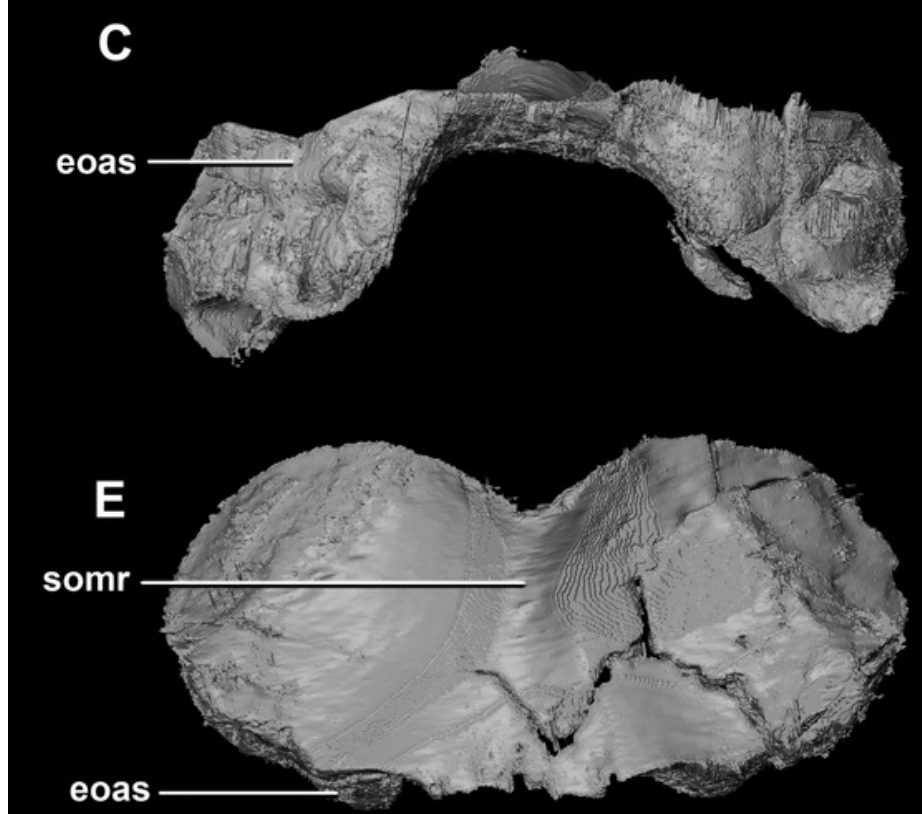

D
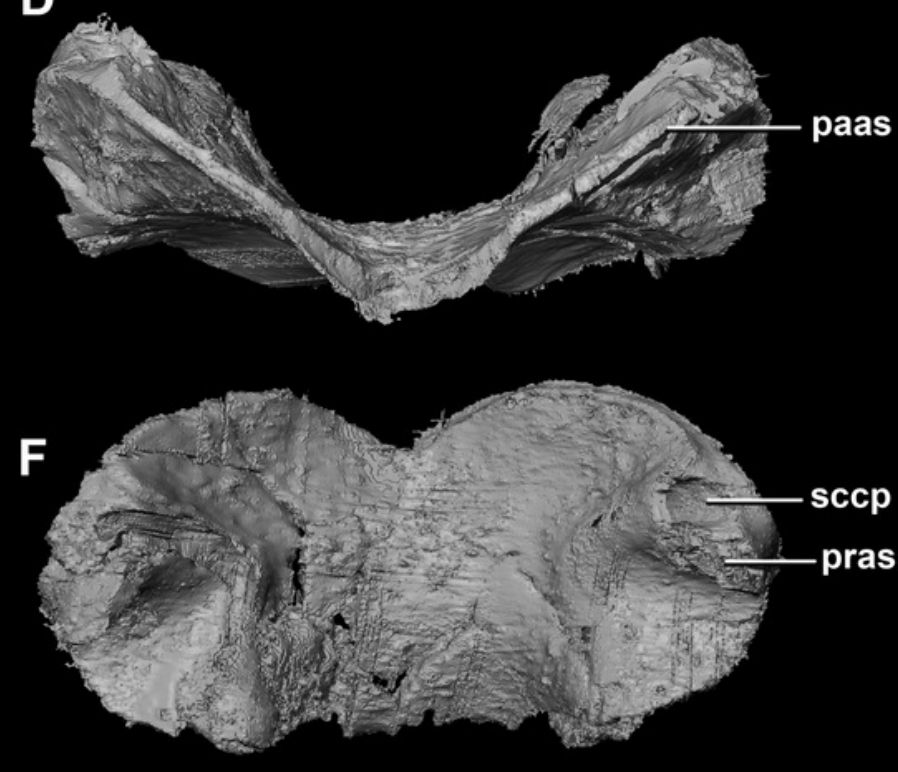


\section{Figure 6}

Paroccipital processes of hatchling P. lujiatunensis (IVPP V15451).

(A) Left lateral view. (B) Ventral view. (C) Dorsal view. (D) Posterior view. (E) Anterior view. boas, basioccipital articular surface; fm, foramen magnum; pop, paroccipital process; pras, prootic articular surface; sccp, semicircular canal pathway; soas, supraoccipital articular surface; vcd, vena capitis dorsalis; CN X, XI, exit for the vagus nerve and the accessory nerve respectively; CN XII, exit for the hypoglossal nerve. scale bar represents $5 \mathrm{~mm}$. 


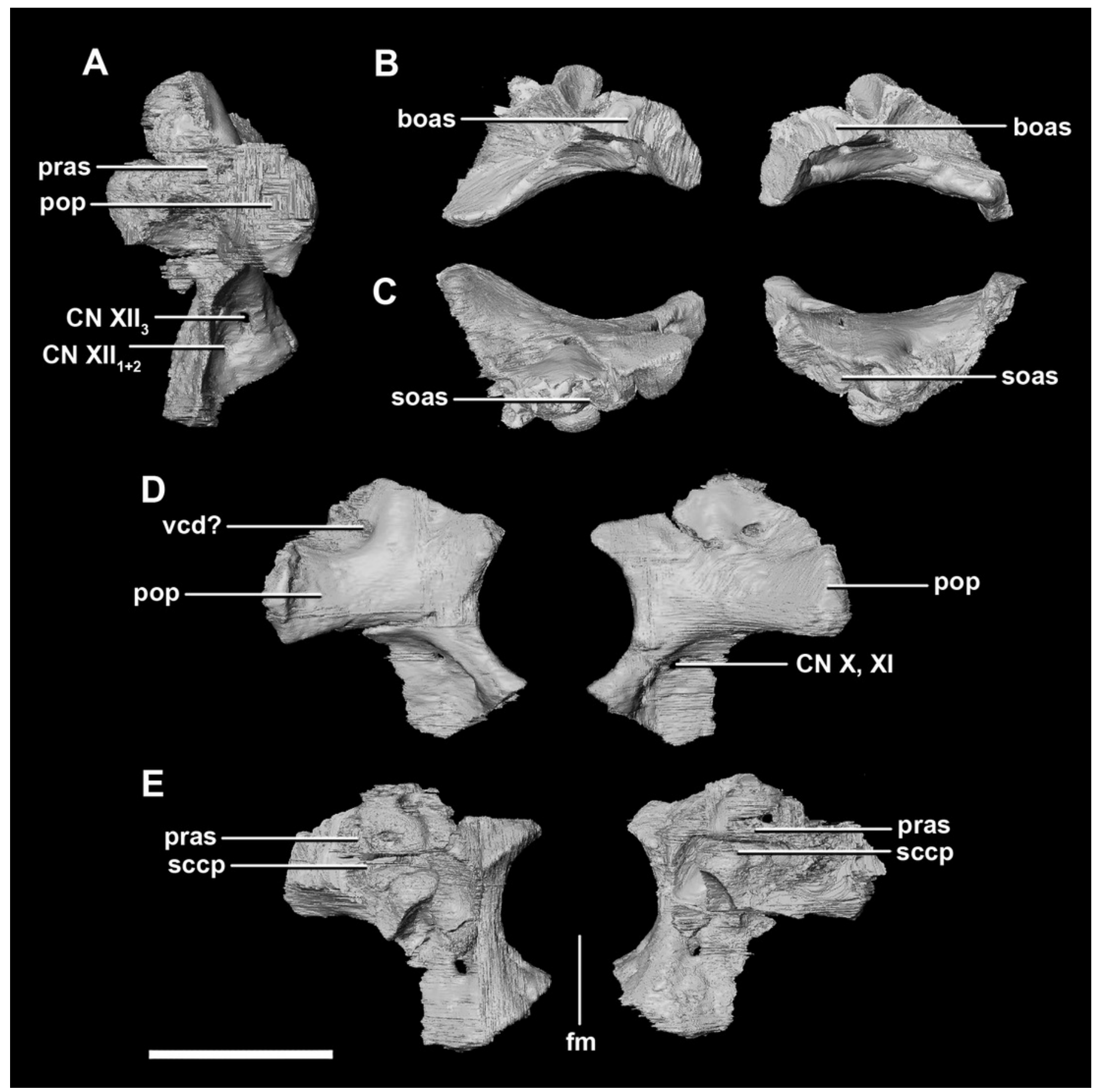




\section{Figure 7}

Laterosphenoid of hatchling P. lujiatunensis (IVPP V15451).

(A) Left lateral view. (B) Right lateral view. (C) Ventral view. (D) Dorsal view. (E) Posterior

view. (F) Anterior view. fras, frontal articular surface; Ish, laterosphenoid head; pras, prootic articular surface; CN V, dorsal margin of trigeminal nerve. Scale bar represents $5 \mathrm{~mm}$. 


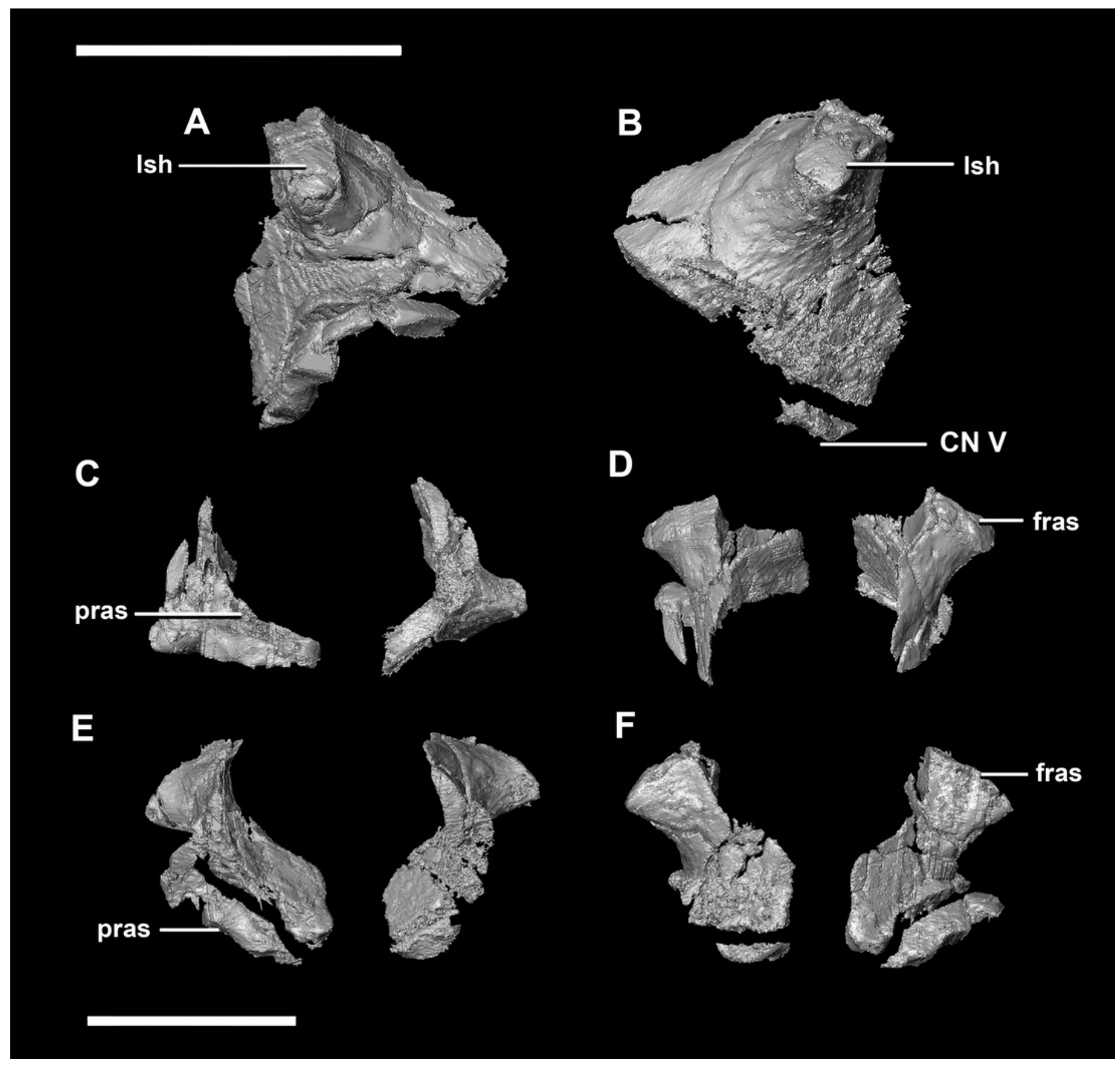




\section{Figure 8}

Prootic of hatchling P. Iujiatunensis (IVPP V15451).

(A) Left lateral view. (B) Right lateral view. (C) Left medial view. (D) Right medial view. (E) Ventral view. (F) Dorsal view. (G) Posterior view. (H) Anterior view. bsas, basisphenoid articular surface; eoas, exoccipital articular surface; Isas, laterosphenoid articular surface; prmr, prootic midline ridge; sccp, semicircular canal pathway; CN V, trigeminal nerve; CN VII, facial nerve. Scale bar represents $5 \mathrm{~mm}$. 


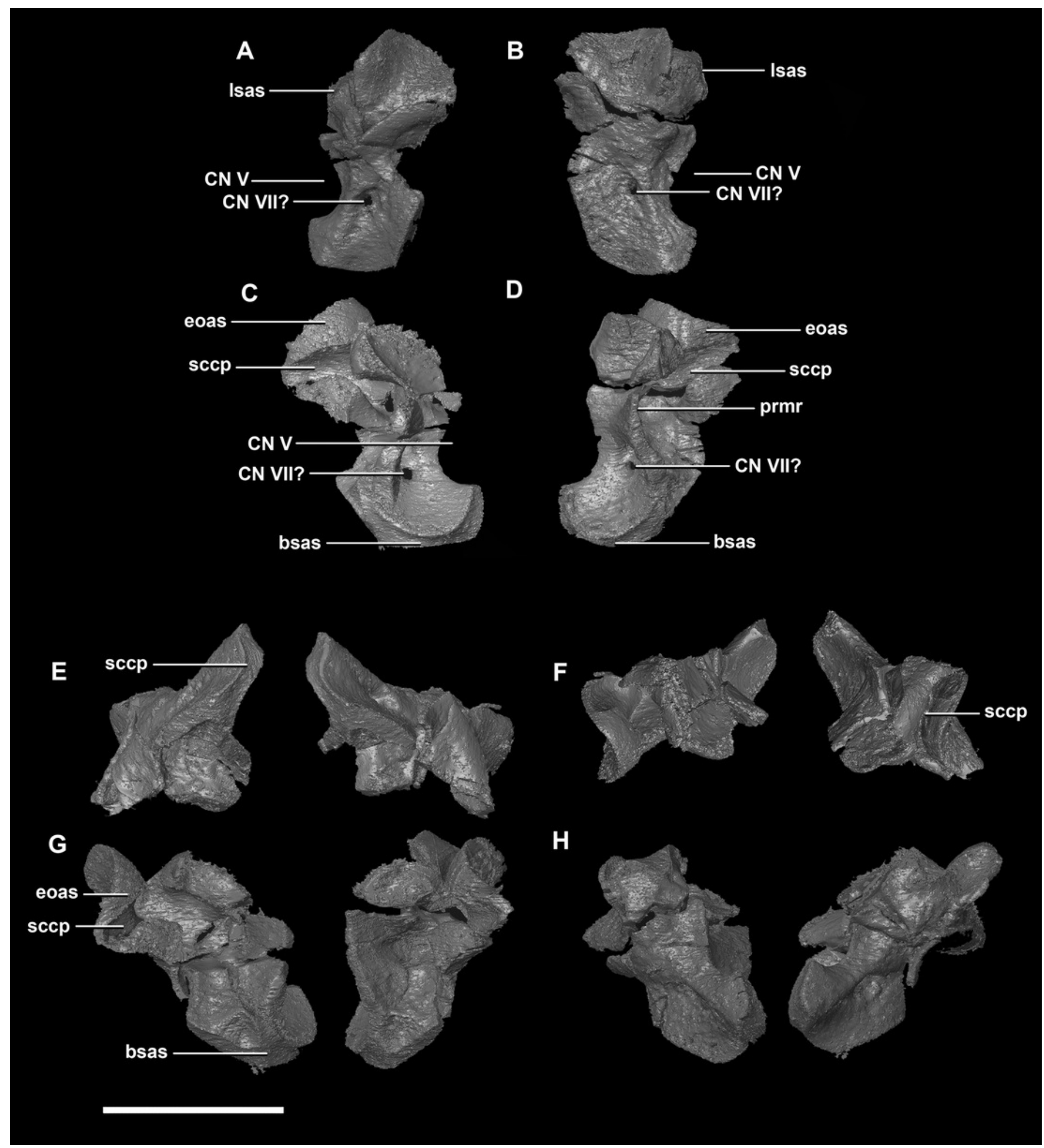




\section{Figure 9}

Parietal of hatchling P. lujiatunensis (IVPP V15451).
(A) Left lateral view.
(B) Right lateral view.
(C) Ventral view.
(D) Dorsal view.
(E) Posterior

view. (F) Anterior view. fras, frontal articular surface; Isas, laterosphenoid articular surface; soas, supraoccipital articular surface; sqas, squamosal articular surface; UTF, upper temporal fenestra. Scale bar represents $5 \mathrm{~mm}$.

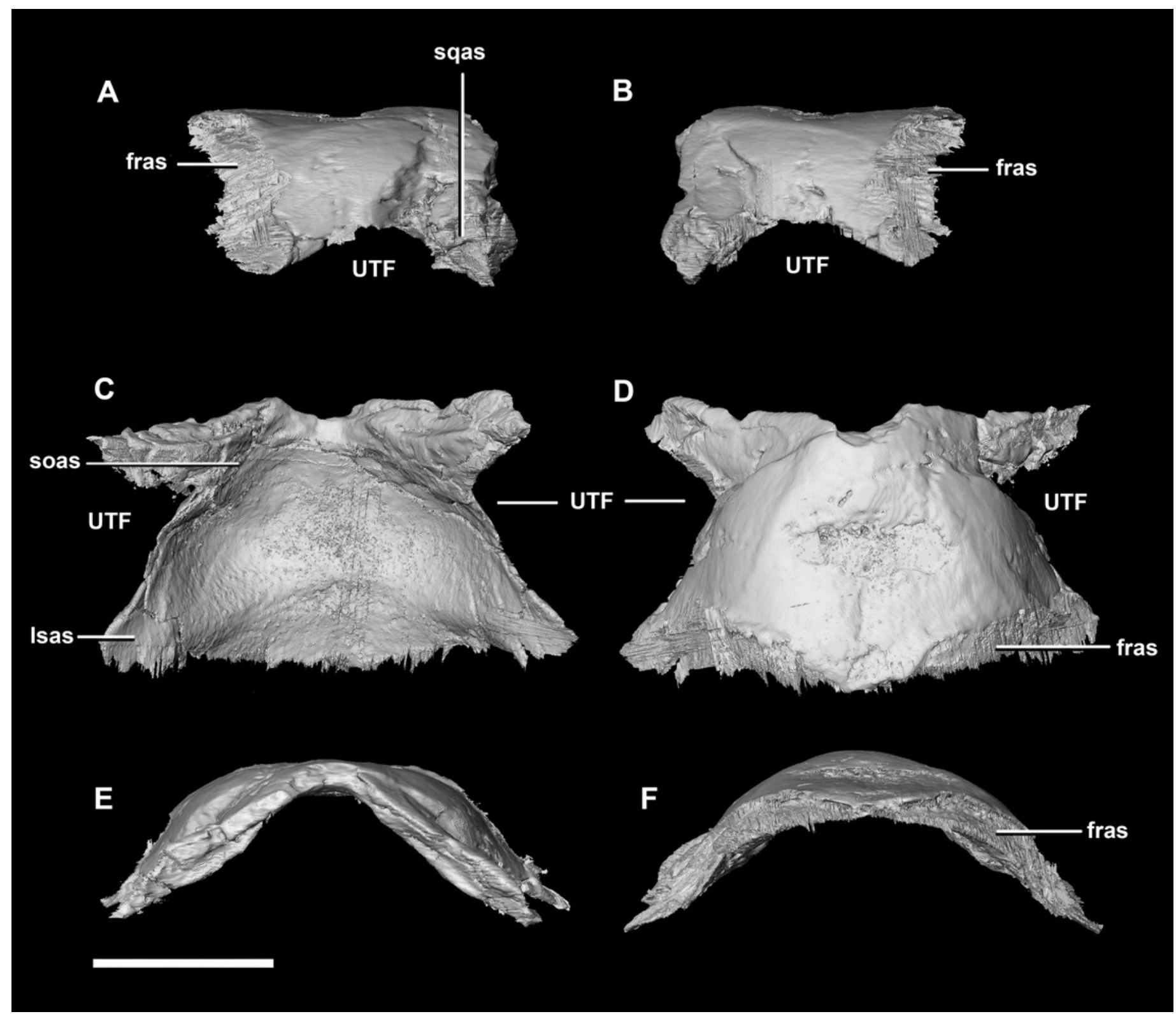




\section{Figure 10}

Frontal of hatchling P. Iujiatunensis (IVPP V15451).

(A) Left lateral view. (B) Right lateral view. (C) Ventral view. (D) Dorsal view. (E) Posterior view. (F) Anterior view. cc, cerebral cavity; fro, frontal ossicle; Isas, laterosphenoid articular surface; nas, nasal articular surface; om, orbital margin; paas, parietal articular surface; poas, postorbital articular surface. Scale bar represents $5 \mathrm{~mm}$. 


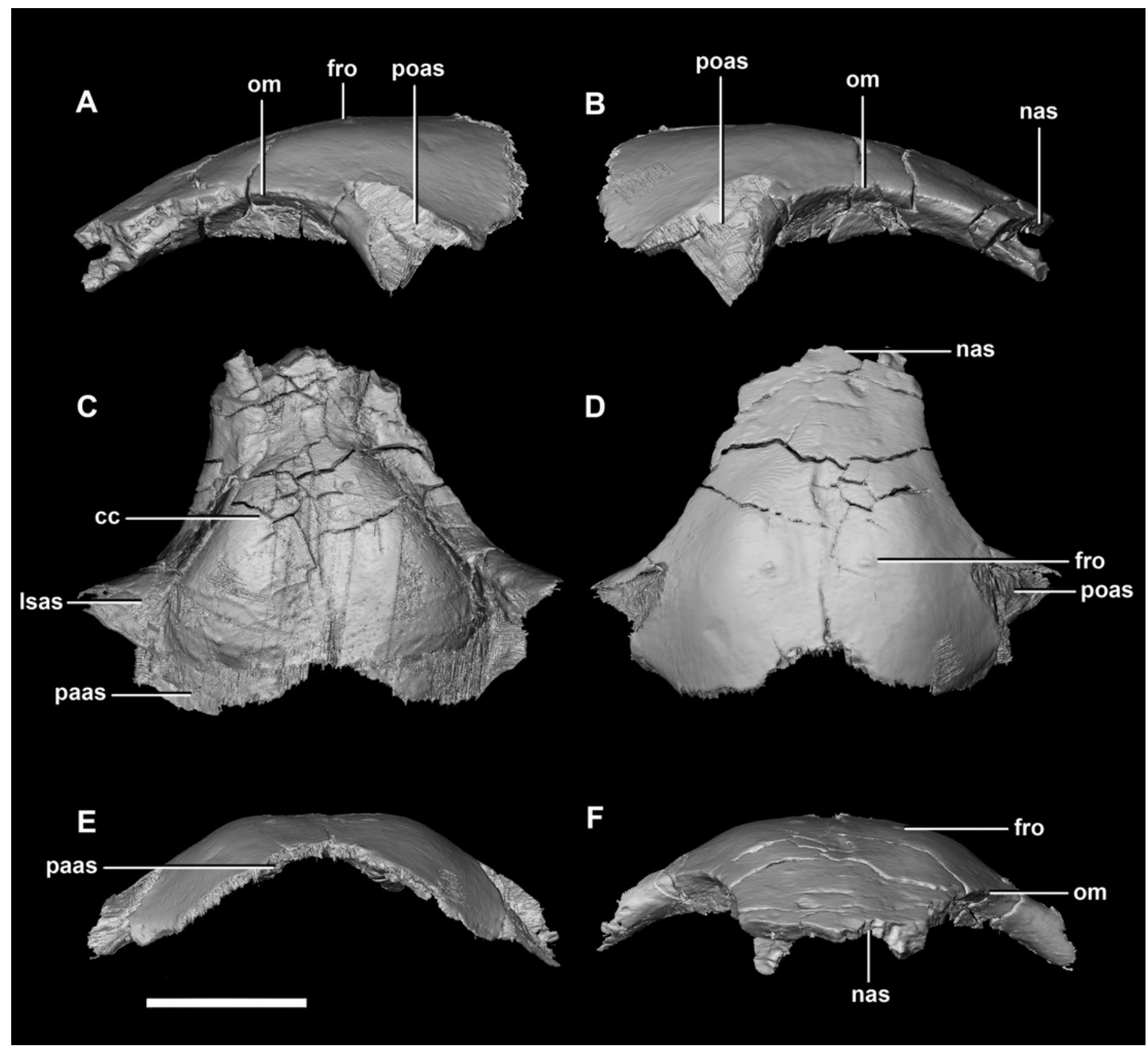


Figure 11

Segmented braincase of a juvenile $P$. Iujiatunensis (IVPP V22647).

(A) Lateral view. (B) Ventral view. (C) Dorsal view. (D) Posterior view. (E) Anterior view. bo, basioccipital; bpc, basisphenoid-parasphenoid complex; fr, frontal; Is, laterosphenoid; pa, parietal; pp, paroccipital processes; pr, prootic. Scale bar represents $10 \mathrm{~mm}$. 


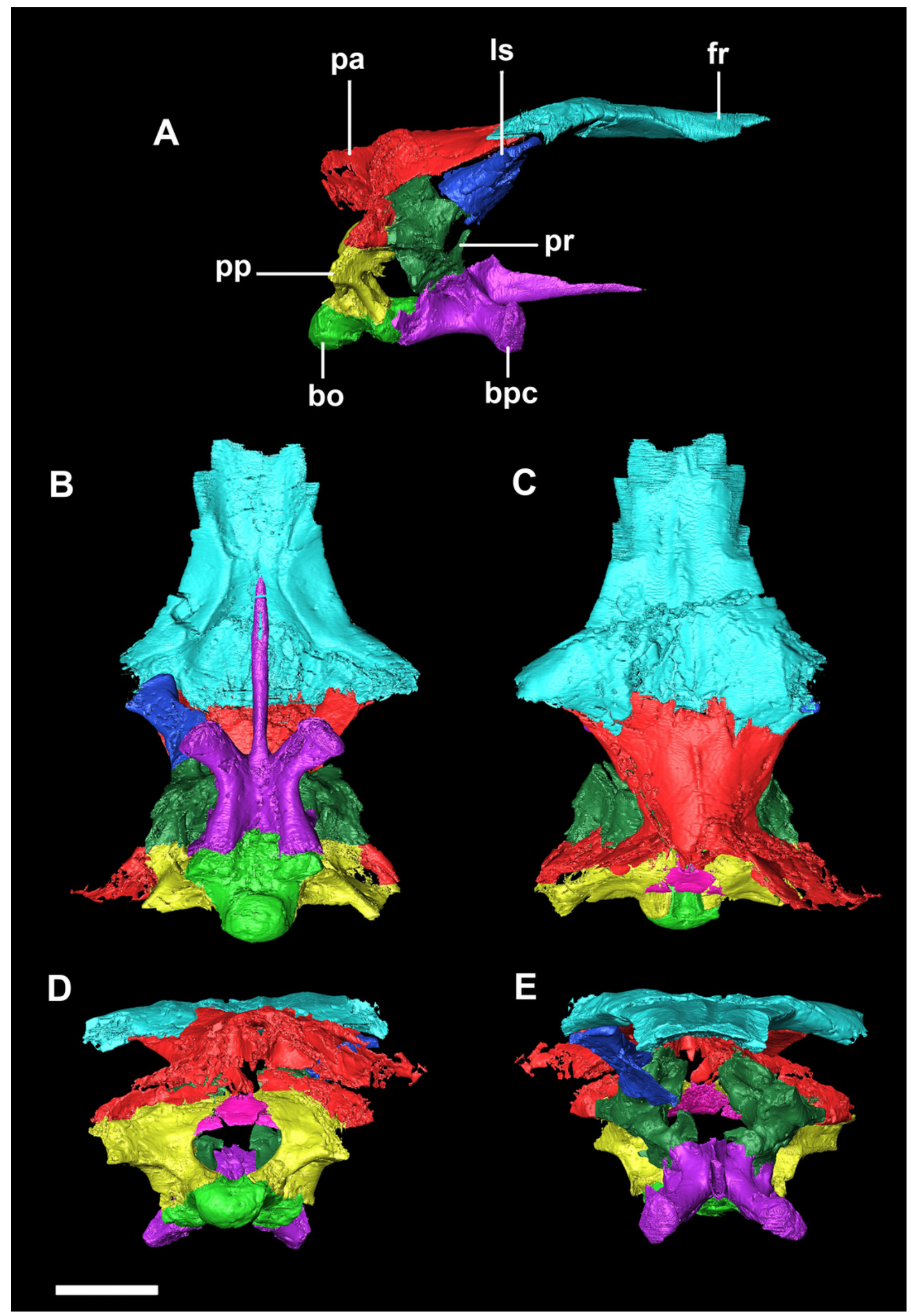

PeerJ reviewing PDF | (2018:05:28661:2:0:NEW 18 Apr 2019) 


\section{Figure 12}

Basioccipital of juvenile P. lujiatunensis (IVPP V22647).

(A) Left lateral view. (B) Right lateral view. (C) Ventral view. (D) Dorsal view. (E) Posterior view. (F) Anterior view. boc, basioccipital condyle; bsas, basisphenoid articular surface; bt, basal tubera; btg, basal tubera groove; cdn, condylar neck; eoas, exoccipital articular surface; ng, neural groove. Scale bar represents $10 \mathrm{~mm}$. 


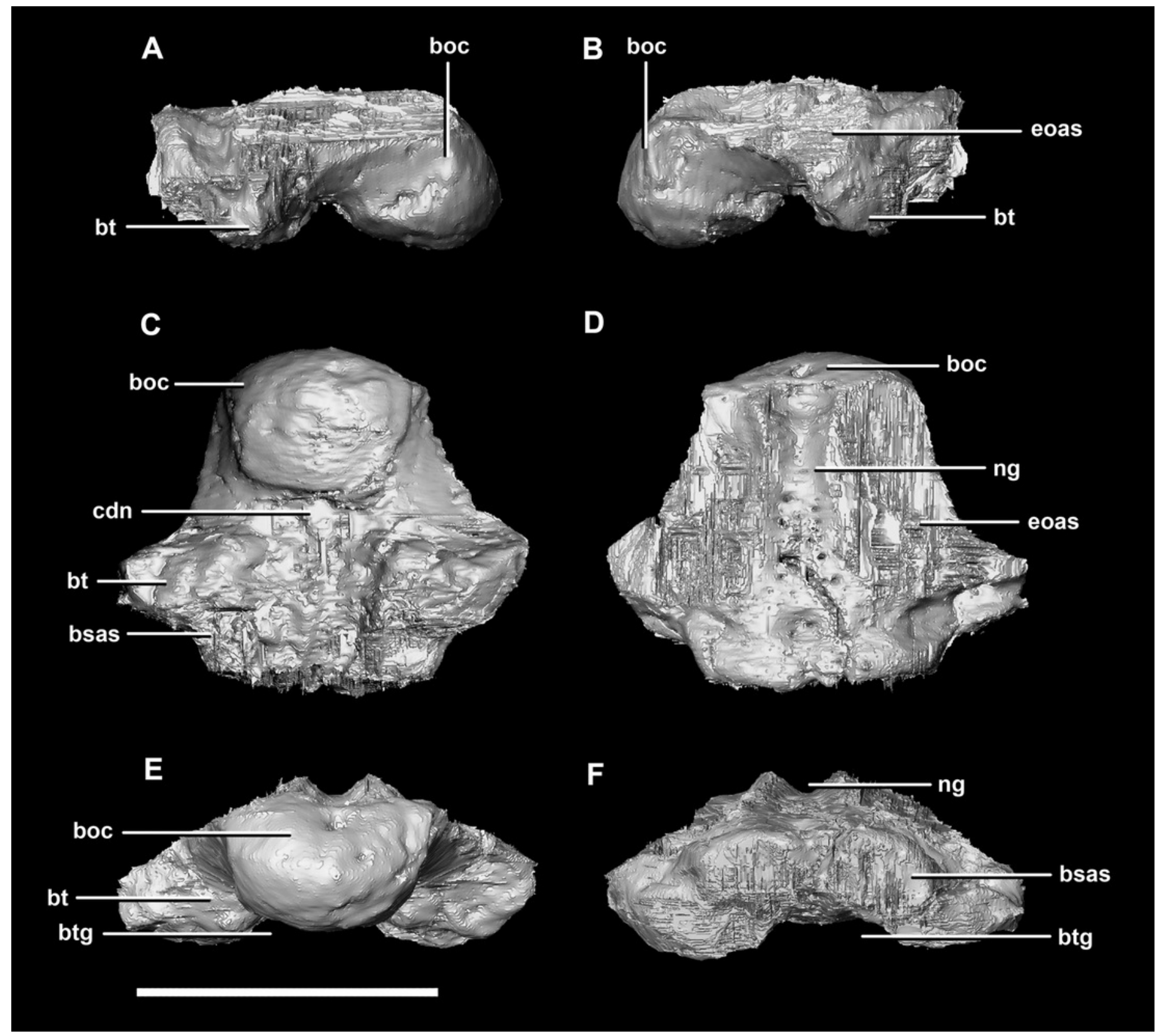




\section{Figure 13}

Basisphenoid of juvenile P. Iujiatunensis (IVPP V22647).

(A) Left lateral view. (B) Right lateral view. (C) Ventral view. (D) Dorsal view. (E) Posterior view. (F) Anterior view. boas, basioccipital articular surface; bpp, basipterygoid process; bt, basal tubera; cfo, carotid foramen; $\mathrm{cp}$, cultriform process; pct, paracultriform trough; pras, prootic articular surface; ptas, pterygoid articular surface; st, sella turcica. Scale bar represents $10 \mathrm{~mm}$. 


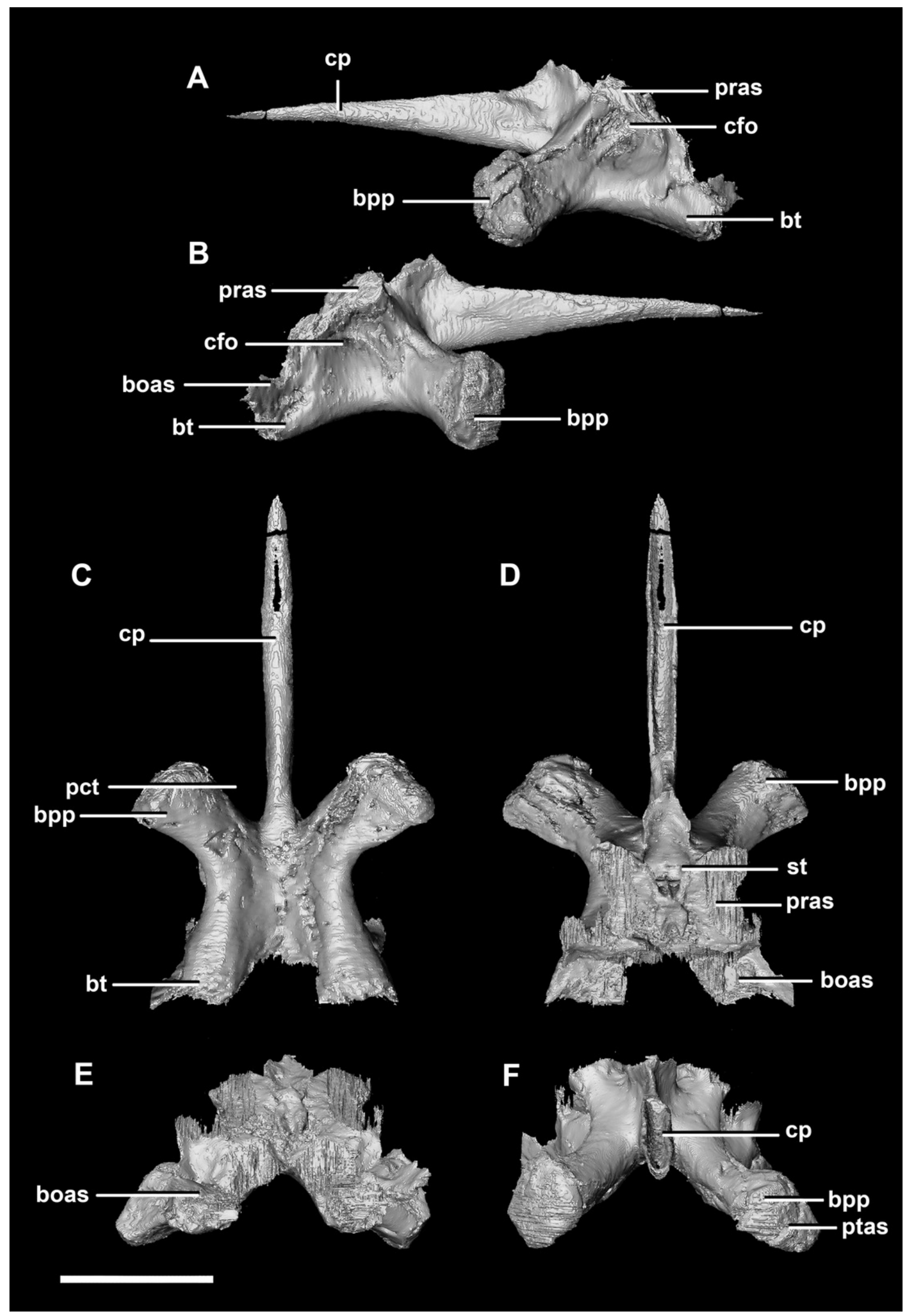




\section{Figure 14}

Supraoccipital of juvenile P. Iujiatunensis (IVPP V22647).

(A) Posterior view. (B) Anterior view. eoas, exoccipital articular surface; fm, foramen magnum; paas, parietal articular surface. Scale bar represents $10 \mathrm{~mm}$.

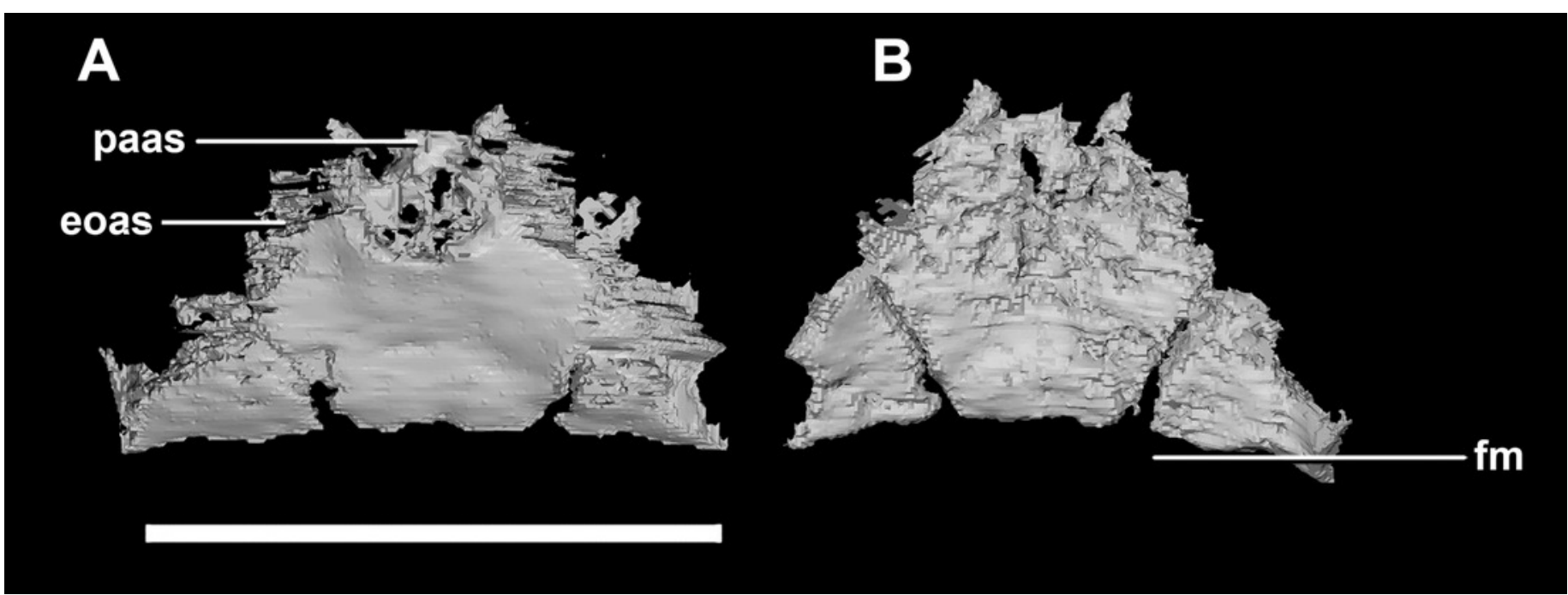




\section{Figure 15}

Paroccipital processes of juvenile $P$. lujiatunensis (IVPP V22647).

(A) Left lateral view. (B) Right lateral view. (C) Posterior view. (D) Anterior view. boas, basioccipital articular surface; fm, foramen magnum; pop, paroccipital process; pras, prootic articular surface; sccp, semicircular canal pathway; soas, supraoccipital articular surface. Scale bar represents $10 \mathrm{~mm}$. 


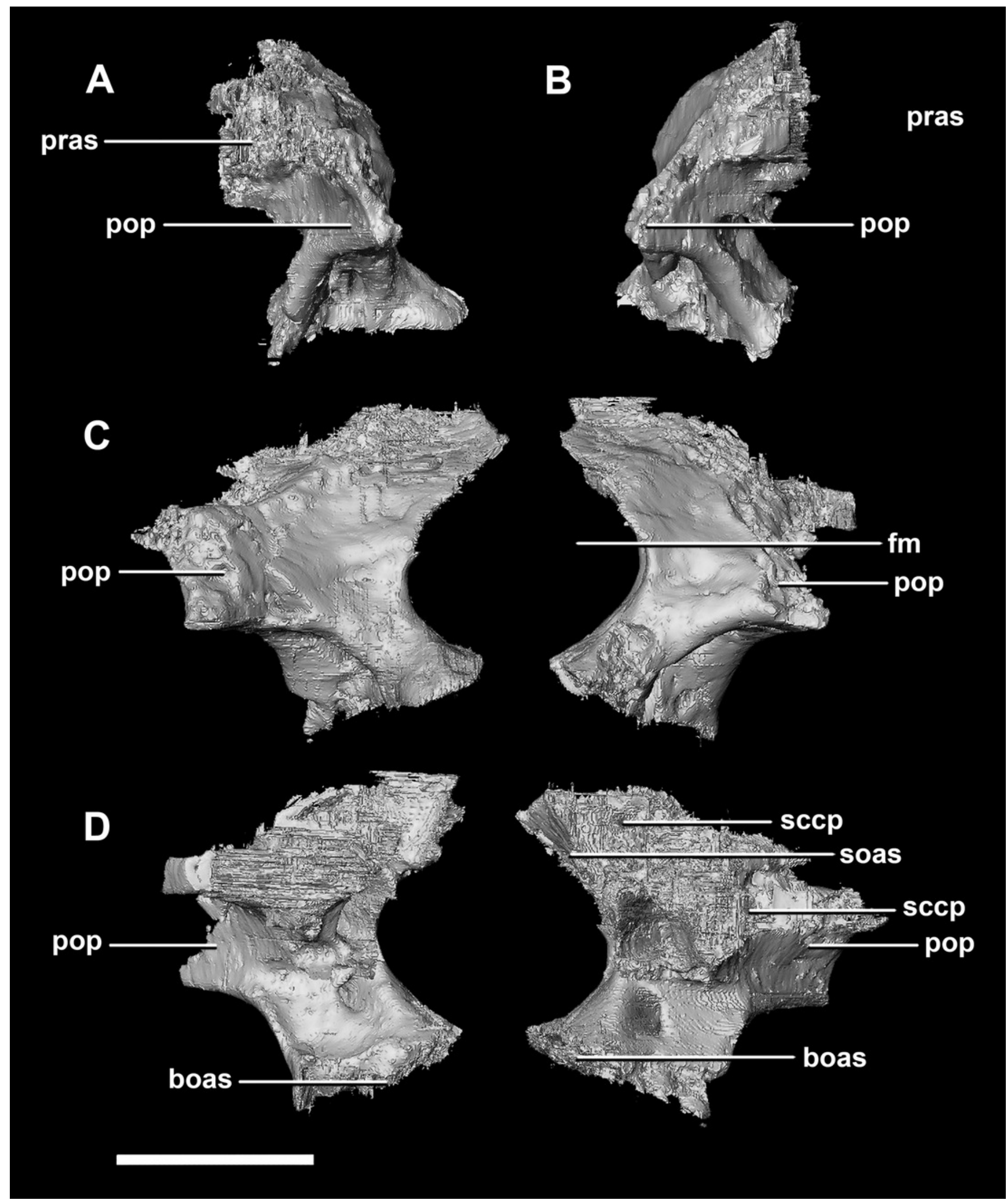




\section{Figure 16}

Laterosphenoid of juvenile $P$. lujiatunensis (IVPP V22647).

(A) Right lateral view. (B) Right medial view. (C) Ventral view. (D) Dorsal view. (E) Posterior view. (F) Anterior view. fras, frontal articular surface; Ish, laterosphenoid head; paas, parietal articular surface; pras, prootic articular surface; CN V, dorsal margin of trigeminal nerve.

Scale bar represents $10 \mathrm{~mm}$. 


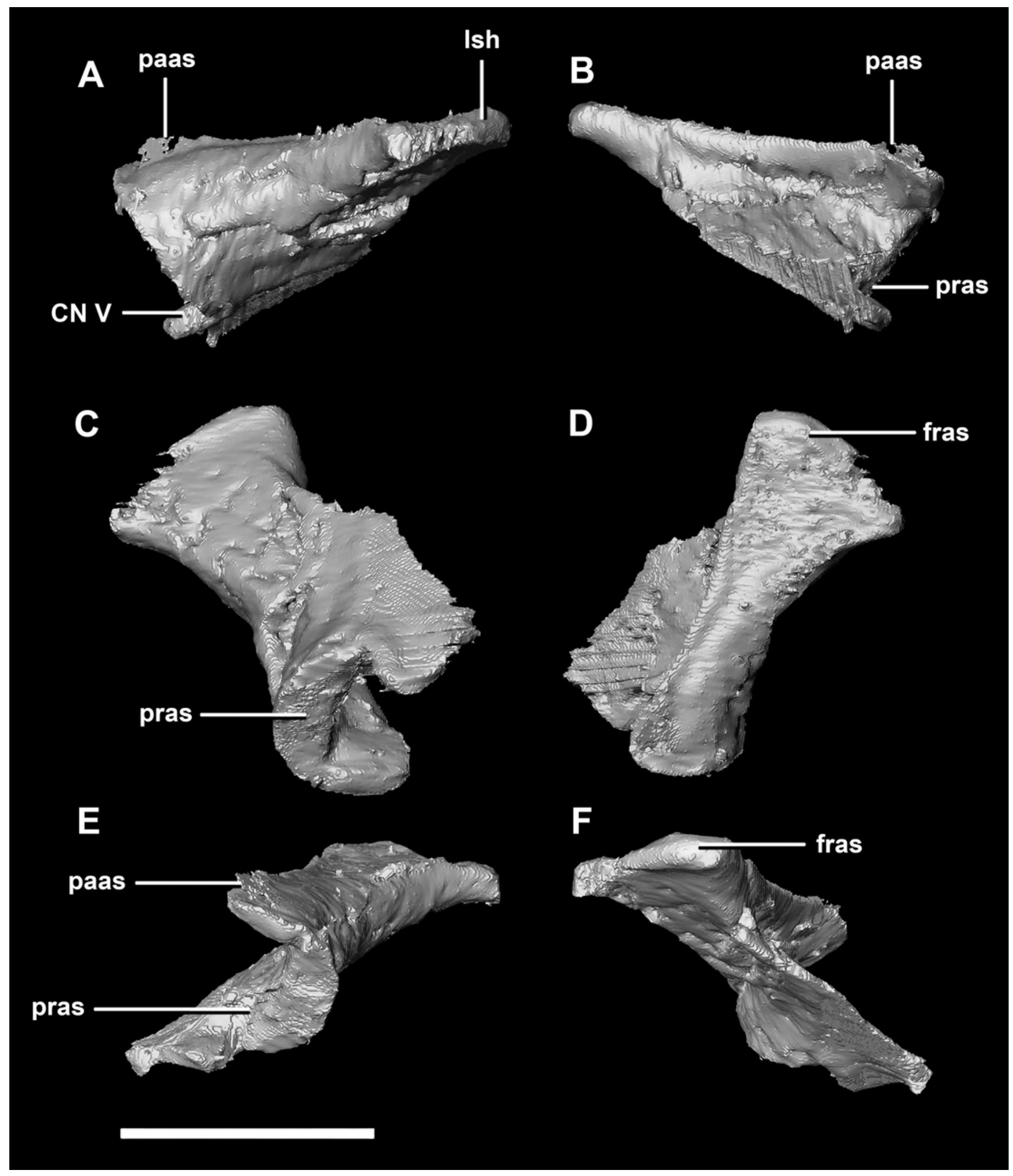




\section{Figure 17}

Prootics of juvenile P. lujiatunensis (IVPP V22647).

(A) Left lateral view. (B) Right lateral view. (C) Left medial view. (D) Right medial view. (E) Ventral view. (F) Dorsal view. (G) Posterior view. (H) Anterior view. bsas, basisphenoid articular surface; eoas, exoccipital articular surface; Isas, laterosphenoid articular surface; paas, parietal articular surface; pps, preprootic strut; CN V, trigeminal nerve; CN VII, facial nerve. Scale bar represents $10 \mathrm{~mm}$. 


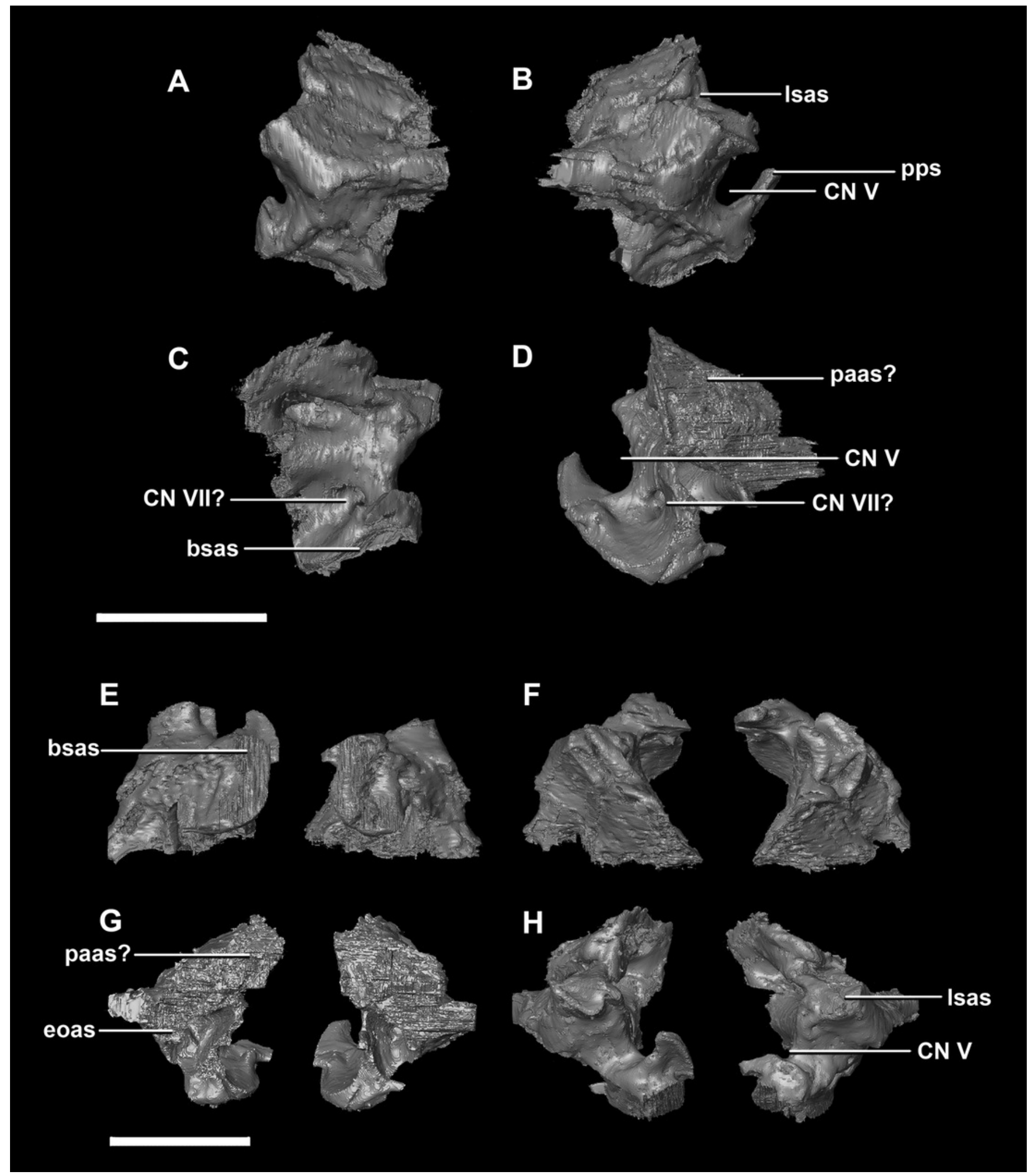




\section{Figure 18}

Parietals of juvenile $P$. lujiatunensis (IVPP V22647).
(A) Left lateral view.
(B) Right lateral view.
(C) Ventral view.
(D) Dorsal view.
(E) Posterior

view. (F) Anterior view. fras, frontal articular surface; Isas, laterosphenoid articular surface; pras, prootic articular surface; ps?, potential parietal shelf; sc, sagittal crest; soas, supraoccipital articular surface. Scale bar represents $10 \mathrm{~mm}$.

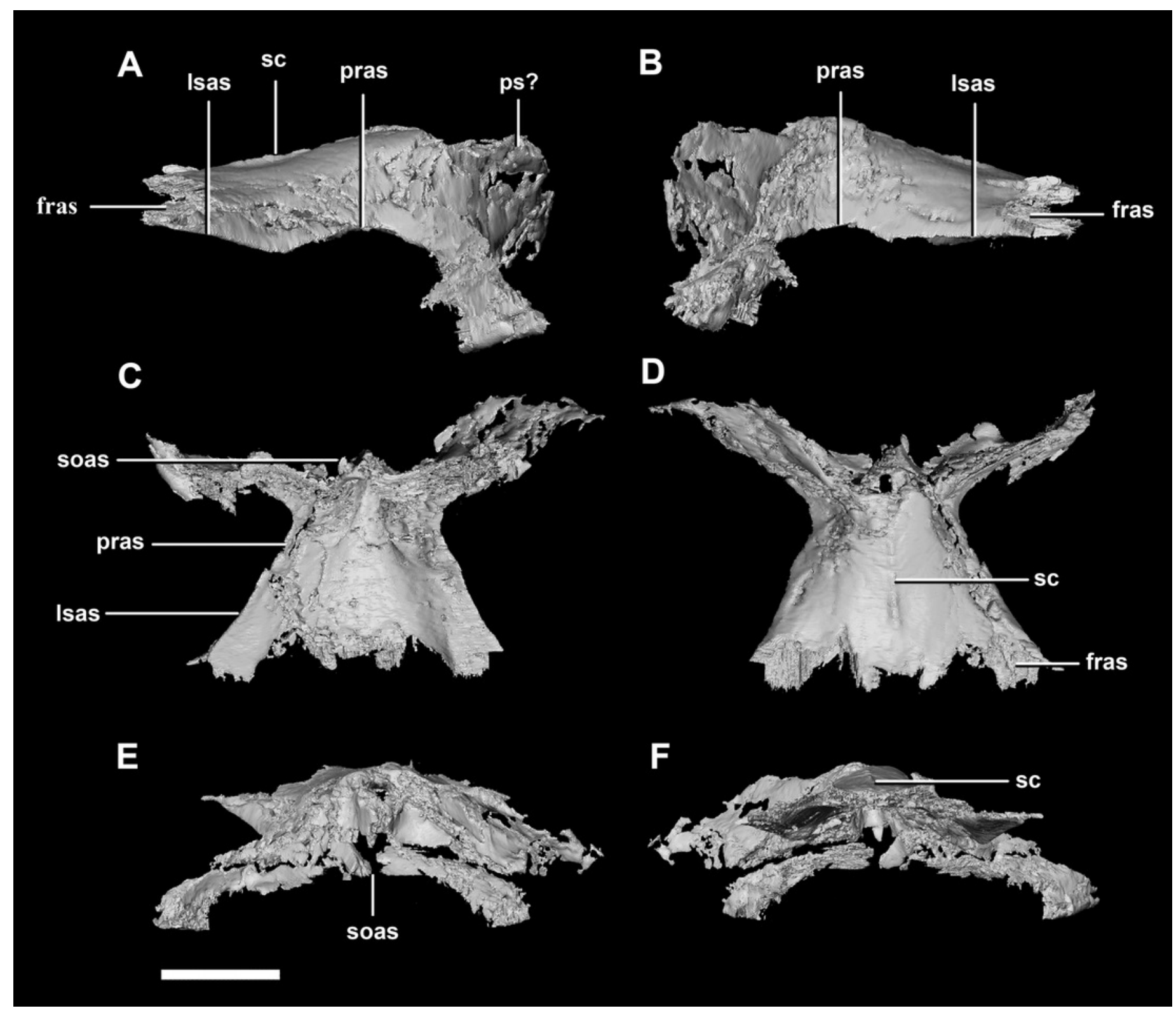




\section{Figure 19}

Frontals of juvenile $P$. Iujiatunensis (IVPP V22647).
(A) Left lateral view.
(B) Right lateral view.
(C) Ventral view.
(D) Dorsal view.
(E) Posterior

view. (F) Anterior view. cc, cerebral cavity; fc, frontal crest; Isas, laterosphenoid articular surface; nas, nasal articular surface; no, notch; om, orbital margin; paas, parietal articular surface; poas, postorbital articular surface. Scale bar represents $10 \mathrm{~mm}$.
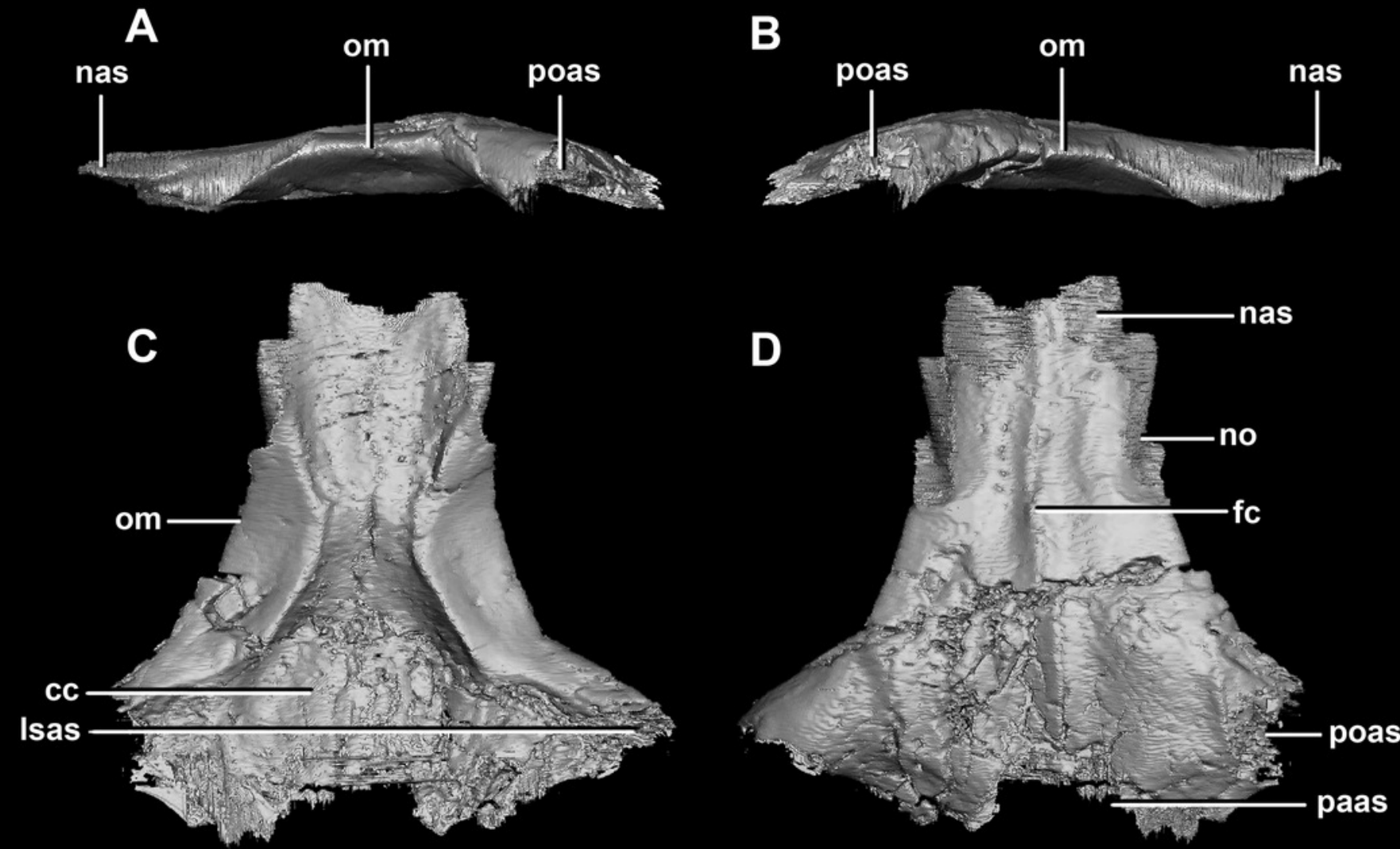

$\mathbf{E}$

F
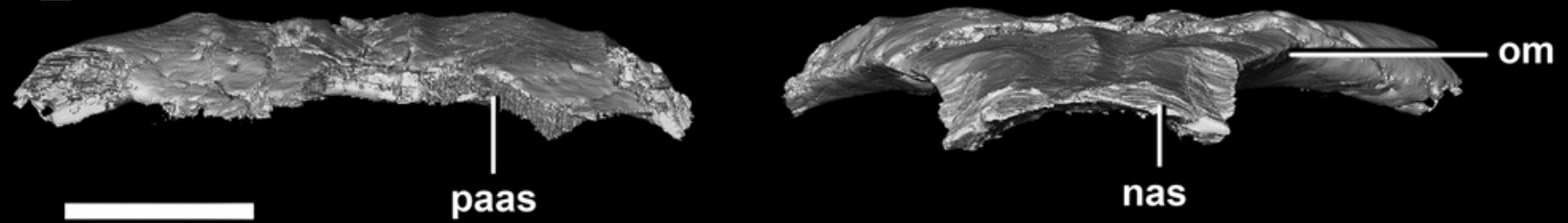


\section{Figure 20}

Segmented braincase of adult $P$. lujiatunensis (IVPP V12617).

(A) Lateral view. (B) Ventral view. (C) Dorsal view. (D) Posterior view. (E) Anterior view. bo, basioccipital; bpc, basisphenoid-parasphenoid complex; fr, frontal; Is, laterosphenoid; os, orbitosphenoid; pa, parietal; pp, paroccipital processes; pr, prootic; so, supraoccipital. Scale bar represents $20 \mathrm{~mm}$. 


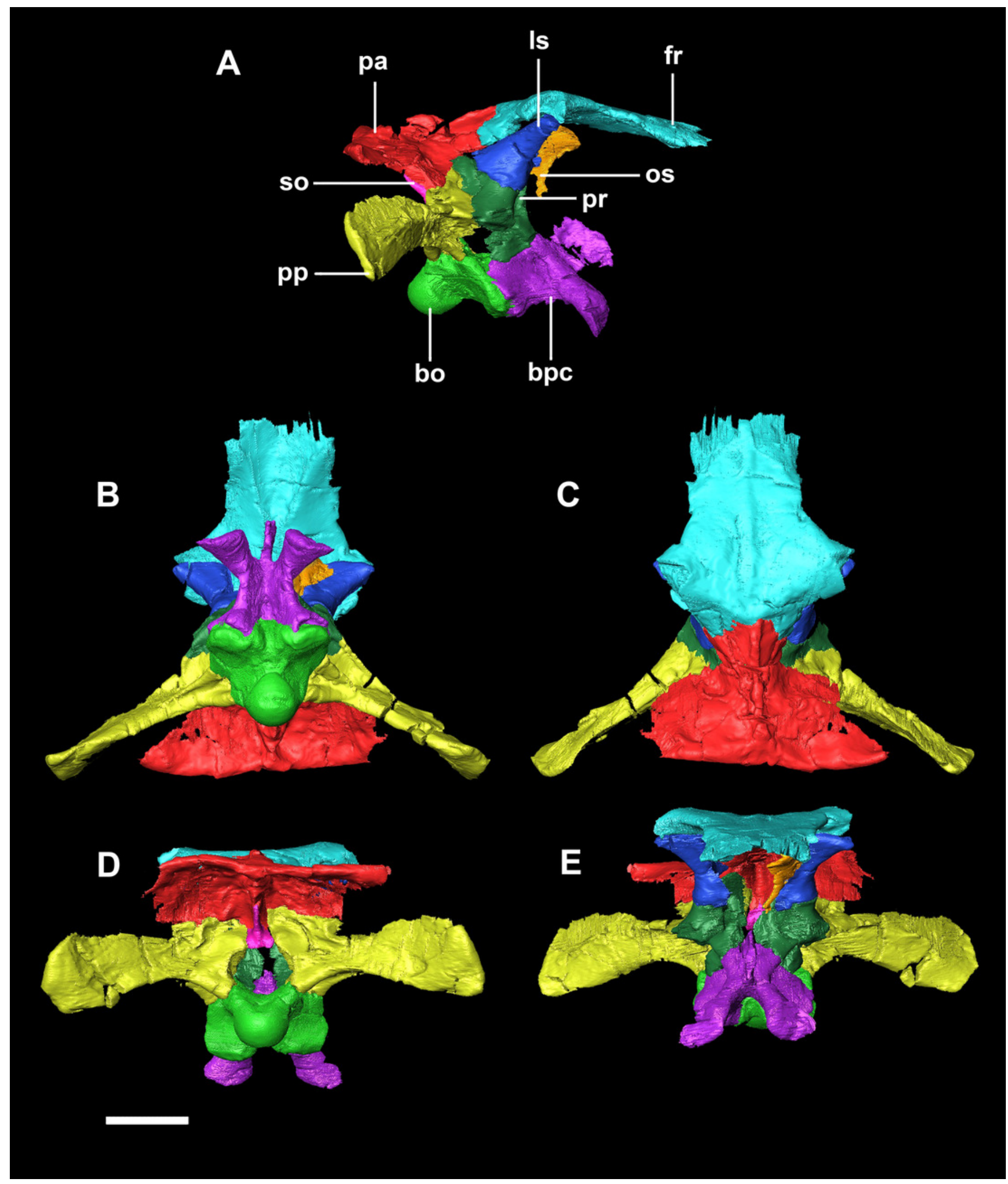


Figure 21

Basioccipital of adult $P$. lujiatunensis (IVPP V12617).

(A) Left lateral view. (B) Right lateral view. (C) Ventral view. (D) Dorsal view. (E) Posterior view. (F) Anterior view. boc, basioccipital condyle; bsas, basisphenoid articular surface; bt, basal tubera; btg, basal tubera groove; cdn, condylar neck; eoas, exoccipital articular surface; ng, neural groove. Scale bar represents $10 \mathrm{~mm}$. 


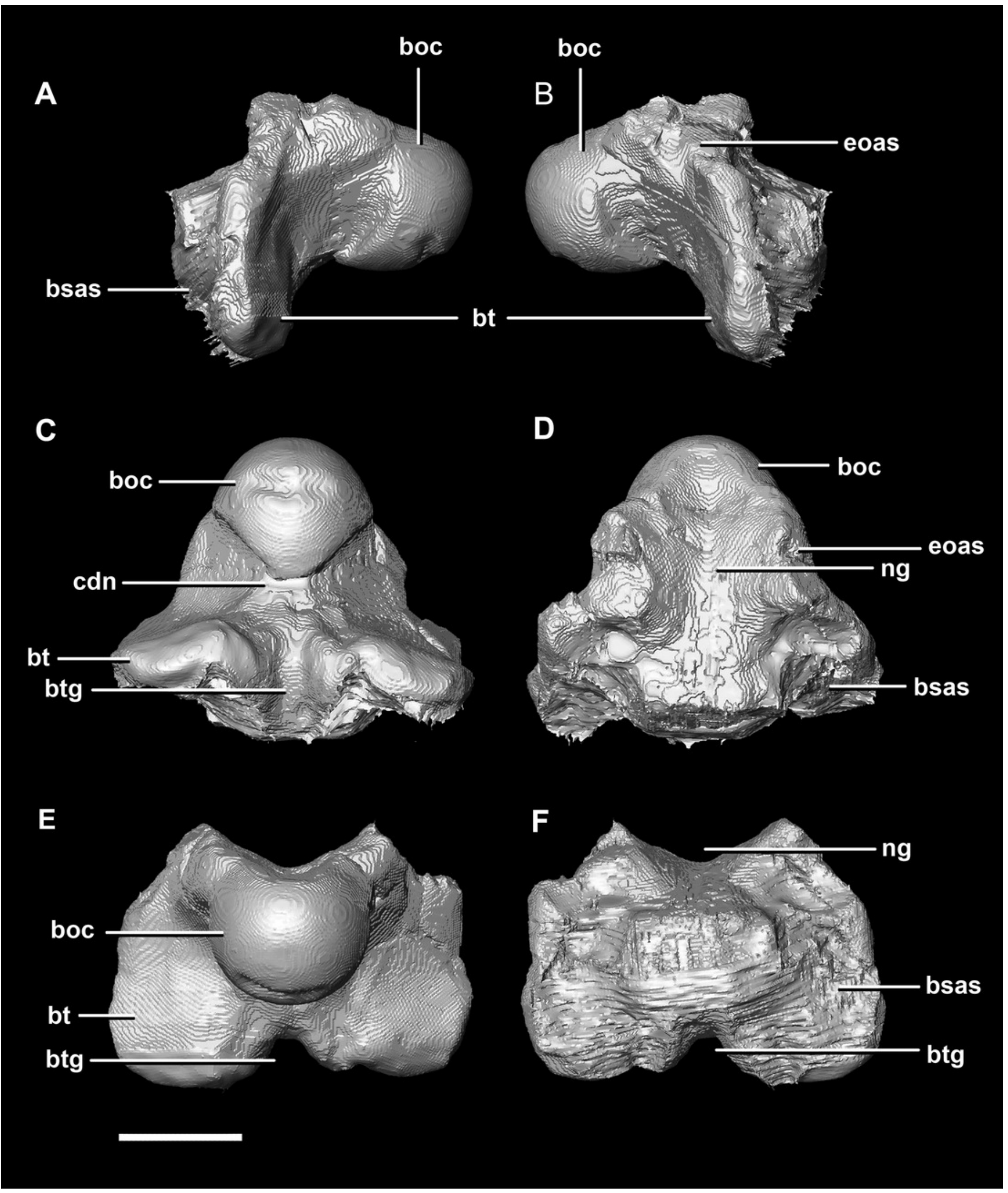




\section{Figure 22}

Basisphenoid of adult P. lujiatunensis (IVPP V12617).

(A) Left lateral view. (B) Right lateral view. (C) Ventral view. (D) Dorsal view. (E) Posterior view. (F) Anterior view. boas, basioccipital articular surface; bpp, basipterygoid process; bsr, basisphenoid recess; bt, basal tubera; cfo, carotid foramen; $c p$, cultriform process; pct, paracultriform trough; pras, prootic articular surface; ptas, pterygoid articular surface; st, sella turcica. Scale bar represents $10 \mathrm{~mm}$. 


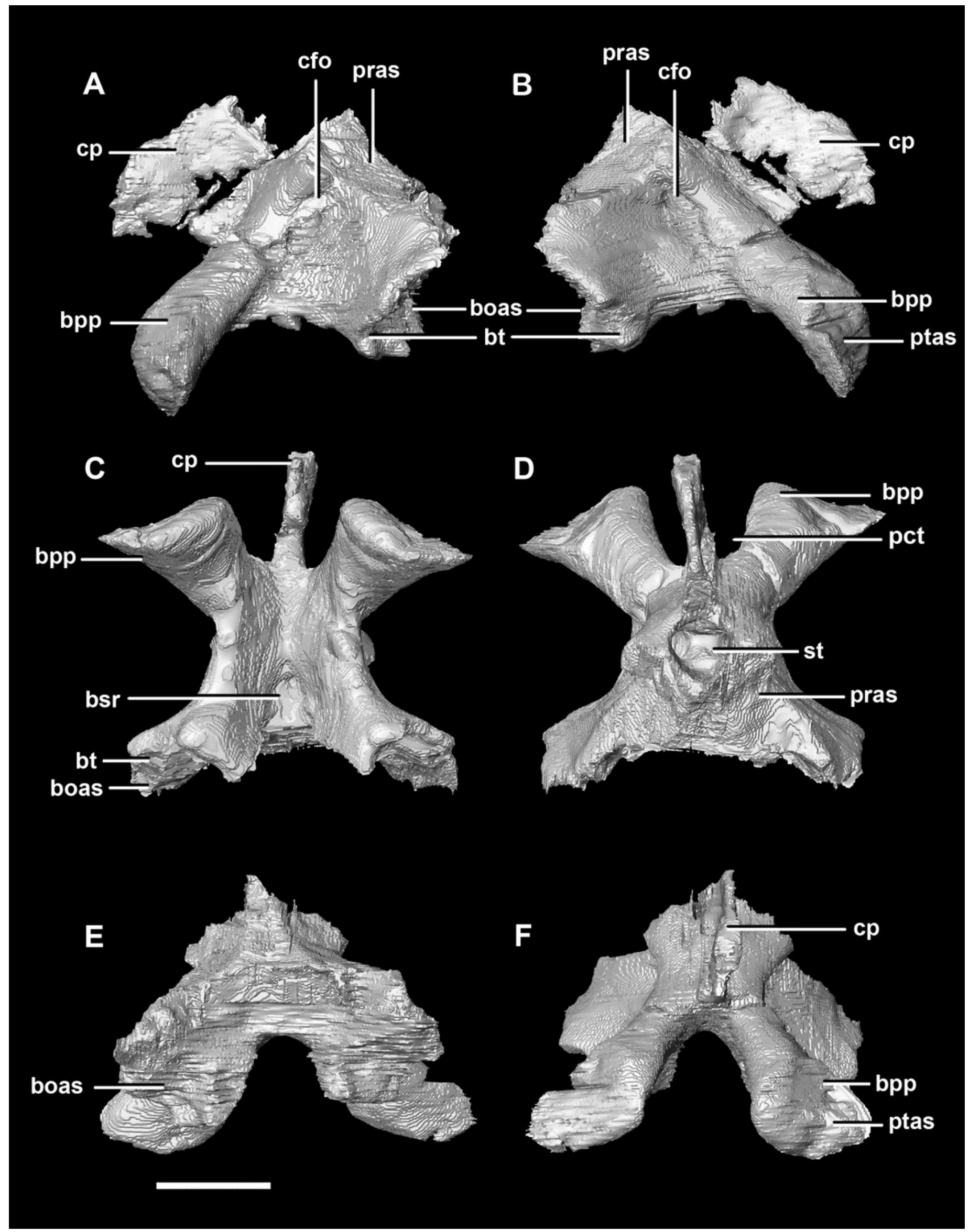


Figure 23

Supraoccipital of adult $P$. lujiatunensis (IVPP V12617).

(A) Left lateral view. (B) Right lateral view. (C) Ventral view. (D) Dorsal view. (E) Posterior view. (F) Anterior view. eoas, exoccipital articular surface; paas, parietal articular surface. Scale bar represents $10 \mathrm{~mm}$. 


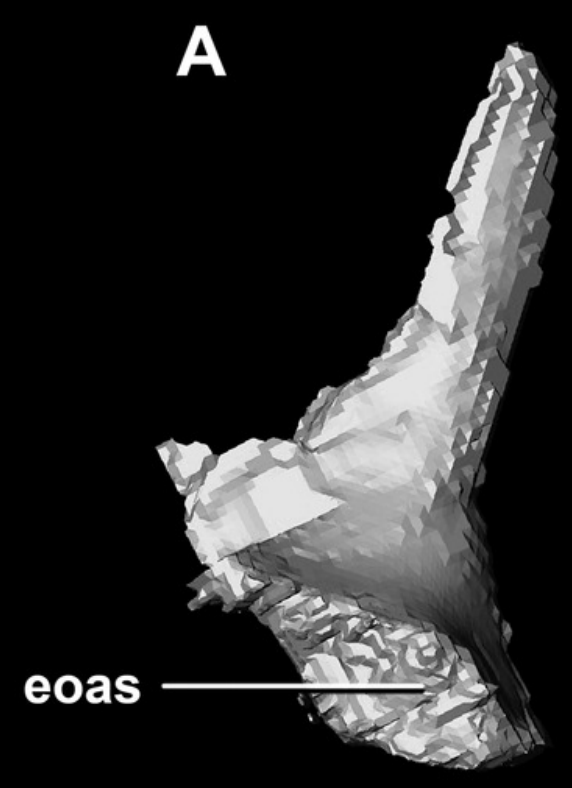

B
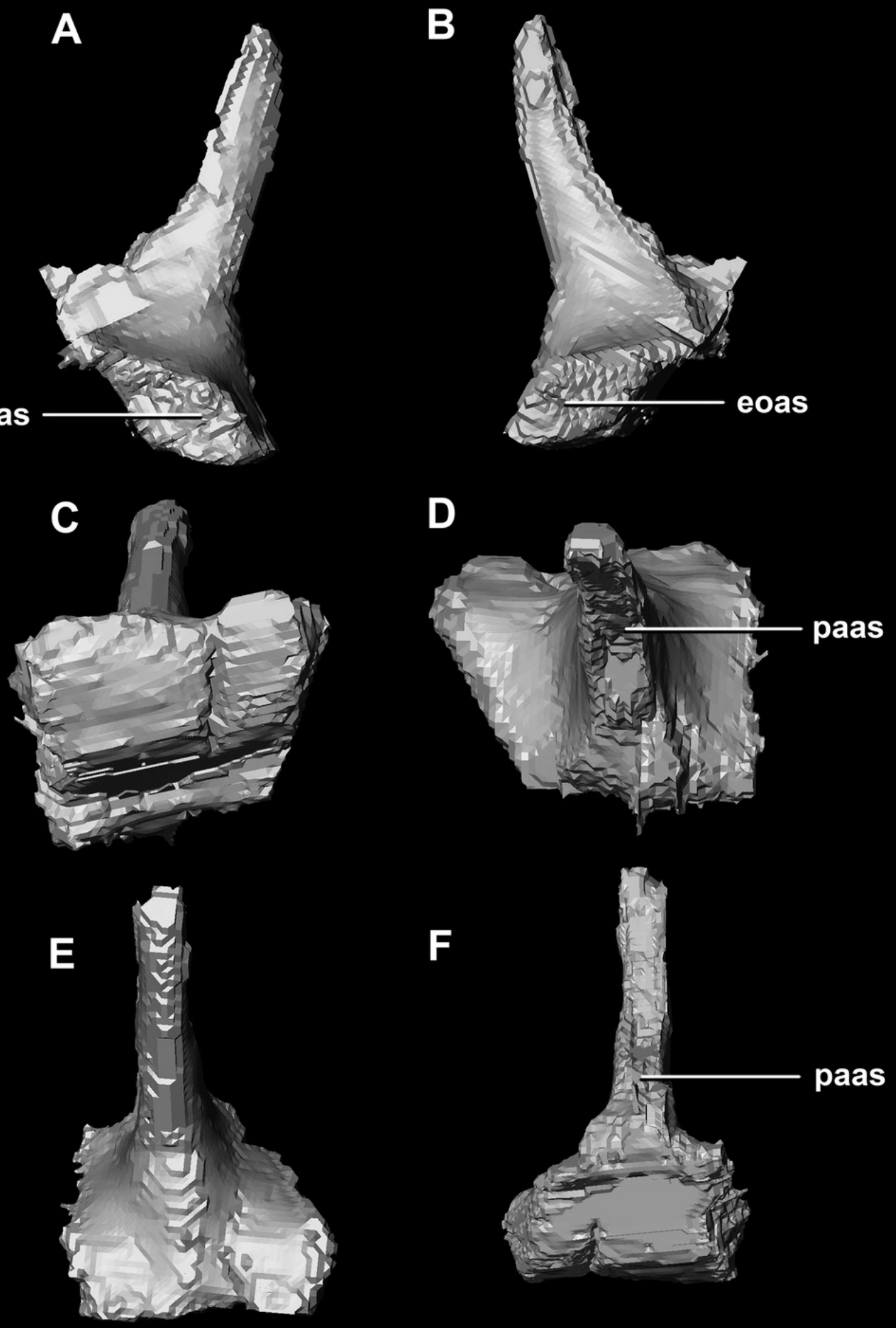


\section{Figure 24}

Paroccipital processes of adult $P$. Iujiatunensis (IVPP V12617).

(A) Left lateral view. (B) Right lateral view. (C) Left medial view. (D) Right medial view. (E) Ventral view. (F) Dorsal view. (G) Posterior view. (H) Anterior view. boas, basioccipital articular surface; fm, foramen magnum; pop, paroccipital process; pras, prootic articular surface; CN X-XII, approximate location of the foramen transmitting the vagus nerve, accessory nerve, and the hypoglossal nerve. Scale bar represents $10 \mathrm{~mm}$. 


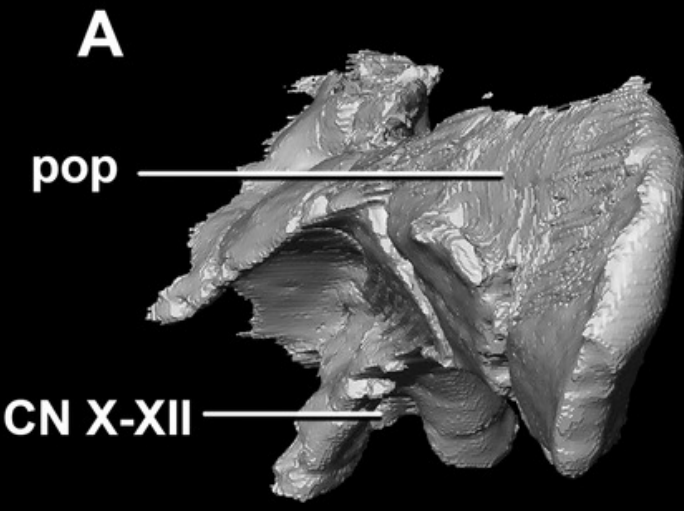

B
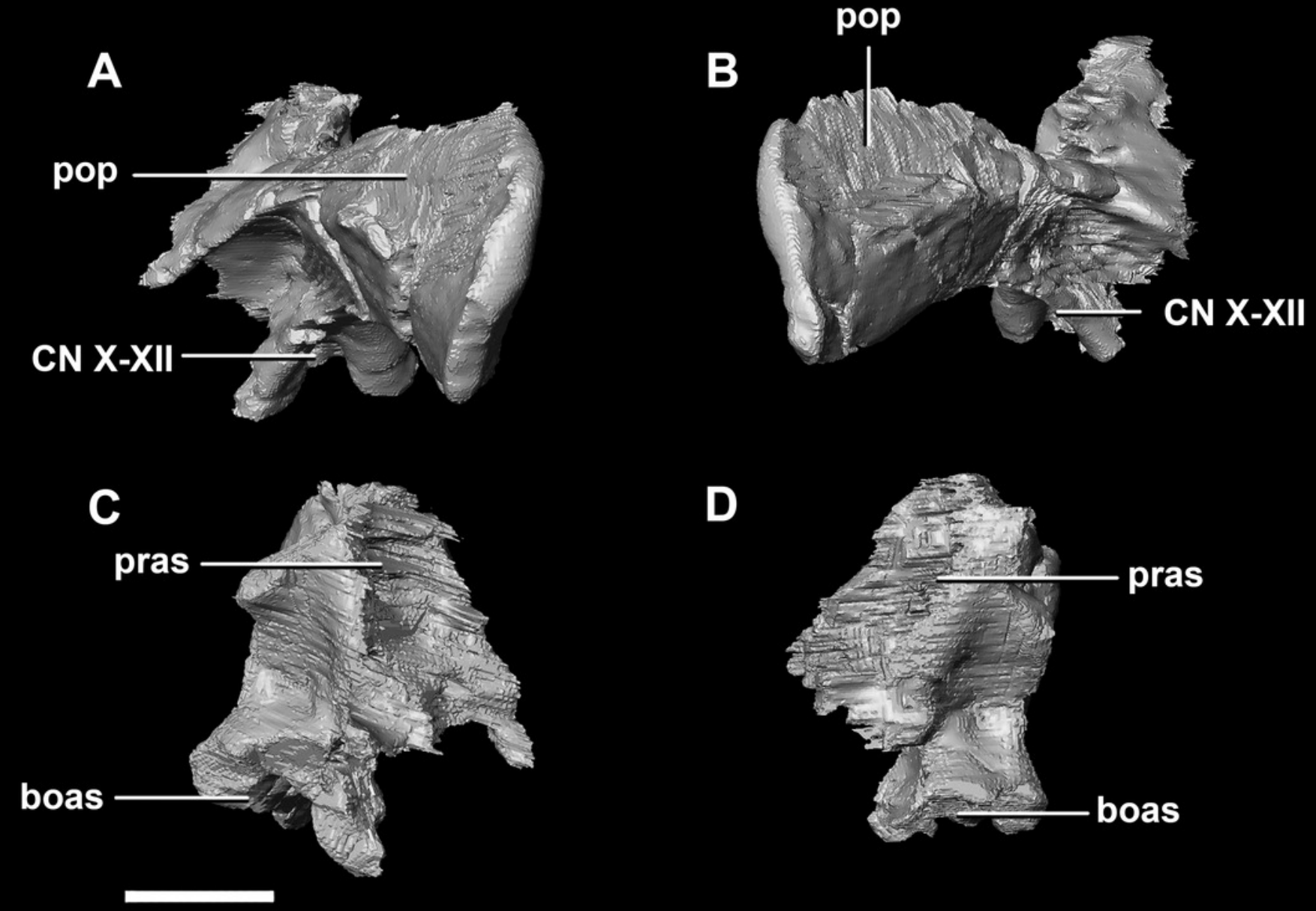

D

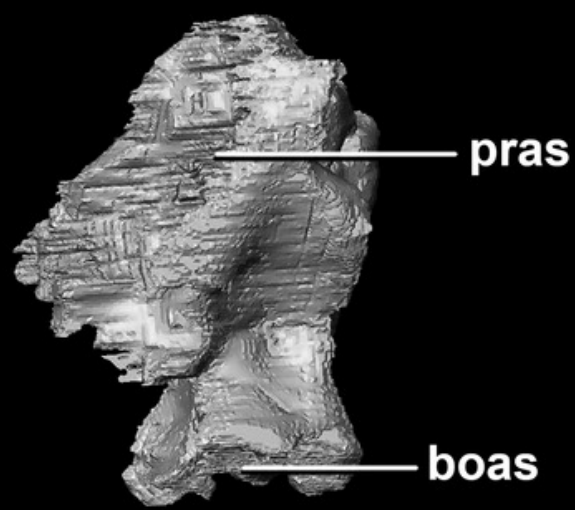

E
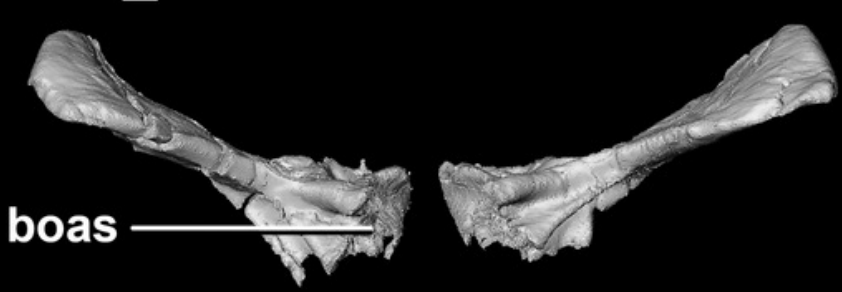

$\mathbf{F}$

G
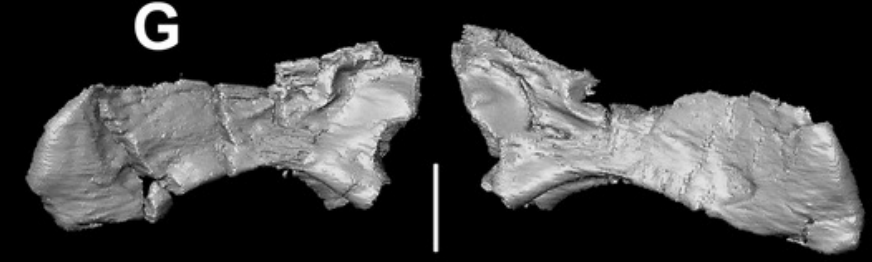

fm
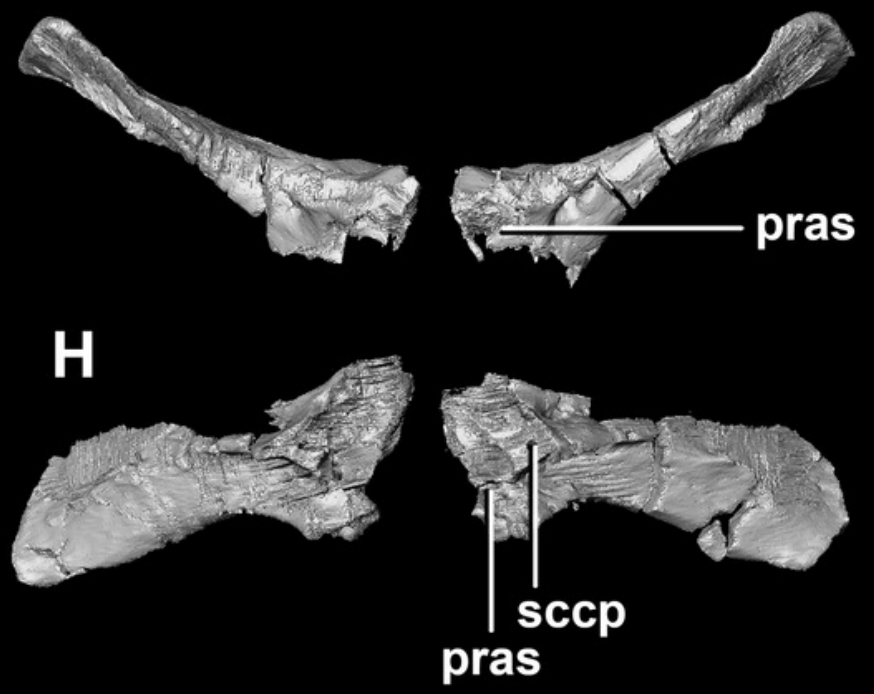


\section{Figure 25}

Laterosphenoid of adult P. lujiatunensis (IVPP V12617).
(A) Left lateral view.
(B) Right lateral view.
(C) Ventral view.
(D) Dorsal view.
(E) Posterior

view. (F) Anterior view. fras, frontal articular surface; Ish, laterosphenoid head; osas, orbitosphenoid articular surface; pras, prootic articular surface. Scale bar represents $10 \mathrm{~mm}$.

A
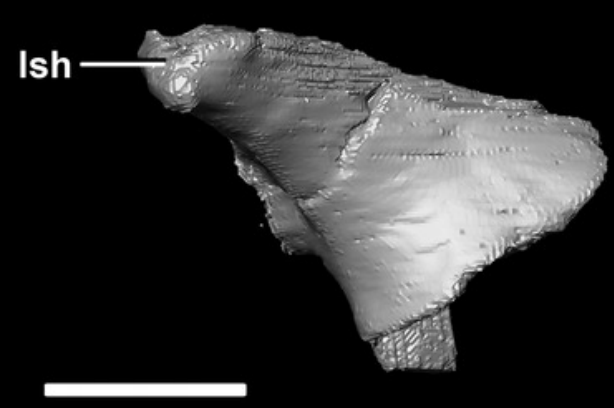

C

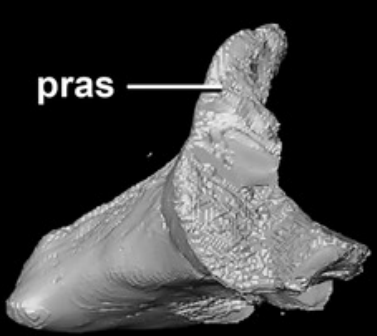

E

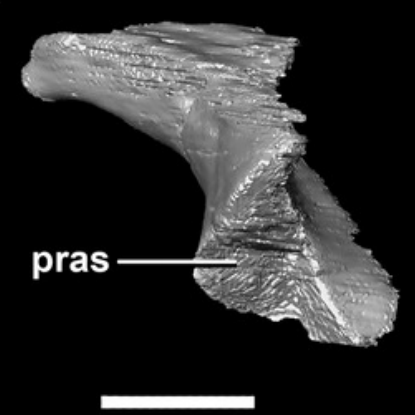

B

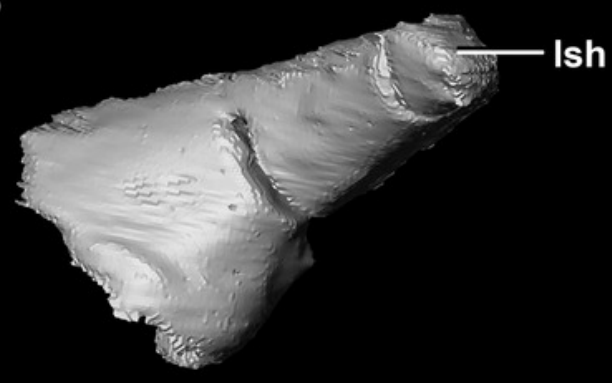

D
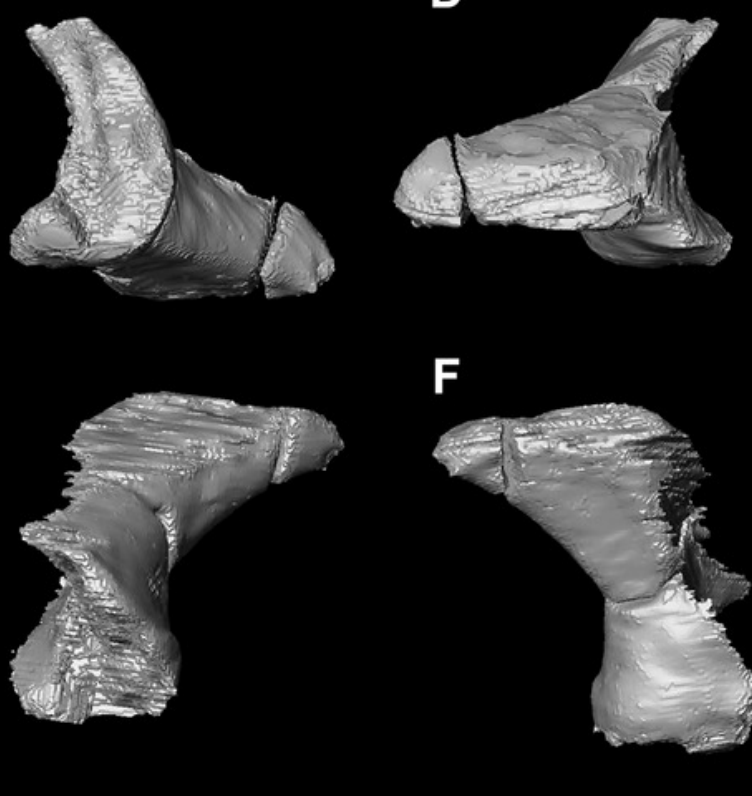

F
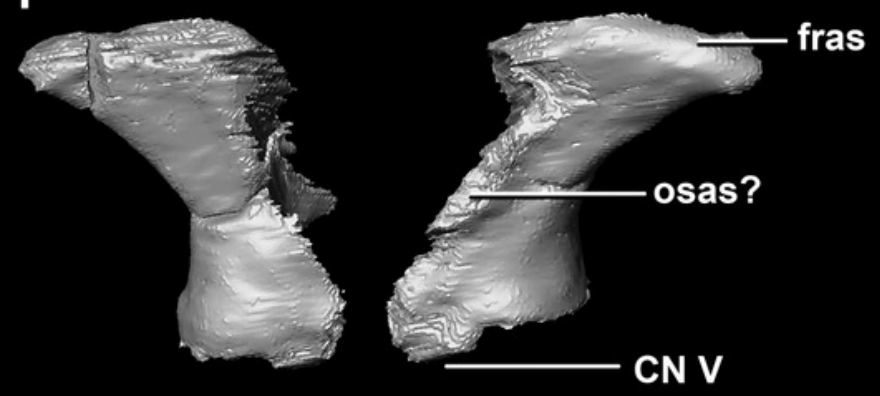
Figure 26

Orbitosphenoid of adult $P$. lujiatunensis (IVPP V12617).

(A) Left lateral view. (B) Left medial view. (C) Posterior view. (D) Anterior view. Isas, laterosphenoid articular surface; CN II, optic nerve. Scale bar represents $10 \mathrm{~mm}$. 


\section{A}
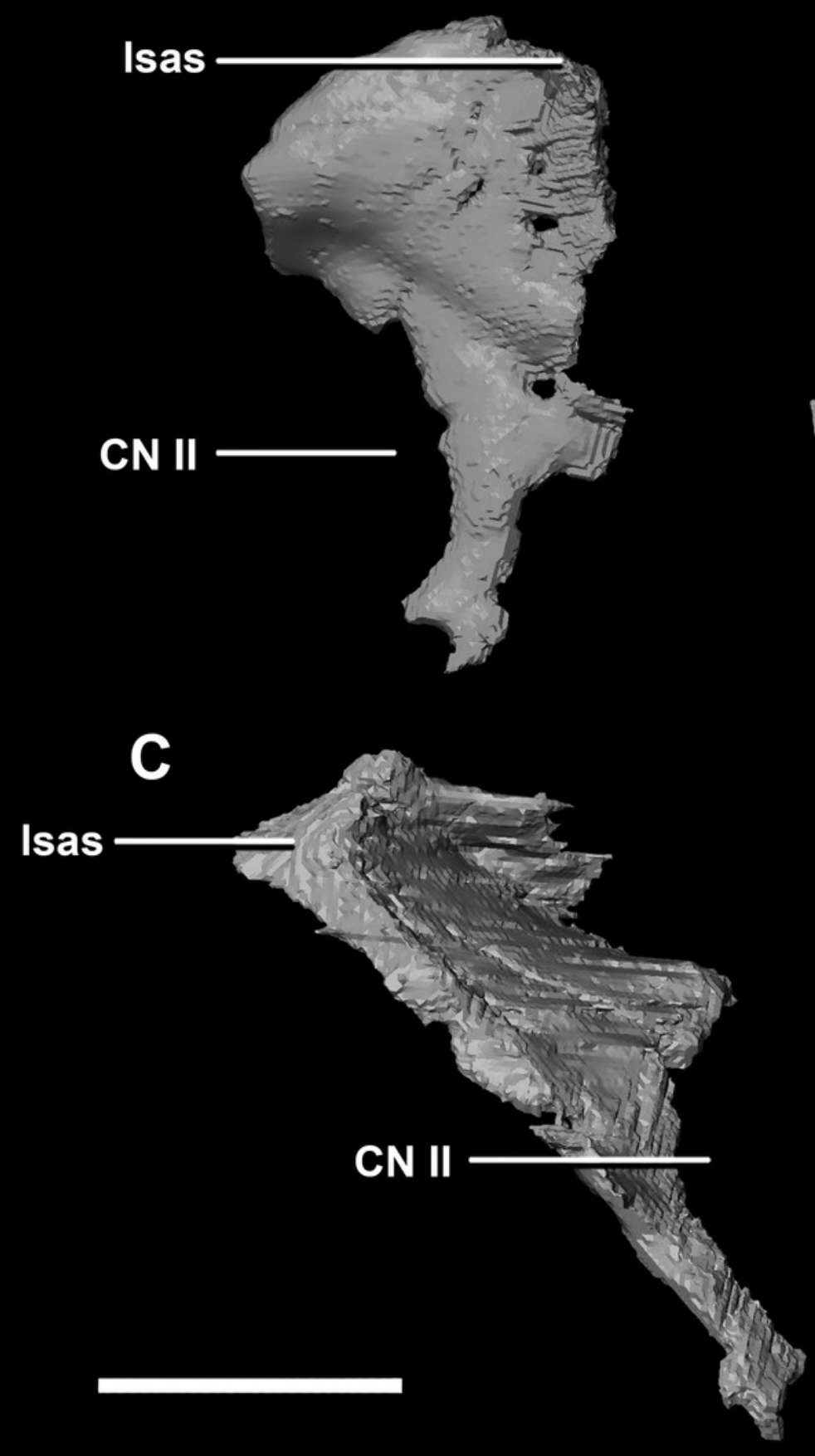

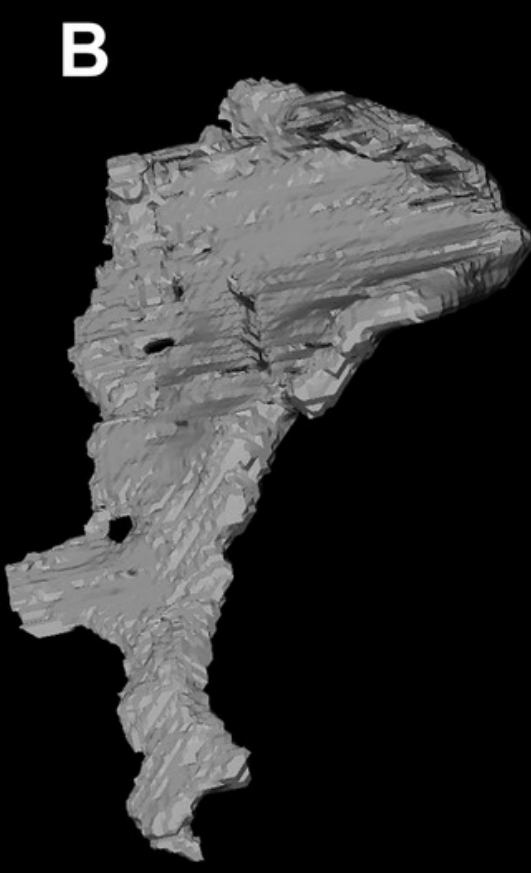

D

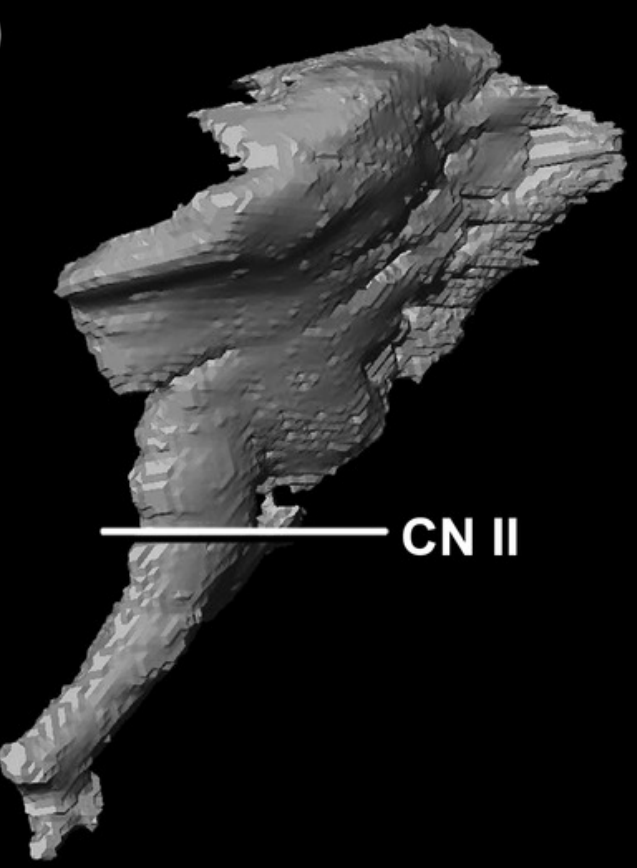




\section{Figure 27}

Prootics of adult P. lujiatunensis (IVPP V12617).

(A) Left lateral view. (B) Right lateral view. (C) Left medial view. (D) Right medial view. (E) Ventral view. (F) Dorsal view. (G) Posterior view. (H) Anterior view. bsas, basioccipital articular surface, eoas, exoccipital articular surface; Isas, laterosphenoid articular surface; pps, preprootic strut; sccp, semicircular canal pathway; CN V, trigeminal nerve. Scale bar represents $10 \mathrm{~mm}$. 


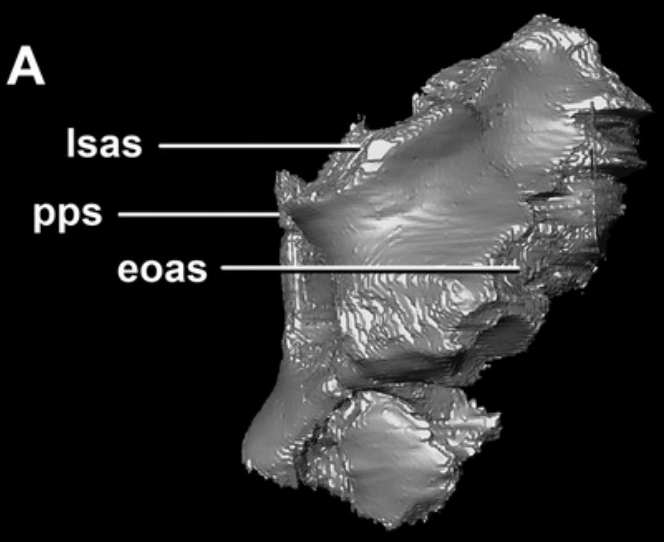

B

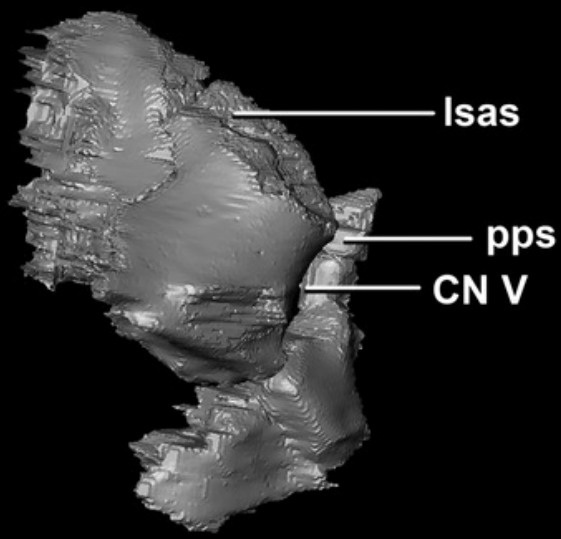

C

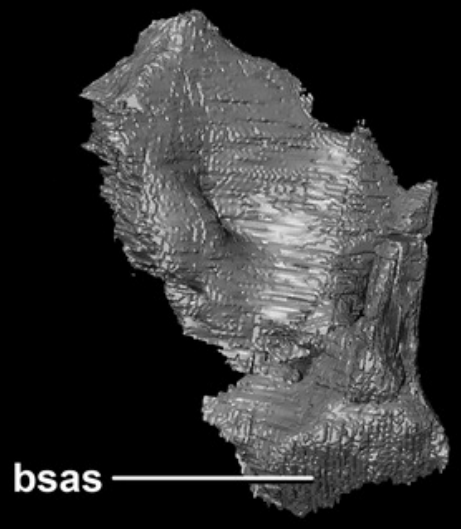

D

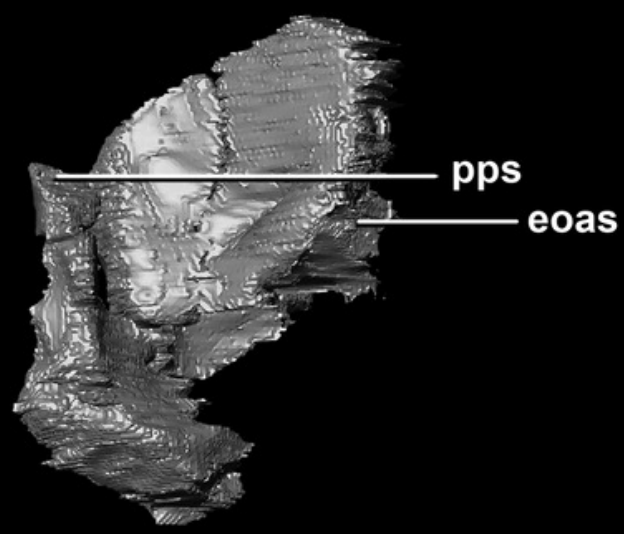

E

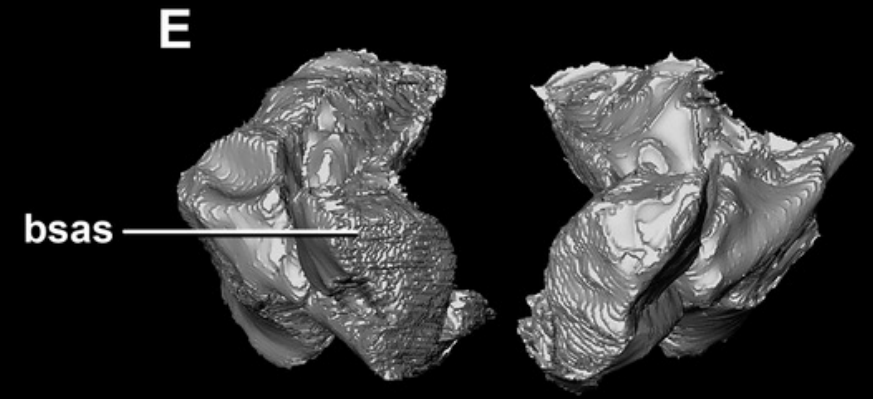

$\mathbf{F}$
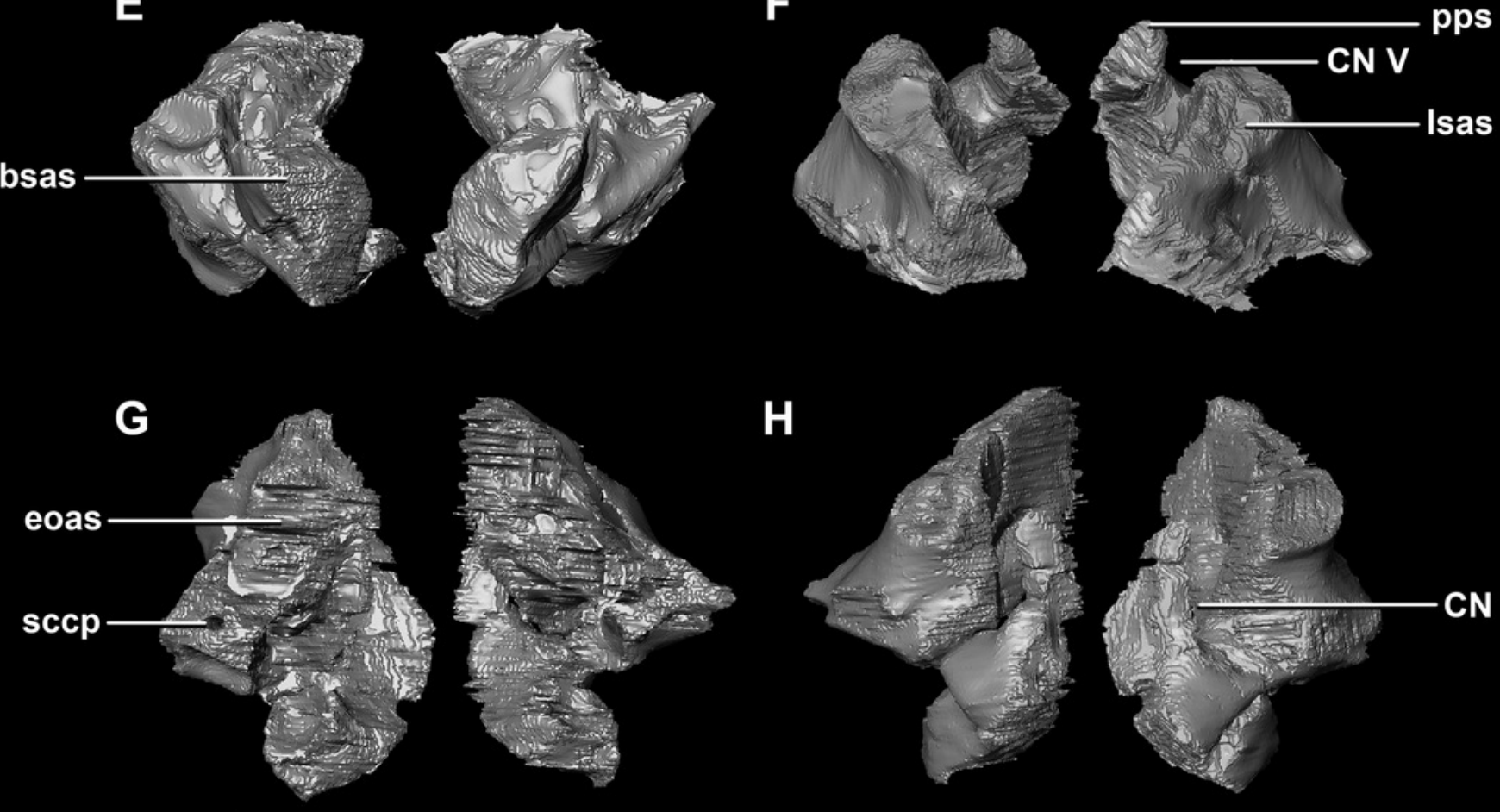

H
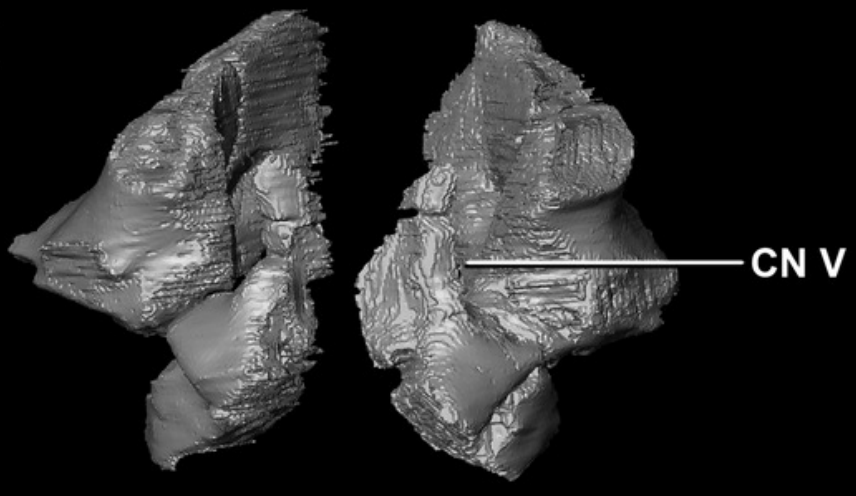


\section{Figure 28}

Parietals of adult P. Iujiatunensis (IVPP V12617). (A) Left lateral view.

(A) Left lateral view. (B) Right lateral view. (C) Ventral view. (D) Dorsal view. (E) Posterior view. (F) Anterior view. eoas, exoccipital articular surface; fras, frontal articular surface; Isas, laterosphenoid articular surface; pmr, parietal midline ridge; sc, sagittal crest; soas, supraoccipital articular surface; sqas, squamosal articular surface. Scale bar represents 10 $\mathrm{mm}$. 


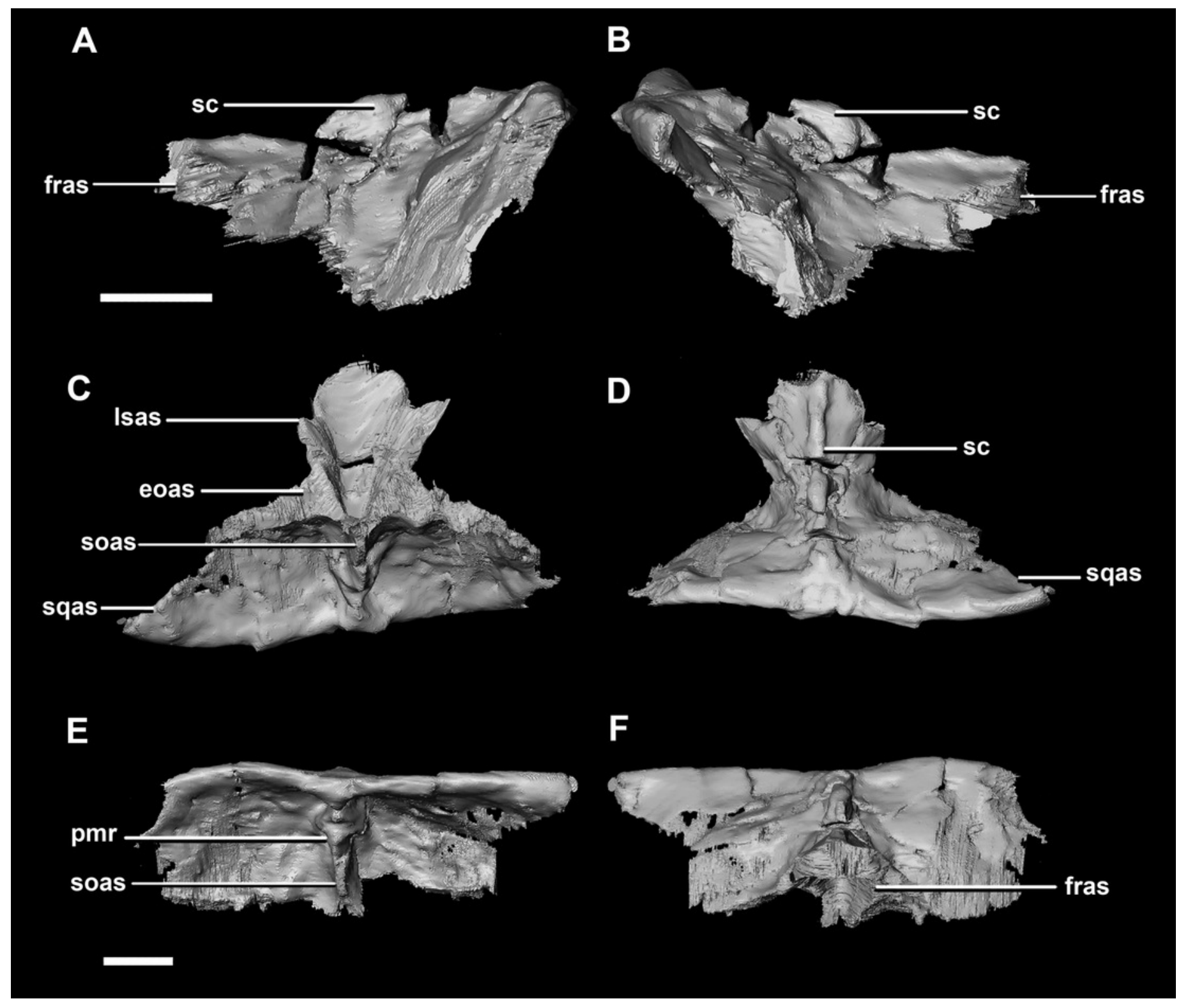




\section{Figure 29}

Frontals of adult $P$. lujiatunensis (IVPP V12617).

(A) Left lateral view. (B) Right lateral view. (C) Ventral view. (D) Dorsal view. (E) Posterior view. (F) Anterior view. cc, cerebral cavity; fc, frontal crest; Isas, laterosphenoid articular surface; nas, nasal articular surface; no, notch; om, orbital margin; paas, parietal articular surface; poas, postorbital articular surface. Scale bar represents $10 \mathrm{~mm}$. 


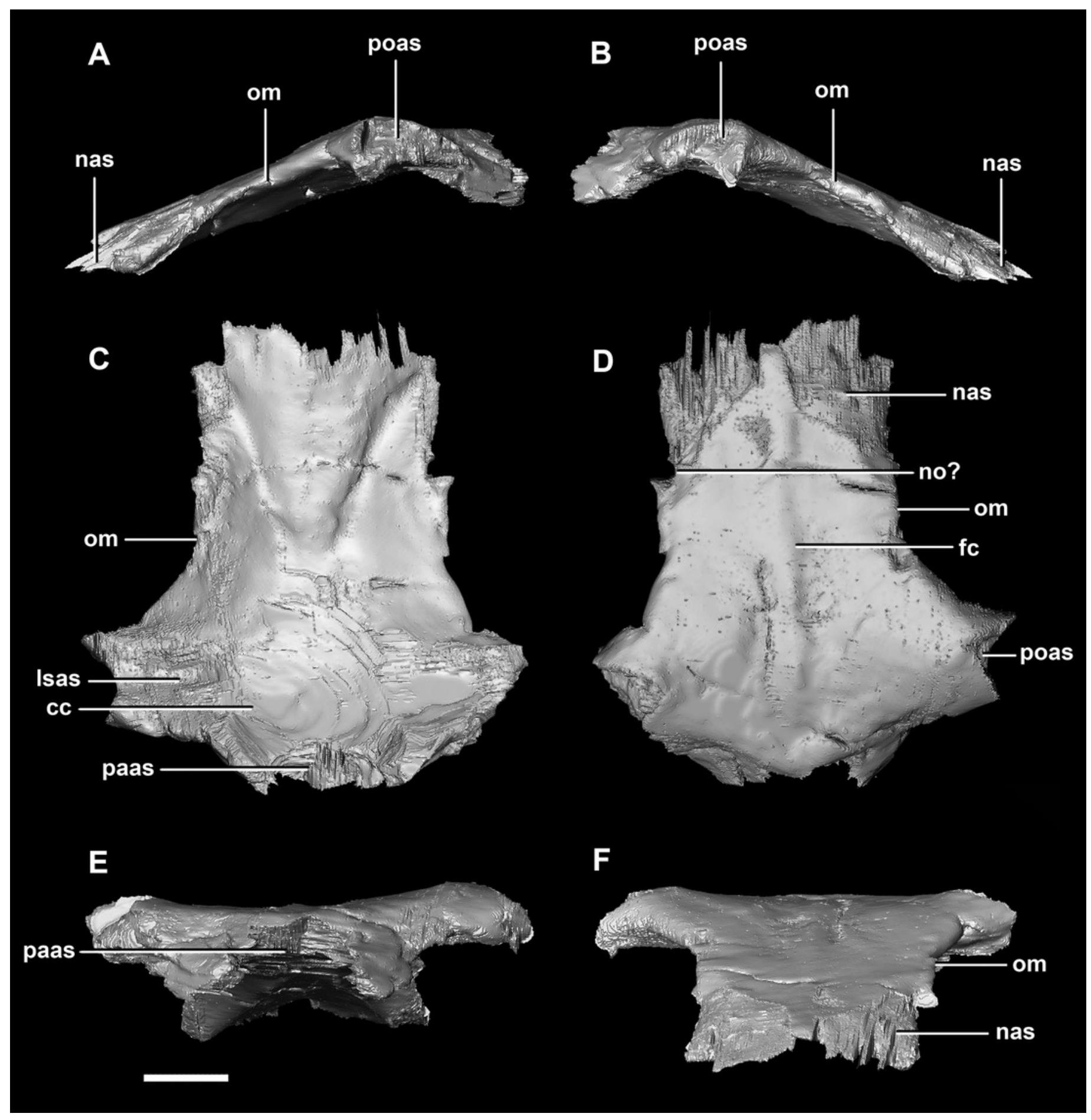


Figure 30

Morphological changes of the basioccipital contribution to the basal tubera in ventral view and the location of the basal tubera within the braincase.

(A) Schematic view and (B) location of basal tubera of hatchling. (C) Schematic view and (D) location of basal tubera of juvenile. (E) Schematic view and (F) location of basal tubera of adult. Not to scale.

A

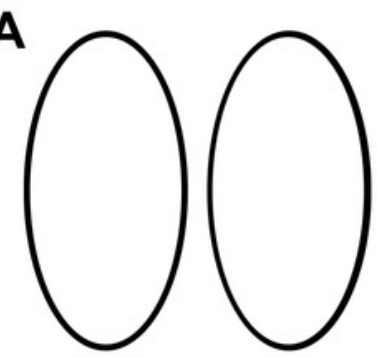

B

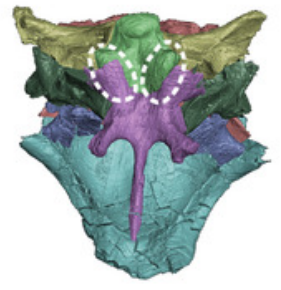

C

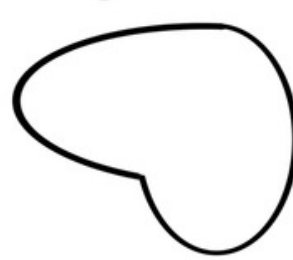

D

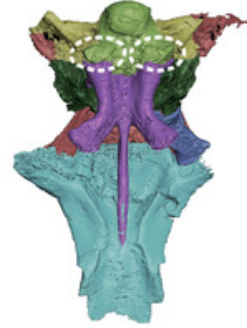

E

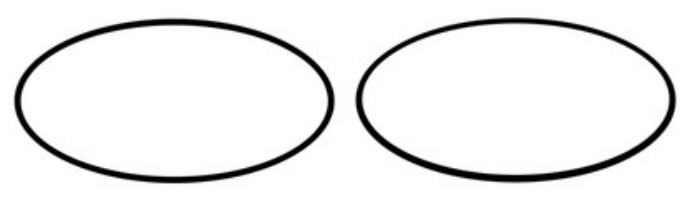

F

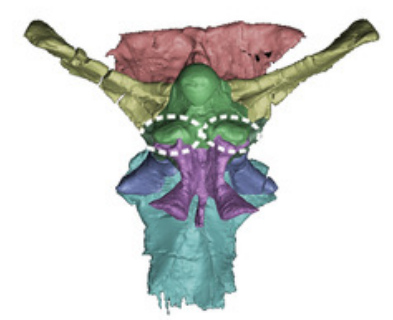




\section{Figure 31}

Left semicircular canals displaying the angle between the ASC and the PSC.

Hatchling in (A) lateral and (B) dorsal views. Juvenile in (C) lateral and (D) dorsal views. Adult in (E) lateral and (F) dorsal views. ASC, anterior semicircular canal; PSC, posterior semicircular canal; HSC, horizontal semicircular canal. Inferred sections in red. Not to scale.
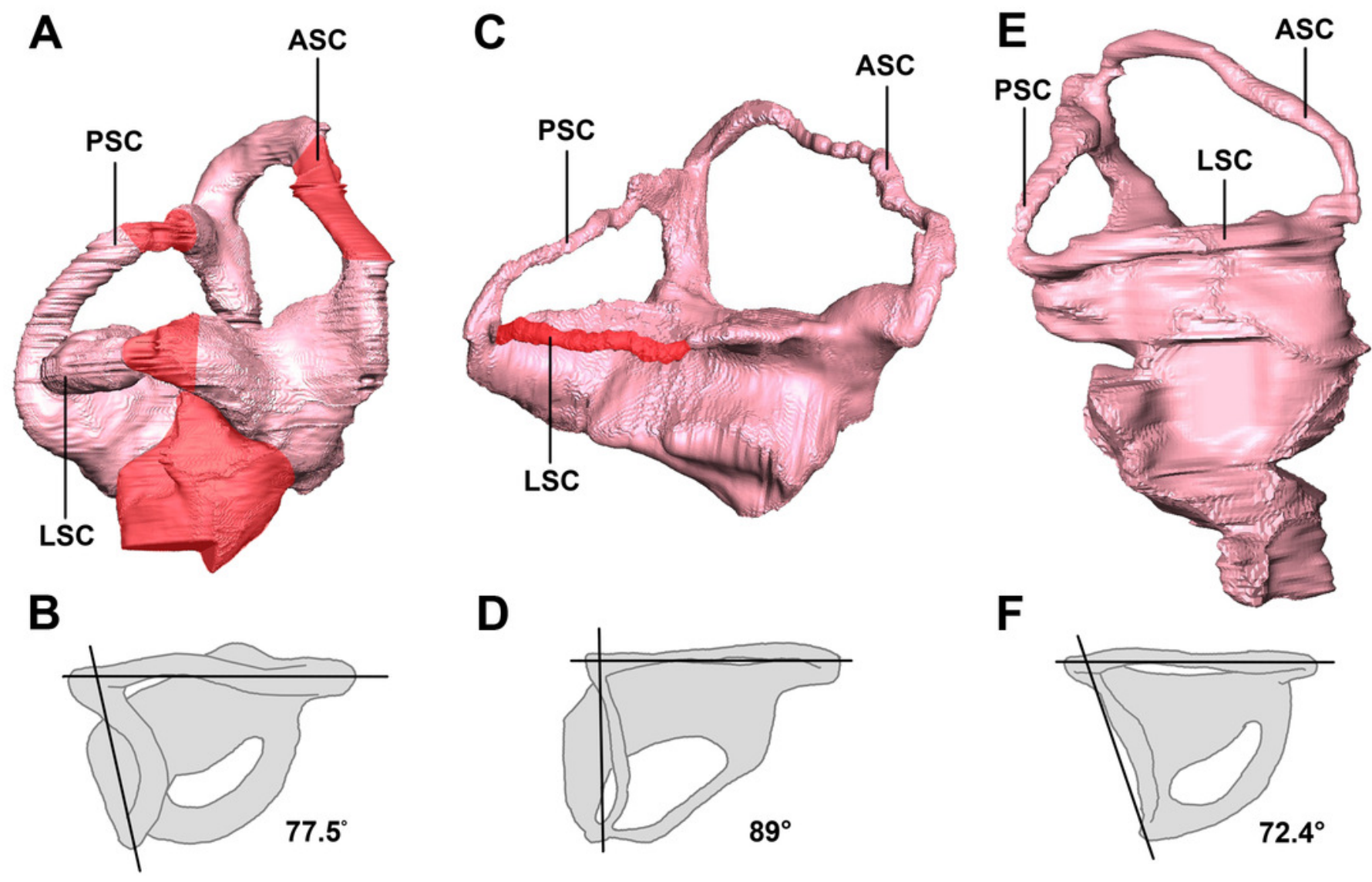

D
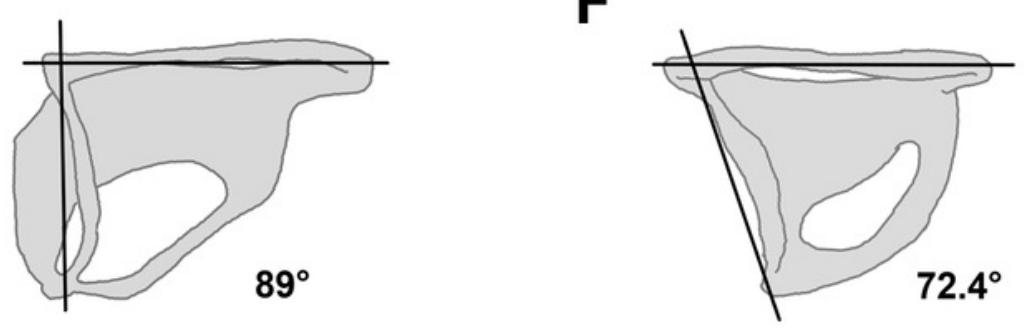
Figure 32

Head posture if LSC is parallel to the ground.

(A) Hatchling. (B) Juvenile. (C) Adult. Not to scale.
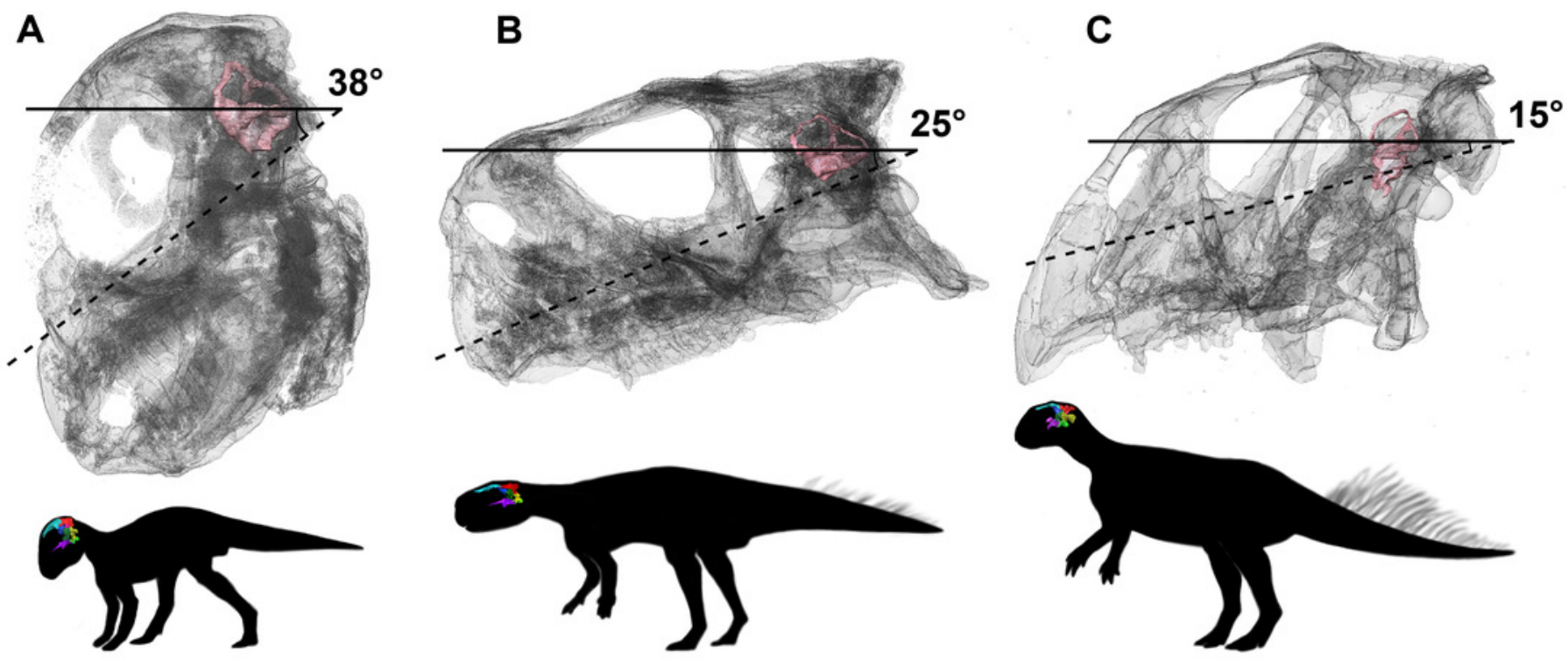
Figure 33

Schematic drawing of foramen for cranial nerves X-XII.

(A) Hatchling. (B) Juvenile. (C) Adult. Not to scale. 

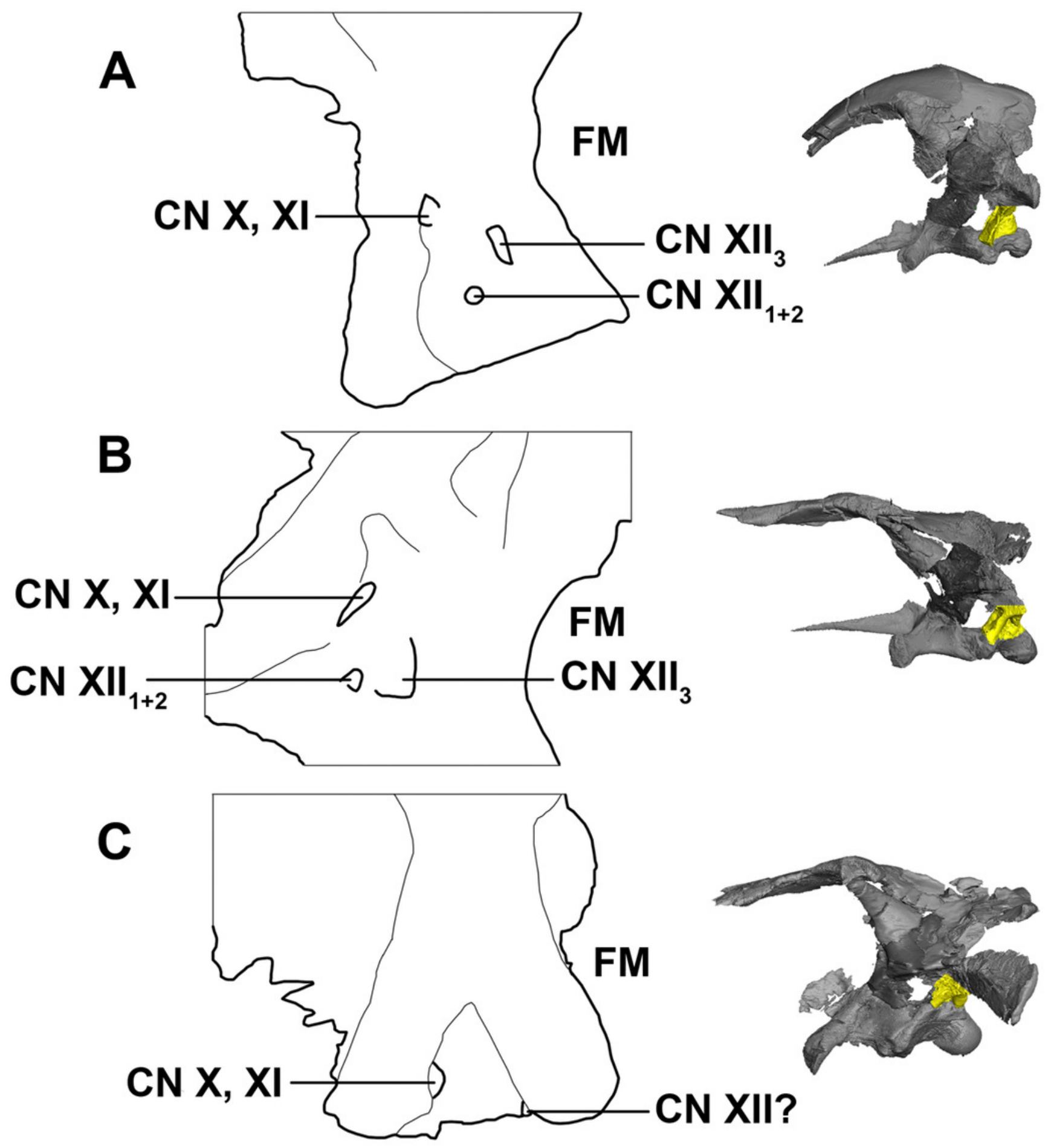
Figure 34

Prominent ontogenetic changes in the braincase of Psittacosaurus lujiatunensis.

(A) Lateral view. (B) Posterior view. (C) Hatchling and (D) adult braincases in situ. Not to scale. 

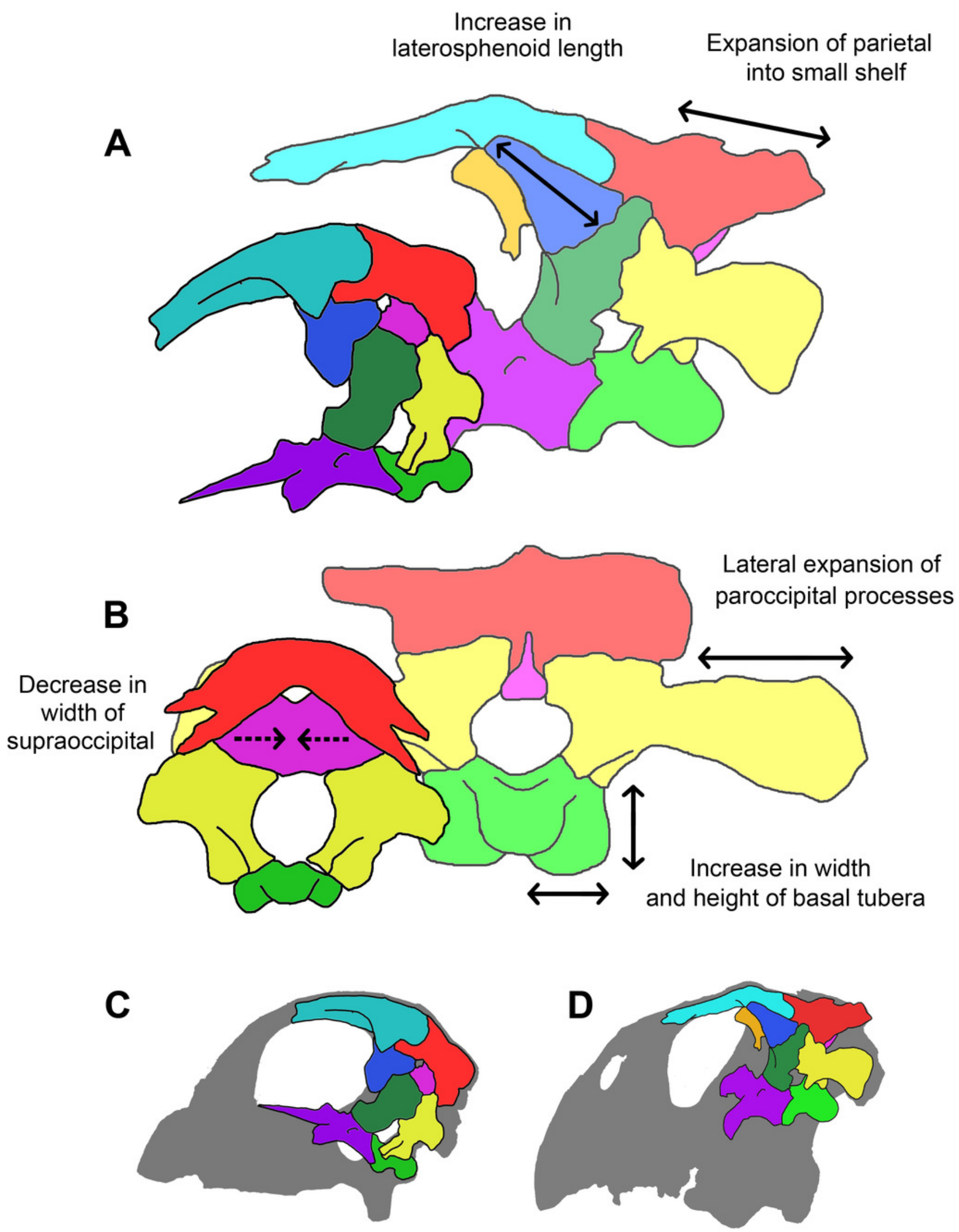


\section{Table $\mathbf{1}$ (on next page)}

Element sizes in relation to base skull length (\%) and the total \% change between hatchling and adult.

bo, basioccipital; bsp, basisphenoid; bt, basal tubera; cp, cultriform process; fr, frontal; Isp, laterosphenoid; OC, occipital condyle; par, parietal; pop, paroccipital process; pr, prootic; soc, supraoccipital. W, width; I, length; $h$, height. 


\begin{tabular}{|c|c|c|c|c|c|c|c|c|c|c|}
\hline & \multicolumn{3}{|c|}{ Hatchling } & \multicolumn{3}{|c|}{ Juvenile } & \multicolumn{3}{|c|}{ Adult } & \multirow[b]{2}{*}{$\begin{array}{l}\text { Total \% } \\
\text { change }\end{array}$} \\
\hline & $\begin{array}{l}\text { Element } \\
(\mathrm{mm})\end{array}$ & $\begin{array}{l}\text { Skull } \\
(\mathrm{mm})\end{array}$ & $\%$ & $\begin{array}{l}\text { Element } \\
(\mathrm{mm})\end{array}$ & $\begin{array}{l}\text { Skull } \\
(\mathbf{m m})\end{array}$ & $\%$ & $\begin{array}{l}\text { Element } \\
(\mathrm{mm})\end{array}$ & $\begin{array}{l}\text { Skull } \\
\text { (mm) }\end{array}$ & $\%$ & \\
\hline BO w & 5.8 & 23.6 & $24.58 \%$ & 16.6 & 86.5 & $19.19 \%$ & 32 & 143.7 & $22.27 \%$ & $-2.31 \%$ \\
\hline BO I & 5.4 & 23.6 & $22.88 \%$ & 14 & 86.5 & $16.18 \%$ & 26.4 & 143.7 & $18.37 \%$ & $-4.51 \%$ \\
\hline bt $h$ & 1.2 & 23.6 & $5.08 \%$ & 4.4 & 86.5 & $5.09 \%$ & 16.4 & 143.7 & $11.41 \%$ & $6.33 \%$ \\
\hline bt w & 2.9 & 23.6 & $12.29 \%$ & 8.8 & 86.5 & $10.17 \%$ & 16 & 143.7 & $11.13 \%$ & $-1.15 \%$ \\
\hline $\mathrm{OC} \mathbf{w}$ & 3 & 23.6 & $12.71 \%$ & 6.8 & 86.5 & $7.86 \%$ & 14.3 & 143.7 & $9.95 \%$ & $-2.76 \%$ \\
\hline OC h & 2 & 23.6 & $8.47 \%$ & 5 & 86.5 & $5.78 \%$ & 11.9 & 143.7 & $8.28 \%$ & $-0.19 \%$ \\
\hline BSp w & 7.3 & 23.6 & $30.93 \%$ & 20 & 86.5 & $23.12 \%$ & 35.9 & 143.7 & $24.98 \%$ & $-5.95 \%$ \\
\hline BSp I & 5.9 & 23.6 & $25.00 \%$ & 15.9 & 86.5 & $18.38 \%$ & 27.8 & 143.7 & $19.35 \%$ & $-5.65 \%$ \\
\hline cp l & 6.9 & 23.6 & $29.24 \%$ & 23.5 & 86.5 & $27.17 \%$ & 11.1 & 143.7 & $7.72 \%$ & $-21.51 \%$ \\
\hline POP I & 6.2 & 23.6 & $26.27 \%$ & 0 & 86.5 & $0.00 \%$ & 59.3 & 143.7 & $41.27 \%$ & $15.00 \%$ \\
\hline POP h & 2.8 & 23.6 & $11.86 \%$ & 0 & 86.5 & $0.00 \%$ & 19.6 & 143.7 & $13.64 \%$ & $1.78 \%$ \\
\hline SOC h & 3.6 & 23.6 & $15.25 \%$ & 0 & 86.5 & $0.00 \%$ & 12.3 & 143.7 & $8.56 \%$ & $-6.69 \%$ \\
\hline SOC w & 8.7 & 23.6 & $36.86 \%$ & 9.8 & 86.5 & $11.33 \%$ & 6.8 & 143.7 & $4.73 \%$ & $-32.13 \%$ \\
\hline Lsp w & 4.2 & 23.6 & $17.80 \%$ & 6.8 & 86.5 & $7.86 \%$ & 14.5 & 143.7 & $10.09 \%$ & $-7.71 \%$ \\
\hline Lsp I & 5.2 & 23.6 & $22.03 \%$ & 15.4 & 86.5 & $17.80 \%$ & 25.9 & 143.7 & $18.02 \%$ & $-4.01 \%$ \\
\hline Pr 1 & 7.1 & 23.6 & $30.08 \%$ & 12.8 & 86.5 & $14.80 \%$ & 29.2 & 143.7 & $20.32 \%$ & $-9.76 \%$ \\
\hline $\operatorname{Pr} w$ & 3.9 & 23.6 & $16.53 \%$ & 0 & 86.5 & $0.00 \%$ & 13.5 & 143.7 & $9.39 \%$ & $-7.13 \%$ \\
\hline Par I & 7.4 & 23.6 & $31.36 \%$ & 16.3 & 86.5 & $18.84 \%$ & 39.8 & 143.7 & $27.70 \%$ & $-3.66 \%$ \\
\hline Fr 1 & 11.2 & 23.6 & $47.46 \%$ & 30.6 & 86.5 & $35.38 \%$ & 54 & 143.7 & $37.58 \%$ & $-9.88 \%$ \\
\hline Fr w & 15.8 & 23.6 & $66.95 \%$ & 36.5 & 86.5 & $42.20 \%$ & 51.5 & 143.7 & $35.84 \%$ & $-31.11 \%$ \\
\hline
\end{tabular}

